DANIEL JOSÉ SzOR

\title{
Avaliação da relação neutrófilo-linfócito como fator prognóstico em pacientes com câncer gástrico submetidos à gastrectomia potencialmente curativa
}

\author{
Tese apresentada à Faculdade de Medicina da \\ Universidade de São Paulo para obtenção do título \\ de Doutor em Ciências \\ Programa de Ciências em Gastroenterologia \\ Orientador: Prof. Dr. Ulysses Ribeiro Júnior
}


Dados Internacionais de Catalogação na Publicação (CIP)

Preparada pela Biblioteca da

Faculdade de Medicina da Universidade de São Paulo

Creprodução autorizada pelo autor

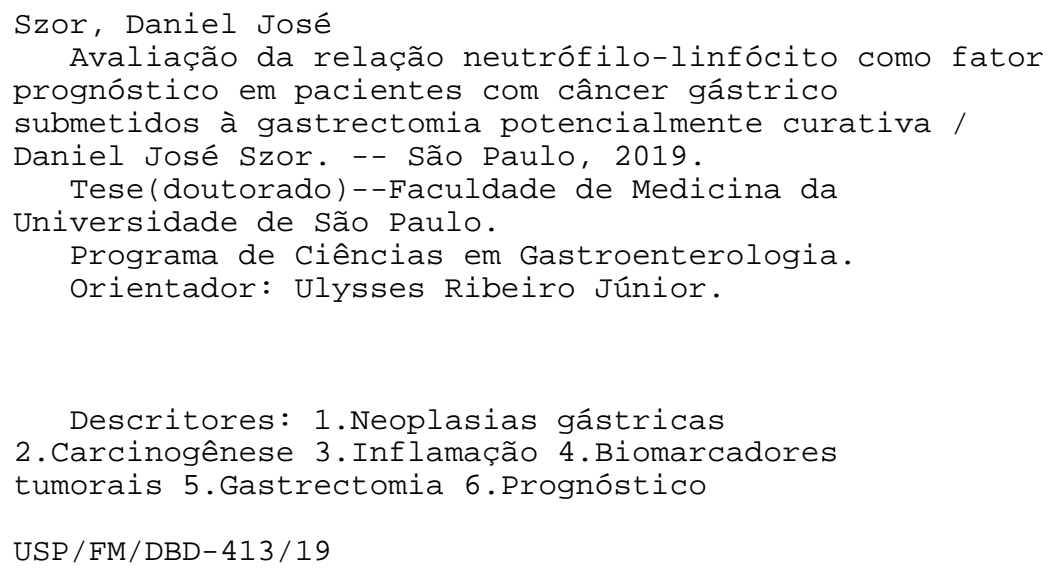


"Until you make the unconscious conscious, it will direct your life and you will call it fate".

Carl Jung (1875 - 1961) 
Aos meus pais, Beni e Flávia, e à minha irmã Simone, meu porto seguro.

À minha esposa Roberta e aos meus filhos David e Michel, a razão de tudo. 


\section{AGRADECIMENTOS}

Ao Prof. Ulysses Ribeiro Júnior, exemplo de dedicação à profissão e à pesquisa científica. Dentre as incontáveis reuniões, cirurgias e demais responsabilidades pessoais e profissionais, multiplica o seu tempo e torna-se disponível para ser o verdadeiro orientador. O meu profundo respeito e admiração.

Ao Dr. André Roncon Dias, exímio cirurgião, capaz de transformar as questões mais complexas em soluções simples e óbvias, tanto na cirurgia quanto na vida. Grande amigo e principal incentivador da realização desta tese.

À Marina Alessandra Pereira por seu verdadeiro altruísmo, empatia e dedicação. Suas incontáveis edições, sugestões e cálculos estatísticos tornaram a jornada mais leve.

Ao Dr. Marcus Kodama, pela ideia do estudo e sugestões que aprimoraram a tese. Um grande exemplo de cirurgião e pesquisador.

Ao Prof. José Jukemura, por todo seu apoio durante a minha passagem pela pós-graduação.

Ao Prof. Bruno Zilberstein, pelo constante estímulo na produção científica na área de estudo do câncer gástrico.

Ao Prof. Ivan Cecconello, por manter as portas do Departamento de Gastroenterologia sempre abertas. 
À Vilma Libério, pela ajuda nos inúmeros passos administrativos necessários para chegar até aqui.

Ao Dr. André Domingues Pereira, grande amigo desde o primeiro ano da faculdade. A bondade em pessoa.

Aos amigos da residência médica Dr. Omar Abduch, Dr. André Passalacqua e Dra. Vivian Carla Gomes. Excelentes profissionais, excelentes pessoas.

Ao Dr. Roberto Nigro, pelas oportunidades e ensinamentos na carreira cirúrgica e na vida.

Ao Prof. Fernando Herbella por traduzir toda a sua genialidade em preciosos comentários e conselhos. 


\section{SUMÁRIO}

Lista de abreviaturas e siglas

Lista de figuras

Lista de tabelas

Lista de gráficos

Resumo

Abstract

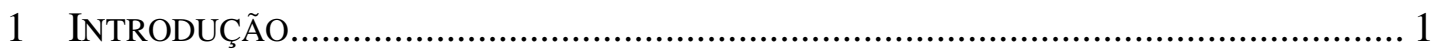

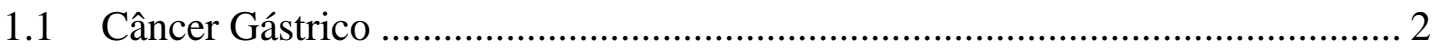

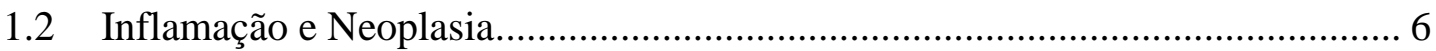

1.3 Estádio e Biomarcadores Inflamatórios ........................................................... 11

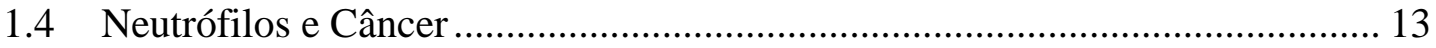

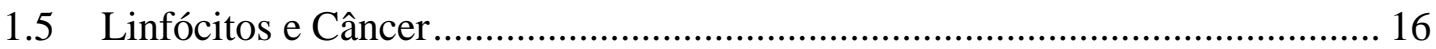

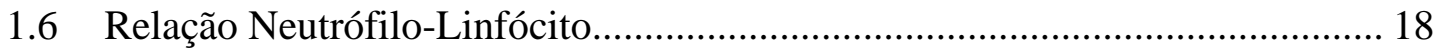

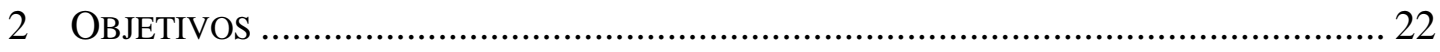

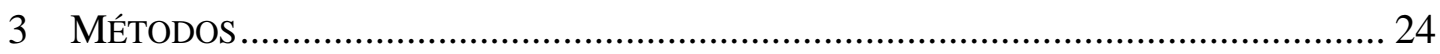

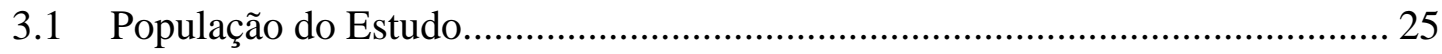

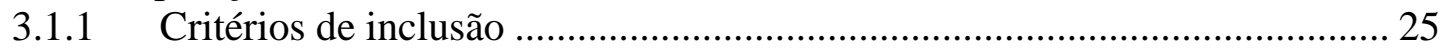

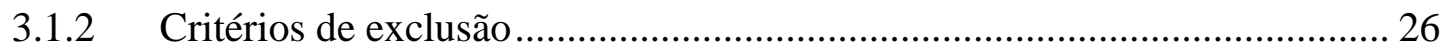

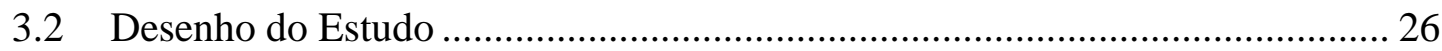

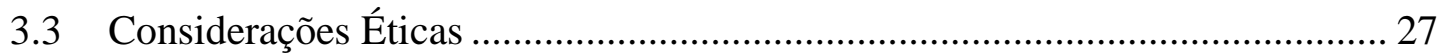

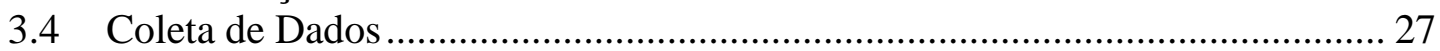

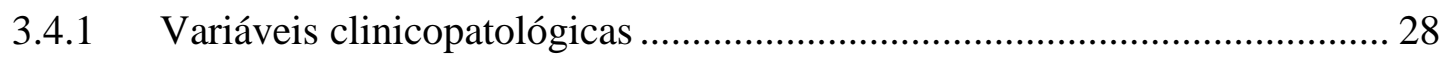

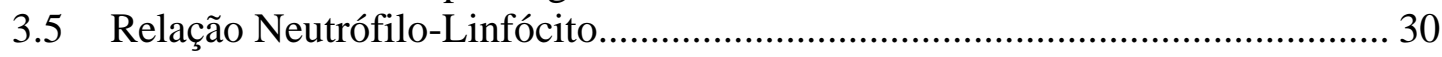

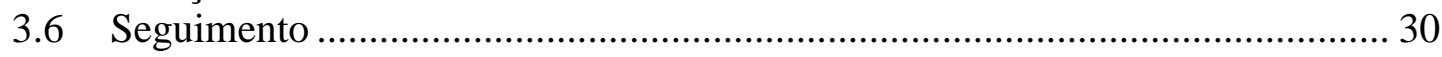

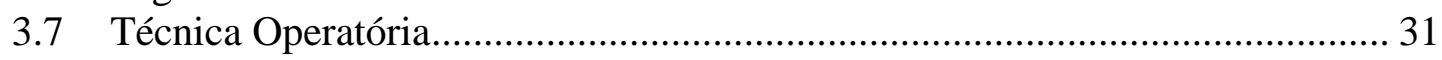

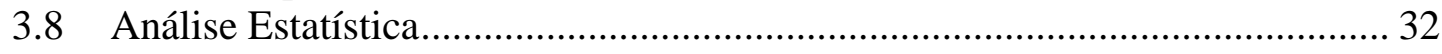

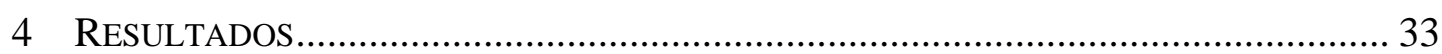

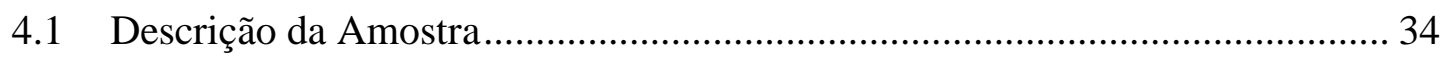

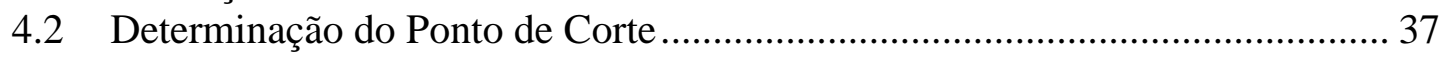

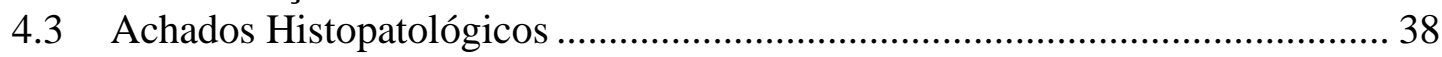

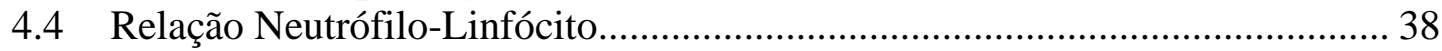

4.5 Relação dos Valores de NLR com Características Clinicopatológicas ............. 40

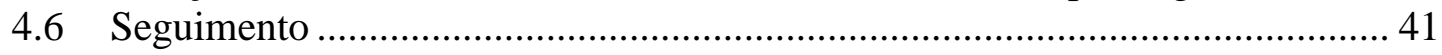

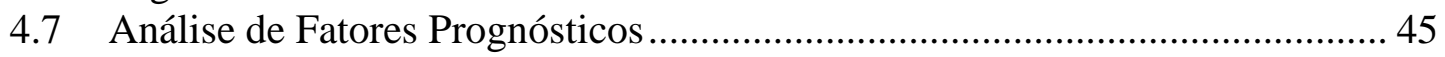

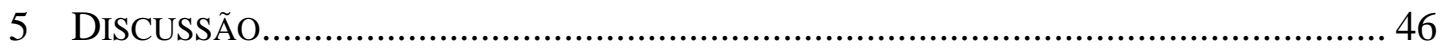

5.1 Relação Neutrófilo-Linfócito e Características Clínico-laboratoriais ............... 53

5.2 Relação Neutrófilo-Linfócito e Características Patológicas .............................. 59

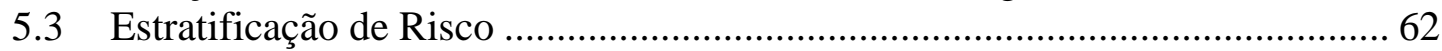

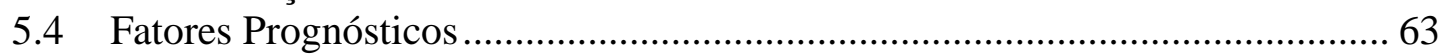

5.5 Considerações Finais e Perspectivas .............................................................. 64 


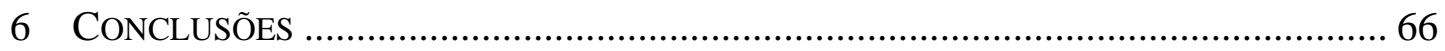

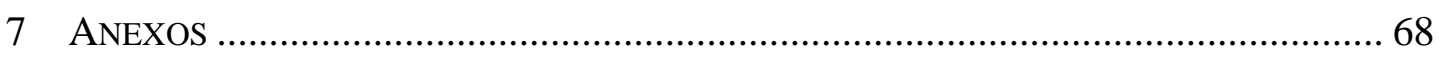

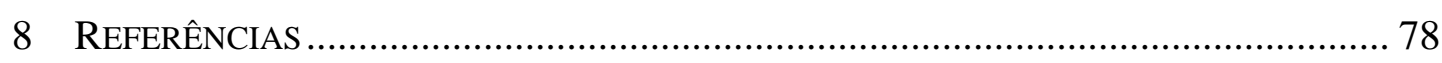

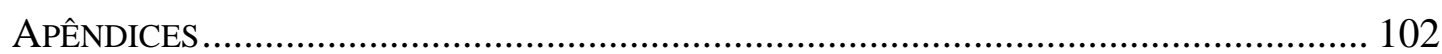




\section{LISTA DE ABREVIATURAS E SIGLAS}

\begin{tabular}{|c|c|}
\hline AJCC & - American Joint Comittee on Cancer \\
\hline ASA & - American Society of Anesthesiologists \\
\hline $\mathrm{CCI}$ & - Charlson-Deyo comorbidity index \\
\hline CG & - Câncer gástrico \\
\hline D1 & - Linfadenectomia D1 \\
\hline D2 & - Linfadenectomia D2 \\
\hline DNA & - Ácido desoxirribonucleico \\
\hline G-CSF & - Fator estimulador de colônias granulocitárias \\
\hline GM-CSF & - Fator estimulador de colônias de granulócitos e macrófagos \\
\hline GPI & - Glasgow prognostic index \\
\hline HCFMUSP & $\begin{array}{l}\text { - Hospital das Clínicas da Faculdade de Medicina da Universidade de } \\
\text { São Paulo }\end{array}$ \\
\hline ICESP & - Instituto do Câncer do Estado de São Paulo \\
\hline IMC & - Índice de massa corpórea \\
\hline iNOS & - Radicais livres de nitrogênio \\
\hline MT & - Microambiente tumoral \\
\hline NLR & - Relação neutrófilo-linfócito \\
\hline PCR & - Proteína C-reativa \\
\hline PLR & - Relação plaqueta-linfócito \\
\hline ROS & - Radicais livres de oxigênio \\
\hline $\mathrm{RR}$ & - Risco relativo \\
\hline SG & - Sobrevida global \\
\hline SLD & - Sobrevida livre de doença \\
\hline TAMs & - Tumoral-associated macrophages \\
\hline TNM & - Tumor, linfonodos, metástases \\
\hline UICC & - Union for International Cancer Control \\
\hline VEGF & - Fator de crescimento vascular endotelial \\
\hline
\end{tabular}




\section{LISTA DE FIGURAS}

Figura 1 - Produto de gastrectomia subtotal, estômago aberto na grande curvatura. Presença de extensa lesão ulcerada compatível com adenocarcinoma gástrico.

Figura 2 - Adenocarcinoma gástrico com estroma linfoide, coloração hematoxilina-eosina (HE), demonstrando intenso infiltrado inflamatório que excede o número de células tumorais. (A) aumento de 10x e (B) aumento de 20x; (C) imuno-histoquímica com citoqueratina AE1/AE3 (IHQ CKAE1/3) onde se observa intenso infiltrado linfocitário em meio às células tumorais coradas, aumento de 10x......

Figura 3 - Mecanismos que demonstram a participação dos neutrófilos e seus subprodutos em diferentes etapas do desenvolvimento tumoral. Os neutrófilos atuam desde fases iniciais como a iniciação e a promoção tumoral até fases mais tardias como a angiogênese e a reconfiguração da matriz extracelular que possibilita a disseminação tumoral. Em todo o processo, a atuação antitumoral dos linfócitos T é inibida pelos neutrófilos

Figura 4 - Fluxograma de seleção dos pacientes até a obtenção dos 383 pacientes com adenocarcinoma gástrico submetidos à gastrectomia com intuito curativo 


\section{LISTA DE TABELAS}

Tabela 1 - Características clínicas e cirúrgicas dos 383 pacientes com adenocarcinoma gástrico submetidos à gastrectomia potencialmente curativa

Tabela 2 - Características patológicas dos 383 pacientes com adenocarcinoma gástrico submetidos à gastrectomia potencialmente curativa ................................................................ 36

Tabela 3 - Valores de NLR de acordo com características clínicas, laboratoriais e patológicas além de recidiva e óbito nos 383 pacientes com adenocarcinoma gástrico submetidos à gastrectomia potencialmente curativa

Tabela 4 - Relação dos grupos NLR baixo $(n=236)$ e alto $(n=147)$ com características clínicopatológicas dos 383 pacientes com adenocarcinoma gástrico submetidos à gastrectomia potencialmente curativa

Tabela 5 - Relação do NLR com o índice de massa corpórea

Tabela 6 - Análise univariada e multivariada para sobrevida livre de doença e sobrevida global nos 383 pacientes com adenocarcinoma gástrico submetidos à gastrectomia potencialmente curativa 


\section{LISTA DE GRÁFICOS}

Gráfico 1 - Curva de Lausen para cálculo do valor de corte de 2,44 da relação neutrófilo-linfócito na população de 383 pacientes com adenocarcinoma gástrico......

Gráfico 2 - Histograma de distribuição dos valores de NLR nos 383 pacientes com adenocarcinoma gástrico submetidos à gastrectomia potencialmente curativo

Gráfico 3 - Curva de Kaplan-Meier demonstrando sobrevida global (A) e livre de doença (B) nos 383 pacientes agrupados de acordo com a relação neutrófilo-linfócito - NLR baixo $(<2,44)$ e NLR alto $(\geq 2,44)$

Gráfico 4 - Curva de Kaplan-Meier de acordo com pT (A), pN (B) e pTNM (C) estratificados pelo NLR - NLR baixo $(<2,44)$ e NLR alto $(\geq$ $2,44)$ 


\section{RESUMO}

Szor DJ. Avaliação da relação neutrófilo-linfócito como fator prognóstico em pacientes com câncer gástrico submetidos à gastrectomia potencialmente curativa [tese]. São Paulo: Faculdade de Medicina, Universidade de São Paulo; 2019.

INTRODUÇÃO: o adenocarcinoma gástrico (AG) persiste com elevada prevalência mundial, apesar da queda progressiva nos casos diagnosticados nas últimas décadas. $\mathrm{O}$ principal pilar do tratamento é a ressecção cirúrgica com intuito curativo. A presença de diferentes prognósticos em pacientes de mesmo estádio indica que fatores não avaliados rotineiramente podem influenciar a sobrevida. Um desses fatores seriam os biomarcadores inflamatórios, sustentados pela ideia que inflamação e câncer são duas entidades intimamente relacionadas. A relação neutrófilo-linfócito (NLR) é um marcador inflamatório que reflete o status inflamatório sistêmico do paciente e que apresenta potencial para predição prognóstica. OBJETIVOS: avaliar a importância prognóstica do NLR em pacientes com AG submetidos à gastrectomia potencialmente curativa. Verificar a associação entre o NLR e características clínicas, laboratoriais e anatomopatológicas dos pacientes. MÉTODOS: Foram avaliados, de forma retrospectiva, 383 pacientes com $\mathrm{AG}$ submetidos à gastrectomia com intuito curativo. $\mathrm{O}$ NLR foi calculado pela divisão entre os neutrófilos e os linfócitos séricos, obtidos de amostras sanguíneas pré-operatórias. Estabeleceu-se o valor de corte do NLR por meio da curva de Lausen e os pacientes foram agrupados em grupos acima ou abaixo deste valor. RESULTADOS: a média e o valor de corte estabelecidos para o NLR foram de 2,53 e 2,44, respectivamente. Dividiram-se os pacientes em grupos de baixo NLR (236 pacientes, 61,6\%) ou alto NLR (147 pacientes, 38,3\%), de acordo com a comparação de seu valor com o valor de corte. O grupo de NLR alto associou-se a pacientes de idade mais avançada $(p=0,03)$, do sexo masculino $(p<0,001)$, com plaquetose $(p=0,015)$ e tumores mais profundos $(p=0,02)$. No seguimento, os pacientes com NLR mais elevado apresentaram menor sobrevida global $(p=0,047)$ e livre de doença $(p=0,045)$. Mais ainda, pacientes com mesmo estádio clínico e grau de invasão tumoral apresentaram pior prognóstico quando o NLR era elevado $(p=0,02$ e $p=0,032$, respectivamente). A análise multivariada identificou o NLR elevado $(p=0,048)$, a hipoalbuminemia $(p=$ $0,019)$, os tumores mais invasivos $(p=0,006)$ e o acometimento linfonodal $(p=0,007)$ como fatores independentes de pior prognóstico para sobrevida global. CONCLUSÃO: o NLR de valor elevado é um fator independente de pior prognóstico, indicando menor sobrevida global em pacientes com câncer gástrico submetidos à gastrectomia com intuito curativo. Seus valores elevados associam-se com idade avançada, sexo masculino, plaquetose e tumores mais invasivos (pT3/pT4). Trata-se de marcador de baixo custo, obtido de forma simples e facilmente reprodutível.

Descritores: Neoplasias gástricas; Carcinogênese; Inflamação; Biomarcadores tumorais; Gastrectomia; Prognóstico. 


\begin{abstract}
Szor DJ. Neutrophil-lymphocyte ratio is associated with prognosis in patients who underwent potentially curative resection for gastric cancer [thesis]. São Paulo: "Faculdade de Medicina, Universidade de São Paulo"; 2019.
\end{abstract}

INTRODUCTION: gastric adenocarcinoma (GA) persists with high worldwide prevalence, despite the progressive fall in cases diagnosed during the last decades. The main cornerstone of the treatment is surgical resection with curative intent. The presence of different prognosis for same stage disease patients indicates that factors not routinely evaluated may influence survival. One of those factors would be the inflammatory biomarkers, supported by the idea that inflammation and cancer are two intimately related entities. The neutrophil-lymphocyte ratio (NLR) is an inflammatory marker, which reflects the systemic inflammatory status of the patient and sets forth a potential for prognosis prediction. OBJECTIVES: to evaluate the prognosis relevance of NLR in patients with GA who underwent potentially curative gastrectomy. To verify the association between NLR and clinical, laboratory and anatomopathological characteristics of the patients. METHODS: 383 patients with GA who underwent gastrectomy were retrospectively evaluated. NLR was calculated by the division between serum neutrophils and lymphocytes, obtained from preoperative blood samples. The cutoff value was established through the Lausen curve and two groups, high and low, were established according to patient's NLR value. RESULTS: the average rate and cutoff value established for NLR were of 2.53 and 2.44 respectively. The patients were divided in groups of low (236 patients, $61.6 \%$ ) and high NLR (147 patients, 38.3\%), according to the comparison of their value with the cutoff value. The high NLR group showed patients of an older age ( $p$ $=0.03)$, male gender $(\mathrm{p}<0.001)$, with thrombocytosis $(\mathrm{p}=0.015)$ and deeper tumors $(p=0.02)$. Subsequently, the patients with a higher NLR presented lower overall survival $(p=0.047)$ and disease-free survival $(p=0.045)$. Even more, patients in the same clinical stage and tumoral invasion grade presented a worse prognosis when NLR was high $(\mathrm{p}=0.02$ and $\mathrm{p}=0.032$, respectively). The multivariate analysis identified NLR ( $\mathrm{p}=0.048)$, hypoalbuminemia $(\mathrm{p}=0.019)$, more invasive tumors ( $\mathrm{p}$ $=0.006)$ and lymph node involvement $(\mathrm{p}=0.007)$ as independent prognosis factors. CONCLUSION: high NLR is an independent factor for worse prognosis, indicating lower overall survival in patients with gastric cancer who underwent curative gastrectomy. Higher values correlates with older age, male gender, thrombocytosis and more invasive tumors (pT3/pT4). This is a low cost marker, obtained through a simple and replicable way.

Descriptors: Stomach neoplasms; Carcinogenesis; Inflammation; Cancer biomarkers; Gastrectomy; Prognosis. 
1 INTRODUÇÃO 
"Se o dano genético é o fósforo que acende o fogo do câncer, alguns tipos de inflamação podem prover o combustível que alimenta a chama"1.

\subsection{Câncer Gástrico}

O câncer gástrico (CG) é uma neoplasia sólida de alta incidência e prevalência que, apesar da redução no número de casos observados ao longo das últimas décadas, ainda representa a quinta neoplasia mais frequente e a terceira causa de óbito por câncer no mundo. Esta posição se traduziu em 1.000.000 de novos casos diagnosticados em 2018, o que representou $6 \%$ de todas as neoplasias. O número de óbitos no mesmo ano foi de $783.000,8 \%$ de todos aqueles relacionados com neoplasia ${ }^{2}$. Ao contrário das atuais estatísticas, o adenocarcinoma gástrico foi a principal causa de óbito relacionada a neoplasia em grande parte do século $20^{3}$.

O número de casos varia entre diferentes partes do mundo, destacando-se o Leste Asiático, Leste Europeu e a América do Sul como locais de maior incidência, com o dobro do número de casos em homens ${ }^{2,4}$. No Brasil, segundo estimativas do Instituto Nacional de Câncer, 21.290 novos casos foram diagnosticados em 2018, sendo 13.540 em homens. Dados mais recentes sobre mortalidade são de 2017, que estimam 14.314 óbitos neste ano. Excluindo-se o câncer de pele não melanótico, o câncer gástrico é a quinta neoplasia mais comum no Brasil, sendo a quarta mais frequente em homens e a sexta nas mulheres ${ }^{5}$. 
Além da diferença de incidência, ocorrem variações entre países concernentes ao estádio clínico no momento do diagnóstico e à mortalidade. Isto porque determinados países do Leste Asiático possuem programas eficazes de rastreamento e detecção precoce do tumor, fato que não ocorre em outros países ${ }^{6}$.

Os principais fatores de risco para o desenvolvimento do câncer gástrico são a infecção pelo Helicobacter pylori, a ingesta elevada de alimentos com alta concentração de sal e a baixa ingesta de frutas e verduras frescas, o tabagismo e o etilismo $^{7}$. Menos frequentes são os casos ocasionados por mutações germinativas na E-caderina ou nos genes de "mismatch repair" que resultam no câncer gástrico familiar e na síndrome de Lynch, respectivamente ${ }^{8,9}$. A redução na incidência observada nas últimas décadas pode ser explicada pela mudança de hábitos alimentares e implementação de métodos eficazes para conservação de alimentos ${ }^{2}$.

Dentre as neoplasias gástricas, destaca-se o adenocarcinoma que representa 90\%-95\% dos casos e é demonstrado na Figura 1. No presente estudo, foi utilizado o termo câncer gástrico como sinônimo de adenocarcinoma gástrico. Outros tipos histológicos de menor incidência são o linfoma (4\%), tumor neuroendócrino (3\%) e o tumor estromal $(2 \%)^{10}$.

Diversas são as classificações destinadas ao câncer gástrico ${ }^{11}$. A principal delas é a classificação de Lauren, que divide os tumores em dois tipos histológicos com diferentes características. O tipo intestinal representa uma variedade bem diferenciada com tendência a formação de glândulas semelhantes à de outras partes do trato gastrointestinal, principalmente o cólon. Caracteriza-se pela disseminação linfática e hematogênica, com menor grau de infiltração da parede gástrica. Associase à presença de gastrite crônica atrófica e metaplasia intestinal decorrentes da 
infecção por H. pylori. Incide mais em homens, populações de países em desenvolvimento e pacientes com idade mais avançada. $\mathrm{O}$ tipo difuso apresenta baixa coesão celular, com tendência à disseminação submucosa. Associa-se com pior prognóstico, metástases precoces e incidência em pacientes mais jovens. Seu evento carcinogênico é a perda da expressão da E-caderina ${ }^{11}$.

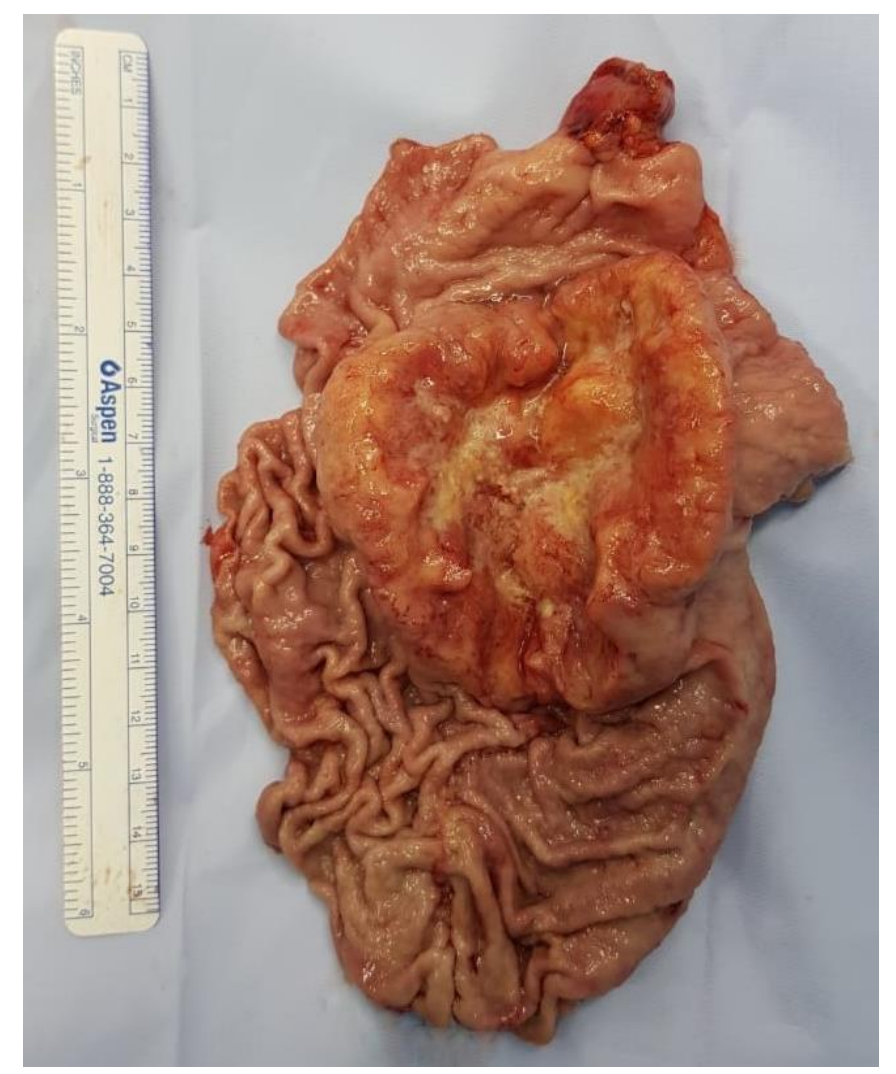

Figura 1 - Produto de gastrectomia subtotal, estômago aberto na grande curvatura. Presença de extensa lesão ulcerada compatível com adenocarcinoma gástrico

Do ponto de vista topográfico, as lesões podem ser classificadas em cárdicas e não cárdicas, lembrando que o declínio de incidência vem acontecendo em lesões do tipo intestinal não cárdicas. As lesões de cárdia apresentaram aumento de seis vezes desde a década de 1980, fato amplamente relacionado com maiores taxas de sobrepeso e aumento no número de casos de esôfago de Barrett ${ }^{12}$. Estas lesões apresentam alta agressividade e tratamento mais complexo. 
Baseado na expressão genética, o câncer gástrico é dividido em quatro tipos de acordo com a classificação proposta pelo Cancer Genome Atlas Research Network: infecção pelo Epstein-Barr vírus, tumores com instabilidade de microssatélites, tumores geneticamente estáveis e tumores cromossomicamente instáveis ${ }^{13}$. Esta classificação apresenta implicação na escolha do tratamento, uma vez que identifica possíveis alvos terapêuticos para cada subtipo ${ }^{14}$.

As classificações utilizadas em pacientes com neoplasias gástricas levam em consideração a topografia, extensão, histologia e padrão molecular. Mais do que agrupar pacientes com características semelhantes de modo a facilitar a predição prognóstica, essas classificações auxiliam na escolha do tratamento adequado e na comparação entre diferentes linhas de tratamento. $\mathrm{O}$ fator de maior relevância para o prognóstico é o estadiamento clínico-patológico, baseado na classificação Tumor, Linfonodos, Metástases (TNM) conforme proposto pela oitava edição da American Joint Comitte on Cancer ${ }^{15}$.

O tratamento do câncer gástrico é multidisciplinar e a cirurgia permanece como principal opção de tratamento definitivo. Variações quanto a extensão da linfadenectomia ocorre entre países, sendo que a linfadenectomia estendida é defendida pelos países orientais ${ }^{16}$. O papel da ressecção endoscópica é restrito para lesões precoces sem sinais de acometimento linfonodal, menores que $2 \mathrm{~cm}$, sem ulcerações e bem diferenciadas ${ }^{17}$. Diversos são os protocolos de quimioterapia perioperatória e não há consenso interinstitucional de protocolos padrões, sendo que o tratamento mais efetivo ainda não foi estabelecido ${ }^{18}$.

O prognóstico após o tratamento depende de algumas variáveis, mas o grande divisor de águas é o acometimento linfonodal. Na ausência de acometimento 
linfonodal, a sobrevida em cinco anos chega a 90\%. Com o acometimento linfonodal e metástases a distância, a sobrevida em 5 anos cai para $31 \%$ e $5 \%$, respectivamente $^{19}$. O câncer gástrico é dito precoce quando acomete mucosa ou submucosa independente do acometimento linfonodal. $\mathrm{O}$ risco de acometimento linfonodal com mucosa ou submucosa comprometida é de 2\%-3\% e 15\%-20\%, respectivamente ${ }^{20}$.

Há que se ressaltar que pacientes com mesmo estádio podem apresentar prognósticos distintos. No intuito de individualizar pacientes e prognósticos, informações complementares ao estádio clássico vêm sendo propostas nas últimas décadas. Uma dessas frentes baseia-se no estudo de marcadores inflamatórios como a relação neutrófilo-linfócito $(\mathrm{NLR})^{21}$ e plaqueta-linfócito $(\mathrm{PLR})^{22}$. Esses biomarcadores particularizam o ambiente no qual o tumor surge e se desenvolve, o que talvez implique em diferentes evoluções e desfechos.

\subsection{Inflamação e Neoplasia}

O desenvolvimento tumoral é um mecanismo complexo realizado em múltiplas etapas. Para tanto, as células tumorais adquirem ao longo da tumorigênese determinadas capacidades biológicas que viabilizam o crescimento, manutenção e disseminação do tumor. Essas capacidades biológicas são separadas em seis marcos: sustentação da sinalização proliferativa, evasão da supressão do crescimento tumoral, imortalidade replicativa, angiogênese, resistência à morte celular e ativação de invasão e metástases ${ }^{23}$. Os agentes geradores e sustentadores dessas características são a instabilidade genômica e a inflamação. 
A ideia de que a inflamação é uma condição inerente a neoplasia não é nova, sendo descrita pela primeira vez em 1863 por Virchow ao observar a presença de leucócitos no parênquima tumoral ${ }^{1}$. A noção de que os tumores, mais do que um conjunto de células autônomas em proliferação, são tecidos complexos nos quais ocorrem inúmeras interações entre diferentes tipos de células se solidificou nas últimas décadas. Atualmente, é consenso que a inflamação pode afetar cada aspecto do desenvolvimento tumoral assim como a resposta ao tratamento ${ }^{24}$.

A proliferação celular sozinha não é capaz de gerar uma neoplasia, porém quando ocorre em um ambiente propenso constituído por células inflamatórias e seus subprodutos, o risco da tumorigênese eleva-se. Neste contexto, o conceito de que tumores são feridas que não cicatrizam foi cunhado por Dvorak ${ }^{25}$, em 1986, na medida em que nos processos cicatriciais normais a resposta inflamatória cessa após o término da cicatrização ou a eliminação do agente agressor. Entretanto, nas neoplasias o processo inflamatório é perpetuado por uma cadeia de ações e reações peritumorais, justificando o termo feridas que não cicatrizam.

Outro dado que corrobora a ligação entre inflamação e câncer é o surgimento de neoplasias em locais com infecção crônica, responsáveis por $15 \%$ do total de neoplasias ${ }^{26}$. Destacam-se alguns exemplos clássicos: associação entre doenças inflamatórias colorretais e o câncer colorretal $^{27}$, infecção crônica pelo vírus da hepatite $\mathrm{C}$ e o hepatocarcinoma ${ }^{28}$, esquistossomose e câncer de bexiga ${ }^{29}$, a infecção pelo H. pylori no câncer gástrico ${ }^{30}$ e o desenvolvimento de carcinoma espinocelular nos casos de esofagite crônica relacionada ao megaesôfago ${ }^{31}$. Neste último caso, estima-se incidência de 2,8\% de carcinoma espinocelular nos casos de megaesôfago chagásico, o que representa um risco 33 vezes maior de desenvolvimento tumoral em relação à população sem megaesôfago ${ }^{31}$. 
Por consequência, a utilização de anti-inflamatórios não esteroidais tem o potencial de reduzir a incidência e mortalidade de alguns tipos de neoplasias, como o câncer colorretal ${ }^{32}$.

A inflamação pode atuar na iniciação e na promoção tumoral. Entende-se por iniciação tumoral o processo onde a célula inicial normal adquire a primeira mutação que a coloca na rota da tumorigênese, conferindo vantagens de crescimento e sobrevivência em relação às células vizinhas ${ }^{33}$. Já a promoção tumoral é o processo de crescimento tumoral a partir da célula inicial mutada até um tumor primário completamente desenvolvido ${ }^{24}$.

O microambiente tumoral (MT) é um tecido composto por diferentes tipos de células, tumorais e inflamatórias, influenciado por moléculas bioativas que desencadeiam cadeias de ações e reações com formação de um leito propício à tumorigênese e desenvolvimento tumoral ${ }^{34}$. Sugere-se que sua complexidade exceda àquelas relacionadas aos tecidos normais e que a vasta maioria dos tumores, senão todos, possuam células inflamatórias associadas independente do fator desencadeador $^{35}$. As células imunes podem regular quase todas as etapas do crescimento tumoral, e podem apresentar efeitos diametralmente opostos, ao bloquear ou estimular o crescimento tumoral ${ }^{36}$.

As células imunes que compõe o MT podem ser inatas (macrófagos, neutrófilos, mastócitos, células supressoras mieloides, células dendríticas e células natural killers) ou adaptativas (linfócitos T e B). O estroma que envolve o conjunto de células inflamatórias e tumorais é formado por fibroblastos, células endoteliais, perícitos e células mesenquimais. As citocinas e quimiocinas permitem a comunicação entre os diferentes tipos de células ${ }^{36}$. 
Vale destacar que não há consenso na literatura médica sobre o termo microambiente tumoral. Certos autores utilizam o termo estroma tumoral para sua definição ${ }^{36,37}$, porém de acordo com Witz et al. ${ }^{38}$ define-se estroma como tecido conjuntivo que compõe a estrutura de órgãos e as células imunes e seus subprodutos, por desempenharem papeis ativos no desenvolvimento tumoral, não poderiam ser definidos somente como estroma.

O MT possui características singulares como a hipóxia, acidose, baixa concentração de glicose e presença de necrose que em conjunto induzem instabilidade genética e modificam a expressão de perfis genéticos que ocorrem nas células neoplásicas ${ }^{39-41}$. A extensa influência do MT não se limita às células neoplásicas, acometendo também células não tumorais, como as endoteliais e os fibroblastos, resultando em alterações citogenéticas nas mesmas ${ }^{42,43}$.

As mutações celulares que ocasionam a iniciação tumoral acima descrita são estimuladas pelo MT, por meio dos radicais livres de oxigênio e espécies de nitrogênio reativo ${ }^{44}$. Ambos subprodutos levam ao estresse oxidativo e nitrosativo com consequente dano celular e instabilidade genética, que é perpetrada pela inibição dos genes de mismatch repair. Esta inibição leva à instabilidade genética, traduzida pela capacidade adquirida da célula em tolerar mutações em seu DNA ${ }^{45}$. Mais ainda, por meio de citocinas como o TNF-alfa, as células inflamatórias promovem o acúmulo de radicais livres também nas células vizinhas à neoplásica, fator característico do $\mathrm{MT}^{45}$.

As Figuras 2A e 2B mostram o intenso infiltrado inflamatório com predomínio de linfócitos no MT de um carcinoma gástrico estroma linfoide. A Figura 2C mostra a imunohistoquimica que destaca em marrom as células neoplásicas, evidenciando o grande infiltrando inflamatório adjacente. 

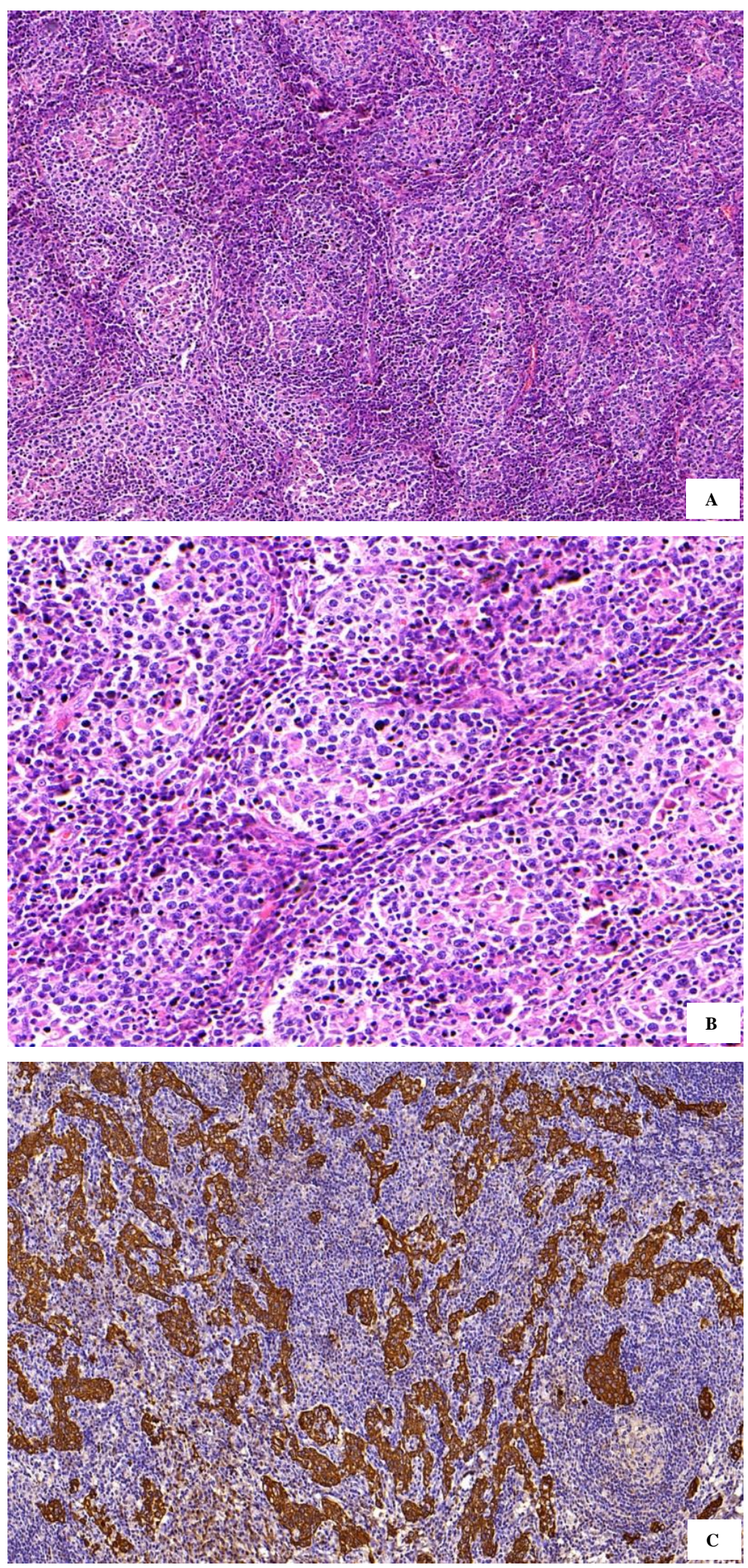

Figura 2 - Adenocarcinoma gástrico com estroma linfoide, coloração hematoxilina-eosina (HE), demonstrando intenso infiltrado inflamatório que excede o número de células tumorais. (A) aumento de 10x e (B) aumento de 20x; (C) imuno-histoquímica com citoqueratina AE1/AE3 (IHQ CKAE1/3) onde se observa intenso infiltrado linfocitário em meio às células tumorais coradas, aumento de 10x. 


\subsection{Estádio e Biomarcadores Inflamatórios}

Estabelecer o prognóstico de pacientes acometidos por neoplasia é um dos pilares que fundamentam a abordagem terapêutica. Para tanto, utiliza-se o estádio clinicopatológico que, tendo por base a experiência com grupos de pacientes previamente avaliados, padroniza a mensuração da extensão da doença e permite estimar a sobrevida individual e comparar tratamentos distintos ${ }^{46}$.

A classificação proposta pela American Joint Comittee on Cancer (AJCC) ${ }^{15}$ foi criada em 1977 e é rotineiramente utilizada para criar uma linguagem comum de compreensão global. Naquela época já era consenso que "estadiar o câncer não é uma ciência exata. Com novas informações sendo disponibilizadas sobre etiologia e métodos diagnósticos e terapêuticos, a classificação e estádio irão mudar"15. Como previsto, realizam-se atualizações periódicas nas classificações de estádio. A tendência das novas versões é a compreensão de que a análise prognóstica é complexa, influenciada por inúmeras variáveis diretamente relacionadas à natureza particular do tumor e do indivíduo no qual ele se desenvolve ${ }^{46}$. O estadiamento atual do câncer gástrico é realizado de acordo com a oitava edição da AJCC que avaliou 25.000 pacientes com câncer gástrico tratados em diferentes países com seguimento mínimo de $5 \operatorname{anos}^{47}$.

Um fato relevante e grande motivador da realização do presente estudo é a existência de pacientes com mesmo estádio patológico que apresentam diferentes prognósticos. O seguimento destes pacientes pode revelar extensa sobrevida livre de doença (SLD) em contraste com recidivas precoces em pacientes com mesmo estádio $^{48}$. A estratificação de risco nesses pacientes se faz necessária para individualização do prognóstico, seguimento e tratamento. Neste ponto encontra-se 
uma fronteira que deve ser ultrapassada pela incorporação de ferramentas mais acuradas, que permitam melhor avaliação dos pacientes, e neste contexto os biomarcadores se destacam ${ }^{49}$. A questão que se coloca é que os esforços realizados neste contexto são descentralizados e com metodologias distintas dificultando a adaptação ao sistema vigente de estádio, o que torna necessária a unificação de resultados multicêntricos ${ }^{46}$.

Os biomarcadores fazem parte do grupo dos sinais médicos, indicadores objetivos de um estado que independe da percepção do paciente. Os biomarcadores integram um diverso grupo de medidas que refletem a interação entre o sistema biológico e um potencial dano. Fazem parte dos biomarcadores medidas básicas como o pulso e a pressão arterial, exames bioquímicos simples até as mais complexas análises séricas e teciduais ${ }^{50}$. Os biomarcadores inflamatórios refletem o status inflamatório sistêmico e dada a relação entre câncer e inflamação, são potenciais indicadores de evolução e desfecho em paciente com neoplasias.

Alguns índices prognósticos baseados em parâmetros inflamatórios já foram propostos e estudados em diversos tipos de tumores primários. Ao se revisar a literatura, identificam-se alguns índices com maior frequência: NLR, PLR, relação monócito-linfócito, Glasgow Prognostic Index (GPI), que utiliza medida de proteína C-reativa e albumina e Prognostic Nutritional Index (NPI), que utiliza os valores de albumina e linfócitos séricos ${ }^{51}$. Independente de resultados obtidos e relevâncias estatísticas, o ponto de comum acordo entre os estudos é a percepção da necessidade de identificar mais variáveis prognósticas além das rotineiramente utilizadas nos sistemas de estádios vigentes. 


\subsection{Neutrófilos e Câncer}

Os granulócitos são células fagocíticas que medem de $12 \mu \mathrm{m}-15 \mu \mathrm{m}$ e apresentam núcleo multilobulado. Seu citoplasma pode conter diferentes tipos de grânulos responsáveis pela subdivisão dos granulócitos em três tipos: neutrófilos, eosinófilos e basófilos.

Os neutrófilos caracterizam-se por reter corantes de $\mathrm{pH}$ neutro e por este motivo receberam esta denominação pelo bacteriologista alemão Paul Ehrlich em $1880^{52}$. Representam 50\%-70\% do total de leucócitos e são os principais responsáveis pela resposta inflamatória aguda e resposta imune inata. Originam-se na medula óssea e apresentam meia-vida curta de 6-7 horas após serem atraídos para os tecidos inflamados ${ }^{53}$. Podem ser produzidos mais de $10^{11}$ neutrófilos por dia ${ }^{54}$ sendo que somente $1 \%-2 \%$ encontra-se na forma madura circulando na corrente sanguínea em condições homeostáticas ${ }^{55}$. Sua principal função é a fagocitose de microrganismos e células mortas, também atuando pela liberação de grânulos com produtos tóxicos, que danificam microrganismos e o próprio tecido saudável do hospedeiro.

O ponto inicial da interação entre o câncer e neutrófilos é a modificação da fisiologia normal de maturação dos neutrófilos na medula óssea. As células tumorais estimulam a produção de G-CSF e GM-CSF, determinando maior taxa e velocidade de maturação dos precursores mieloides ${ }^{52}$. A formação de um neutrófilo hipersegmentado resulta de uma cadeia de maturação que se inicia com as células tronco hematopoiéticas e passa por todas as etapas de maturação do mieloblasto. Vale ressaltar que estímulos intensos resultam na hematopoese de emergência, aonde órgãos extramedulares como o baço têm estimulada a liberação de células imunes ${ }^{56}$. 
Uma vez maduros, a liberação dos neutrófilos para a corrente sanguínea é estimulada pela interleucina-17 e interleucina- $23^{44}$. Já na corrente sanguínea, a própria meia vida dos neutrófilos aumenta de 7 horas para 17 horas, provavelmente em resposta a maior concentração de G-CSF${ }^{44}$. Esse aumento de duração permita ao neutrófilo mais tempo para sintetizar e liberar seus subprodutos.

As formas nas quais os neutrófilos interagem com a célula tumoral são diversas e complexas. O principal é a compreensão de que ocorre uma atuação em grande parte das etapas da tumorigênese, destacando-se: iniciação tumoral, promoção tumoral, angiogênese e disseminação tumoral. A ação dos neutrófilos se faz na prática pela liberação do conteúdo dos seus grânulos. Cada componente exerce ação específica em cada uma dessas etapas. A Figura 3 traz um resumo da ação dos neutrófilos por meio dos seus subprodutos nas principais etapas da tumorigênese.

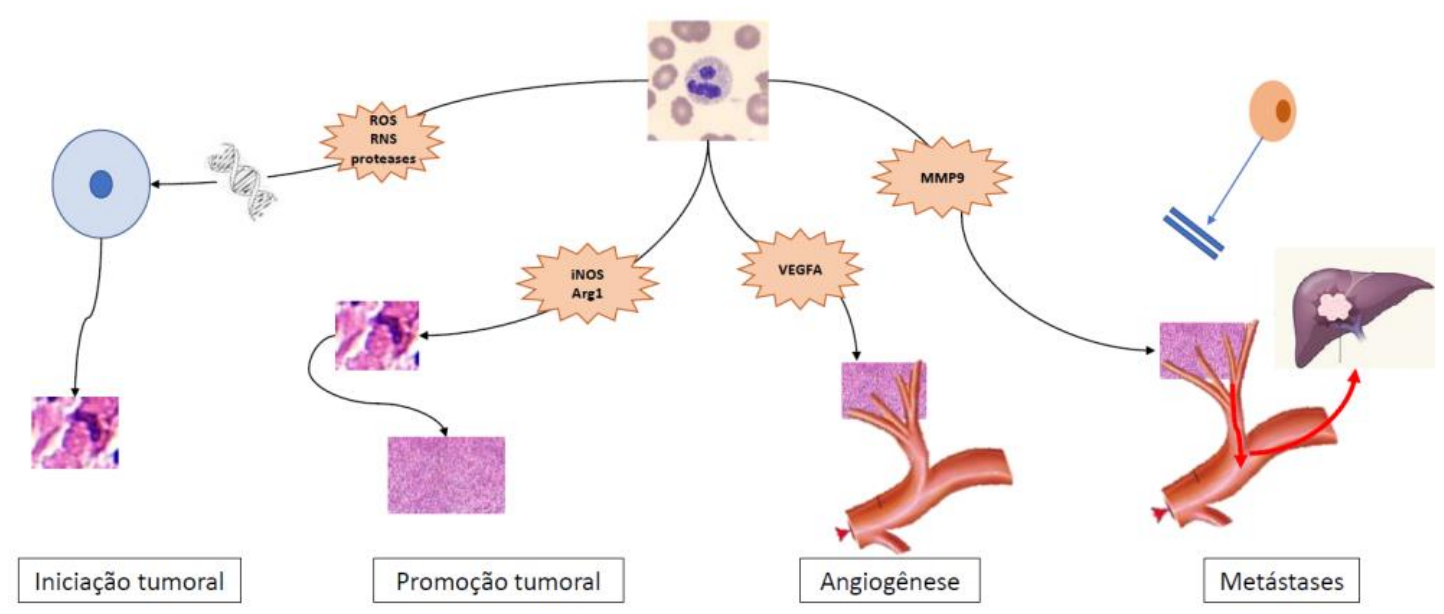

Figura 3 - Mecanismos que demonstram a participação dos neutrófilos e seus subprodutos em diferentes etapas do desenvolvimento tumoral. Os neutrófilos atuam desde fases iniciais como a iniciação e a promoção tumoral até fases mais tardias como a angiogênese e a reconfiguração da matriz extracelular que possibilita a disseminação tumoral. Em todo o processo, a atuação antitumoral dos linfócitos $T$ é inibida pelos neutrófilos [Fonte: Adaptado de Ocana et al. ${ }^{44}$ ] 
Na iniciação tumoral, a liberação dos radicais livres de oxigênio (ROS) e de nitrogênio (RNS) pelos neutrófilos causa dano ao DNA celular e consequente instabilidade genética ${ }^{57}$. A célula tumoral primária inicia seu processo de proliferação para formação do tecido tumoral. Nesta etapa de proliferação tumoral, a ação dos neutrófilos se faz pela elastase neutrofílica e do iNOS ${ }^{58,59}$.

A angiogênese caracteriza-se pela formação de novos vasos sanguíneos e envolve proliferação, migração e diferenciação de células endoteliais ${ }^{60}$. O fator de crescimento vascular endotelial (VEGF) é um potente fator angiogênico, armazenado e prontamente liberado pelos neutrófilos após estímulo específico. No microambiente tumoral, a taxa de produção e liberação do VEGF aumenta, com consequente formação de microvascularização imprescindível para a nutrição tumoral ${ }^{44}$.

A matriz extracelular que envolve as células tumorais e inflamatórias sofre um remodelamento por meio da ação da metaloproteinase 9 secretada pelos neutrófilos. Este remodelamento permite maior mobilidade celular pelo microambiente tumoral. As células endoteliais promotoras de angiogênese tem sua ação facilitada por este processo ${ }^{61}$. Da mesma forma, a célula tumoral encontra menor dificuldade em se liberar da lesão principal e alcançar a rede vascular, no intuito de promover a disseminação tumoral ${ }^{61}$.

É importante destacar que todas as etapas citadas no parágrafo acima podem ser antagonizadas pela ação dos linfócitos T que infiltram o microambiente tumoral. Porém, os neutrófilos promovem ação inibitória justamente contra esses linfócitos que seriam os responsáveis pela vigilância imunológica antitumoral. Por meio da liberação de ROS e arginase, os neutrófilos promovem a apoptose dos linfócitos ${ }^{62,63}$. 
Algumas etapas acima descritas foram reproduzidas in vitro e em modelos animais. Collota et al. ${ }^{64}$ submeteram granulócitos polimorfonucleares a ação de citocinas como TNF, interleucina-1, G-CSF o que resultou na inibição da apoptose destas células e consequente aumento de sua meia-vida.

Já em modelos tumorais em animais, a depleção dos neutrófilos leva a redução do crescimento tumoral ${ }^{65,66}$. Inversamente, a inoculação de granulócitos promove angiogênese e crescimento tumoral ${ }^{67}$.

Os neutrófilos não são as únicas células com potencial pró-tumoral. O microambiente tumoral também é composto pelos tumoral-associated macrophages (TAMs), que se originam dos monócitos presentes na corrente sanguínea. Estima-se que mais da metade dos pacientes com câncer gástrico apresente infiltração tumoral pelos $\mathrm{TAMs}^{68}$. Os macrófagos atuam de forma pró-tumoral promovendo a angiogênese, o remodelamento tissular e a inibição dos linfócitos $\mathrm{T}^{69}$.

\subsection{Linfócitos e Câncer}

Os linfócitos são células que se originam na medula óssea e se dividem em dois tipos de acordo com seu local de maturação: linfócitos T migram para o timo e linfócitos B permanecem na medula óssea. Compõe aproximadamente 10\% das células do mielograma ${ }^{70}$. Caracterizam-se pela presença de receptores específicos em sua superfície e possuem ação direcionada contra antígenos, promovendo uma memória imunológica específica mediada por anticorpos ou por células. São as únicas células do sistema imune adaptativo. Após sua formação, migram para orgãos linfoides secundários onde são apresentados aos antígenos específicos pelas células dendríticas, se diferenciam e proliferam, conjunto resumido pelo termo expansão clonal ${ }^{70}$. 
A ação dos linfócitos T citotóxicos é o principal mecanismo antitumoral do sistema imune, fato inicialmente descrito em $1975^{71}$. É importante a distinção entre os diferentes tipos de linfócitos $\mathrm{T}$ uma vez que apresentam diferentes funções no microambiente tumoral. Os linfócitos T CD8+ citotóxicos atuam diretamente contra a célula tumoral. Os CD4+ helper são divididos em dois tipos, sendo que o $\mathrm{T}$ helper 1 ativa os linfócitos CD8+e o helper 2 atua na resposta humoral e na ativação dos eosinófilos $^{72}$. A divisão em grupos mais específicos continua, porém foge do escopo do presente estudo.

O princípio-chave da resposta imune contra o câncer é a capacidade dos linfócitos reconhecerem antígenos expressados pelas células tumorais por meio do complexo maior de histocompatibilidade. Esses antígenos produzidos por tumores são gerados por genes mutados em diferentes clones de células tumorais e não são produzidos por células saudáveis, motivo pelo qual são reconhecidos pelo sistema imune $^{73}$. Vale ressaltar que este conceito foi primeiro descrito de forma mais simples por Paul Ehrlich em 1909, quando o autor destacou que células transformadas são constantemente geradas no corpo humano, e que o sistema imune as rastreava e eliminava $^{74}$.

A resposta adaptativa do sistema imune é capaz de reconhecer diversos tipos de antígenos, resultando em eficiente resposta antígeno-específica. Esses princípios sustentam o conceito da "vigilância imunológica" proposto por Macfarlane Burnet em $1953^{75}$. Este conceito determina que uma das funções fisiológicas do sistema imune é reconhecer e destruir clones de células mutadas antes da sua transformação em tumores, assim como atuar similarmente em tumores já formados. A maior incidência de neoplasia em organismos imunocomprometidos vai ao encontro com essa teoria ${ }^{76}$. 
A taxa de apoptose dos linfócitos em pacientes com câncer mostra-se elevada. Saito et al. ${ }^{77}$ avaliaram amostras sanguíneas de pacientes com tumor de cabeça e pescoço nos tempos 0 e em 24 horas. Por meio da citometria de fluxo, concluíram que os linfócitos $\mathrm{T}$ eram as células com maiores taxas de apoptose nos pacientes quando comparados com o grupo controle. Destaca-se que no momento da coleta essa taxa já era maior, o que indica que a neoplasia promoveria a apoptose in vivo com consequente linfocitopenia.

Além de apresentar diminuição de seu valor absoluto devido à apoptose, os linfócitos também sofrem com a redução de sua atividade funcional pela interação com os neutrófilos. Em 1985, Petrie et al. ${ }^{78}$ coincubaram linfócitos T com neutrófilos e observaram que a atividade citolítica linfocitária foi comprometida.

\subsection{Relação Neutrófilo-Linfócito}

A relação neutrófilo-linfócito é um marcador calculado pela divisão entre os neutrófilos e linfócitos séricos. O conceito envolvido baseia-se na interação entre as células tumorais e as células imunes. Mais precisamente, na ideia de que neutrófilos e linfócitos exercem atividades diametralmente opostas. Conforme exposto nos parágrafos acima, os neutrófilos atuam de forma pró-tumoral, favorecendo o crescimento e desenvolvimento do tumor. Já os linfócitos, inversamente, combatem as células tumorais dentro do conceito de vigilância imunológica. Portanto, estima-se que quanto maior esta relação, maior é a condição sistêmica oferecida ao desenvolvimento tumoral.

O crescente interesse no estudo do NLR é demonstrado pelo aumento no número de artigos publicados na última década. A primeira citação na literatura desta relação ocorreu em 1967 em um artigo sobre as consequências da exposição ao ozônio 
em modelos murinos ${ }^{79}$. De 1985 até 1998 , os estudos sobre o tema estavam voltados somente para doenças infecciosas ${ }^{80}$ até que em 1998 seu vínculo com as neoplasias começou a ser divulgado, sendo o primeiro artigo voltado para pacientes com câncer gástrico $^{81}$. Até 2012, 125 artigos haviam sido publicados com foco principal no NLR. O grande salto se deu a partir de 2013 , com mais de 2.400 publicações até meados de 2019, números obtidos por pesquisa na plataforma Scopus.

Por se tratar de um marcador inespecífico, diversas especialidades estudam o NLR relacionando-o com a gravidade e o prognóstico de inúmeras patologias. As áreas que concentram o maior número de estudo sobre o tema são a oncologia e cirurgia oncológica, infectologia, cardiologia e neurologia ${ }^{82-84}$.

A função do NLR no contexto das doenças neoplásicas não deve ser considerada de forma isolada. Mais importante é a sua incorporação nos sistemas de estadiamento vigentes com intuito de refinar informações sobre a doença. Um artigo nomeado "Relação neutrófilo-linfócito: outra gota no oceano de biomarcadores no câncer de próstata?" ${ }^{\circ 5}$ defende essa ideia.

O valor prognóstico do NLR relaciona-se com diferentes tipos de tumores sólidos, além das neoplasias gástricas ${ }^{86}$. Uma importante metanálise avaliou cem estudos totalizando quarenta mil pacientes com neoplasia sólidas. Sua conclusão demonstra que valores elevados de NLR associam-se com pior sobrevida em pacientes com neoplasias sólidas gastrointestinais, ginecológicas, pulmonares, neurológicas, urológicas e de cabeça e pescoço ${ }^{21}$.

Os estudos avaliados nesta metanálise mostram uma heterogeneidade quanto aos grupos de pacientes e características tumorais. Diferentes topografias, estádios patológicos e intenções de tratamento (curativos ou paliativos) se misturam. Deste 
fato, conclui-se que a percepção sobre o valor prognóstico do NLR já se concretizou. Porém, sustentado pelo ideal de individualização e estratificação de risco, a avaliação do NLR em subpopulações específicas com tratamentos homogêneos se faz necessária, embasando com maior solidez estatísticas que potencializem a confiança no NLR, a ponto de torná-lo apto para compor o sistema de estadiamento atual.

O foco do NLR no câncer gástrico começou em 1998, quando Hirashima et $a l .{ }^{81}$ demonstraram em análise univariada a relação de um valor alto de NLR com menor sobrevida global (SG). A pequena amostra de 55 pacientes impediu a realização de uma análise multivariada. Os autores destacam na introdução do artigo que "a predição prognóstica de pacientes com câncer pelo exame dos leucócitos no sangue periférico parece um procedimento mais fácil e útil que a análise histopatológica".

Nove anos após esta publicação, Yamanaka et al. ${ }^{87}$ confirmaram por meio da análise multivariada que valores elevados de NLR se relacionam com pior prognóstico. Este artigo ainda destaca o baixo custo e ampla disponibilidade do hemograma necessário para cálculo do NLR quando comparado a outros biomarcadores. Um dado interessante destacado por Wang et al. ${ }^{88}$ ao avaliarem uma população com câncer gástrico e de transição esofagogástrica é que para cada um ponto de elevação do NLR, há um aumento de $10 \%$ no risco de óbito relacionado ao câncer.

A avaliação do NLR em pacientes com neoplasia gástrica submetidos ao tratamento cirúrgico potencialmente curativo foi realizada em alguns estudos ${ }^{89,90}$. Da mesma forma, o NLR mostra-se um marcador eficaz na avaliação prognóstica e seus valores elevados indicam menor sobrevida. 
Em suma, o cenário atual da abordagem do câncer mostra forte tendência a individualização do paciente, a fim de se refinar seu estádio, tratamento e predição prognóstica. A inflamação apresenta intima relação nesta dinâmica e um de seus marcadores sistêmicos é o NLR. Maior volume de dados e análises sobre o NLR são necessárias em populações oncológicas específicas, com características tumorais semelhantes e submetidas à mesmo tipo de tratamento. Neste contexto, este estudo tem por intuito preencher esse espaço com foco em pacientes com tumores gástricos não metastáticos submetidos a tratamento cirúrgico potencialmente curativo. 
2 OBJetivos 
a) Avaliar a importância prognóstica da relação neutrófilo-linfócito em pacientes com câncer gástrico submetidos à gastrectomia potencialmente curativa.

b) Verificar a associação entre a relação neutrófilo-linfócito com características clínicas, laboratoriais e anatomopatológicas dos pacientes. 
3 Métodos 


\subsection{População do Estudo}

Incluíram-se pacientes submetidos à gastrectomia com intuito curativo por adenocarcinoma gástrico operados entre os anos de 2009 e 2016 no Serviço de Cirurgia do Aparelho Digestivo do Instituto do Câncer do Estado de São Paulo do Hospital das Clínicas da Faculdade de Medicina da Universidade de São Paulo (ICESP-HCFMUSP). Os casos foram selecionados com base nos critérios abaixo relacionados.

\subsubsection{Critérios de inclusão}

a) diagnóstico histológico de adenocarcinoma gástrico;

b) ausência de doença metastática pré e/ou intraoperatória;

c) realização de gastrectomia com linfadenectomia com intuito curativo;

d) hemograma completo disponível do período de até 100 dias antes da cirurgia. 


\subsubsection{Critérios de exclusão}

a) gastrectomia realizada em situação de emergência;

b) pacientes submetidos à neoadjuvância;

c) margens cirúrgicas comprometidas microscópica ou macroscopicamente;

d) vigência de infecção, uso de antibióticos, corticoides ou imunomoduladores no período pré-operatório;

e) pacientes que apresentaram óbito intra-hospitalar pós-operatório ou nos primeiros 30 dias após a cirurgia.

Os procedimentos foram realizados por cirurgiões especializados no tratamento cirúrgico do câncer gástrico. A técnica cirúrgica, extensão de ressecção e cadeias linfonodais dissecadas seguiram as recomendações da $\mathrm{JGCA}^{91}$ e foram definidas em reunião multidisciplinar pré-operatória e julgamento intraoperatório do cirurgião responsável pelo caso.

\subsection{Desenho do Estudo}

Trata-se de um estudo observacional, retrospectivo e unicêntrico, com base em dados clínicos, laboratoriais e patológicos de um banco de dados coletado prospectivamente. 


\subsection{Considerações Éticas}

A aprovação da presente pesquisa foi realizada pelo Comitê de ética em Pesquisa da Faculdade de Medicina da Universidade de São Paulo (ICESP-FMUSP) sob o número de registro NP 1159/17, em 12 de julho de 2017 (Anexo A). A aprovação na Plataforma Brasil, que engloba todas as pesquisas científicas envolvendo seres humanos do país, foi obtida em 20/09/2017, sob o CAAE 76483517.8.0000.0065 (Anexo B).

Coletaram-se os dados clínicos por meio de registros em prontuário eletrônico armazenados em banco de dados médicos, conforme projeto de pesquisa intitulado "Banco de dado de pacientes do Serviço de Cirurgia Oncológica do Aparelho Digestivo do ICESP-HCFMUSP”, com aprovação pelo Comitê de ética em Pesquisa da Faculdade de Medicina da Universidade de São Paulo (ICESP-FMUSP) sob o número de registro NP 993/2016, em 5 de agosto de 2016.

\subsection{Coleta de Dados}

Os dados foram coletados e inseridos na base por médicos assistentes do grupo de estômago do ICESP e o seguimento dos pacientes é atualizado anualmente. 


\subsubsection{Variáveis clinicopatológicas}

Os pacientes foram avaliados no pré-operatório de forma padronizada que inclui exames laboratoriais, endoscopia digestiva alta com biópsia, tomografia computadorizada de tórax, abdome e pelve.

Os dados clínicos, laboratoriais e patológicos coletados no período perioperatório foram os abaixo listados:

a) idade: em anos, da data de nascimento à data da cirurgia;

b) registro hospitalar (RGHC);

c) sexo: masculino ou feminino;

d) índice de massa corpórea: calculado pela divisão entre o peso em quilogramas pela altura em centímetros elevada ao quadrado. Valor dado $\mathrm{em} \mathrm{kg} / \mathrm{m}^{2}$

e) comorbidades: foi utilizado o índice de comorbidades de Charlson ${ }^{92}$. A partir dos 40 anos, foi acrescentado 1 ponto para cada década de vida. Valores de CCI $\geq$ a 5 foram considerados como altos. Presença de neoplasia não foi considerada para pontuação;

f) classificação de ASA: escore utilizado pela anestesiologia seguindo os seguintes critérios: I- paciente saudavel II- doença sistêmica moderada, sem limitação de funções vitais III- doença sistêmica severa, com funnções vitais comprometidas IV- doença sistêmica severa com ameaça à vida ${ }^{93}$;

g) hemoglobina: número absoluto determinado por $\mathrm{g} / \mathrm{dL}$;

h) neutrófilos: número absoluto determinado por $\mathrm{mm}^{3}$;

i) linfócitos: número absoluto determinado por $\mathrm{mm}^{3}$; 
j) plaquetas: número absoluto determinado por $\mathrm{mm}^{3}$;

k) albumina: número absoluto determinado por $\mathrm{g} / \mathrm{dL}$;

1) localização do tumor: classificado em proximal (cárdia e fundo), médio (corpo), distal (antro e incisura angular) ou total (acometimento difuso);

m) extensão da ressecção: classificada como subtotal ou total;

n) extensão da linfadenectomia: definido em D1 (linfonodos perigástricos) ou D2 (D1 + linfonodos nos trajetos grandes vasos perigástricos);

o) tipo histológico de Lauren: determinado como intestinal, difuso, misto ou indeterminado;

p) grau de diferenciação histológica: classificado como bem diferenciado, moderadamente diferenciado ou pouco diferenciado;

q) grau de penetração tumoral: determinado em pT1 (pT1a: invasão mucosa pT1b: invasão submucosa), pT2 (invasão muscular própria), pT3 (invasão subserosa) ou pT4 (pT4a: invasão serosa pT4b: invasão orgãos adjacentes. Utilizado de acordo com os critérios de estadiamento $8^{\circ}$ edição (UICC 2016);

r) número de linfonodos dissecados: número total de linfonodos submetidos à análise histológica, independente da cadeia linfonodal;

s) presença de metástase linfonodal: Presente ou ausente. Definição categórica, independente do número de linfonodos acometidos;

t) estádio pTNM: definidos em estádio I, II, III ou IV de acordo com os critérios de estádio oitava edição (UICC 2016). 


\subsection{Relação Neutrófilo-Linfócito}

O cálculo da relação neutrófilo-linfócito foi realizado pela divisão dos neutrófilos pelos linfócitos séricos obtidos do mesmo hemograma. O hemograma considerado foi após o diagnóstico e antes da cirurgia. Foram incluídas duas casas decimais no valor do NLR.

As análises laboratoriais foram realizadas no ICESP, com utilização do analisador hematológico XT-2000i e XE-2100D da companhia Sysmex ${ }^{\circledR}$ (Kobe, Japão).

Para fins de divisão da população em dois grupos de acordo com o NLR, foi calculado um valor de corte pela curva de Lausen. Os grupos foram divididos da seguinte forma:

1. Grupo NLR alto: pacientes que apresentaram valor do NLR maior ou igual ao valor de corte.

2. Grupo NLR baixo: pacientes que apresentaram valor do NLR menor que o valor de corte.

\subsection{Seguimento}

O seguimento ambulatorial foi realizado de forma trimestral no primeiro ano e semestral nos anos seguintes à cirurgia. Considerou-se como perda de seguimento a ausência em consulta por mais de 12 meses consecutivos.

Os dados coletados no seguimento foram os seguintes:

a) ocorrência de recidiva: confirmada através de exame de imagem e/ou histopatológico;

b) data da recidiva;

c) ocorrência de óbito;

d) data do óbito. 


\subsection{Técnica Operatória}

A técnica anestésica realizada consistiu em sua maioria de bloqueio peridural associado a anestesia geral, com necessidades individuais decididas pela equipe de anestesia. Com o paciente posicionado em decúbito dorsal, uma incisão mediana xifo-umbilical é realizada, a parede abdominal é aberta por planos e a cavidade é inspecionada para identificação de eventuais lesões metastáticas ou carcinomatosas. Procede-se com a coleta da citologia oncótica.

$\mathrm{Na}$ ausência de lesões sugestivas de acometimento secundário, procede-se com a gastrectomia. A extensão da linfadenectomia e o tipo de ressecção (gastrectomia subtotal ou total) são decididos no intraoperatório pelo médico assistente responsável.

Inicia-se o procedimento pelo descolamento intercolo-epiploico por meio do plano avascular entre o mesocolon e o grande omento, com atenção à preservação dos vasos cólicos. Atinge-se o platô pancreático e resseca-se a cápsula pancreática seletivamente. A artéria hepática comum é identificada e segue-se para dissecção da veia e artéria gastroepiplóica direitas com linfadenectomia da cadeia 6. A porção supraduodenal é isolada no local a ser grampeado e o duodeno é seccionado com grampeador linear. Reforço da linha de grampeamento duodenal é realizado com sutura contínua de prolene 3-0. Na sequência, a artéria gástrica direita é isolada e ligada em sua origem com fio de algodão 2-0. A linfadenectomia estende-se ao longo da cadeia 8a e 12a com posterior ressecção da pars flácida em direção ao pilar diafragmático direito, com linfadenectomia da cadeia 1. A veia e artéria gástrica esquerda são isoladas e ligadas em sua origem, com linfadenectomia das cadeias 7 e 9 . 
Em se tratando de gastrectomia subtotal, o estômago é seccionado com margens adequadas com grampeador linear e a peça é retirada. No caso da gastrectomia total, liberam-se os vasos gástricos curtos e gastroepiplóicos esquerdos, isola-se o esôfago abdominal e o mesmo é seccionado, com congelação da margem se necessário.

Após a realização das anastomoses, a cavidade é drenada com dreno siliconado vigiando o coto duodenal e a anastomose esôfago-jejunal nos casos de gastrectomia total.

\subsection{Análise Estatística}

O estabelecimento do valor de corte do NLR foi realizado pelo método de Lausen. A comparação de características clínico-patológicas foi realizada pelo teste de chi-quadrado para variáveis categóricas e $t$ de student para variáveis contínuas. As sobrevidas global e livre de doença foram avaliadas pelo método de Kaplan-Meier e a comparação entre as curvas foi obtida pelo teste de log-rank.

Os fatores de risco independentes para sobrevida global e livre de doença foram determinados pela análise multivariada de Cox. Somente variáveis que foram significativas na análise univariada foram incluídas como covariáveis na análise multivariada. O valor de significância aplicado foi de 5\%, sempre considerando a hipótese alternativa bicaudal.

A sobrevida livre de doença e global foram calculadas em meses da data da cirurgia até a recidiva ou o óbito, respectivamente. Os pacientes vivos foram censurados no dia do último contato.

O software R versão 3.4.1 foi utilizado para realização de todas as análises. 
4 ReSUltados 


\subsection{Descrição da Amostra}

Entre março de 2009 e fevereiro de 2016, 818 pacientes foram submetidos à procedimentos cirúrgicos por câncer gástrico (todos os tipos) no Instituto do Câncer da Faculdade de Medicina da Universidade de São Paulo. A Figura 4 ilustra a seleção dos casos.

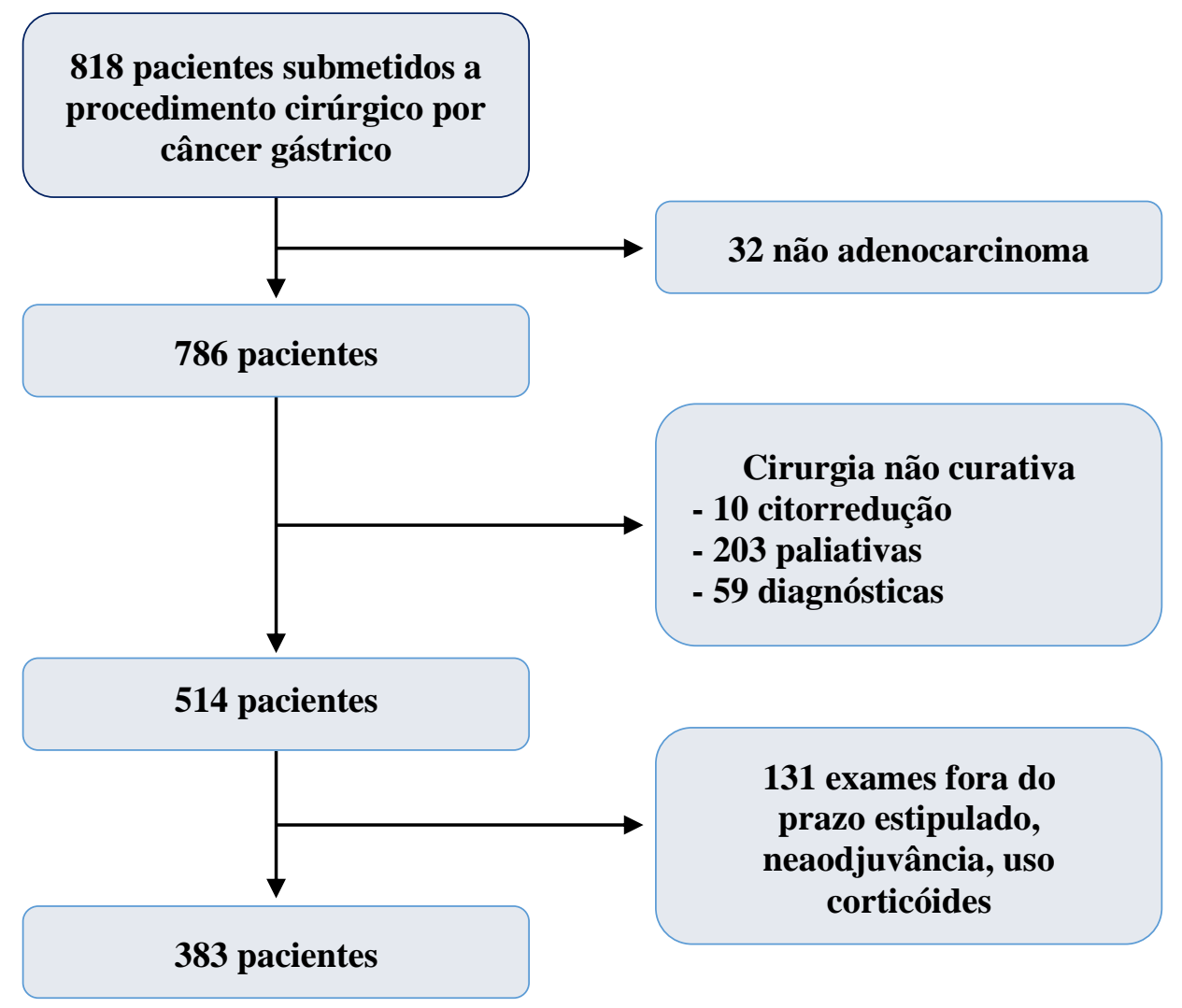

Figura 4 - Fluxograma de seleção dos pacientes até a obtenção dos 383 pacientes com adenocarcinoma gástrico submetidos à gastrectomia com intuito curativo 
Após a seleção, 383 pacientes foram incluídos no estudo. As características clínicas e cirúrgicas são descritas na Tabela 1. A média de idade foi 62,9 anos, predominando o sexo masculino $(60,3 \%)$. O procedimento mais realizado foi a gastrectomia subtotal (64\%) com linfadenectomia D2 (90\%).

Tabela 1 - Características clínicas e cirúrgicas dos 383 pacientes com adenocarcinoma gástrico submetidos à gastrectomia potencialmente curativa

\begin{tabular}{|c|c|c|}
\hline Variáve & $n=383$ & $\%$ \\
\hline \multicolumn{3}{|c|}{ Idade (anos) } \\
\hline Média \pm DP & $62,9 \pm 12,48$ & - \\
\hline Min-max & $25-94$ & - \\
\hline \multicolumn{3}{|l|}{ Sexo } \\
\hline Feminino & 152 & 39,6 \\
\hline Masculino & 231 & 60,4 \\
\hline \multicolumn{3}{|l|}{$\operatorname{IMC}\left(\mathrm{kg} / \mathrm{m}^{2}\right)^{*}$} \\
\hline Média \pm DP & $24,2 \pm 4,7$ & - \\
\hline Min-max & $13,9-46,5$ & - \\
\hline \multicolumn{3}{|c|}{ Neutrófilos $\left(/ \mathrm{mm}^{3}\right)$} \\
\hline Média \pm DP & $4294,8 \pm 2283,2$ & - \\
\hline Min-max & $550-19100$ & - \\
\hline \multicolumn{3}{|c|}{ Linfócitos $\left(/ \mathrm{mm}^{3}\right)$} \\
\hline Média \pm DP & $1954,7 \pm 870,6$ & - \\
\hline Min-max & $260-11370$ & - \\
\hline \multicolumn{3}{|c|}{ Plaquetas $\left(/ \mathrm{mm}^{3}\right)$} \\
\hline Média \pm DP & $272 \times 10^{3} \pm 171 \times 10^{3}$ & - \\
\hline Min-max & $32 \times 10^{3}-291 \times 10^{3}$ & - \\
\hline \multicolumn{3}{|l|}{ Albumina } \\
\hline Média \pm DP & $3,99 \pm 0,58$ & - \\
\hline Min-max & $1,4-5$ & - \\
\hline \multicolumn{3}{|c|}{ Relação neutrófilo-linfócito } \\
\hline Média \pm DP & $2,53 \pm 1,86$ & - \\
\hline Min-max & $0,36-16,98$ & - \\
\hline \multicolumn{3}{|c|}{ Extensão da ressecção } \\
\hline Subtotal & 245 & 64 \\
\hline Total & 138 & 36 \\
\hline \multicolumn{3}{|c|}{ Extensão da linfadenectomia } \\
\hline D1 & 39 & 10,1 \\
\hline D2 & 344 & 89,8 \\
\hline \multicolumn{3}{|c|}{ Localização do tumor } \\
\hline Proximal & 43 & 11,2 \\
\hline Média & 94 & 24,5 \\
\hline Distal & 236 & 61,6 \\
\hline Todo órgão & 10 & 2,6 \\
\hline
\end{tabular}

$\mathrm{n}=359$. 
As características patológicas são descritas na Tabela 2. O tipo de tumor mais comum foi o avançado $(73,4 \%)$, distal $(61,6 \%)$, do tipo intestinal $(51,1 \%)$ com acometimento linfonodal $(55,3 \%)$.

Tabela 2 - Características patológicas dos 383 pacientes com adenocarcinoma gástrico submetidos à gastrectomia potencialmente curativa

\begin{tabular}{lcc}
\multicolumn{1}{c}{ Variáveis } & $\mathbf{n = 3 8 3}$ & $\mathbf{\%}$ \\
Tipo histológico & & \\
$\quad$ Intestinal & 196 & 51,1 \\
Difuso & 132 & 34,4 \\
Misto & 37 & 9,6 \\
Indeterminado & 18 & 4,6 \\
Grau de diferenciação histológica & \\
G1/G2 & 191 & 49,9 \\
G3 & 192 & 50,1 \\
Invasão tumoral (pT) & & \\
pT1 & 106 & 27,6 \\
pT2 & 52 & 13,5 \\
pT3 & 123 & 32,1 \\
pT4 & 102 & 26,6 \\
Metástase linfonodal & & \\
N- & 171 & 44,6 \\
N+ & 212 & 55,3 \\
Número de linfonodos dissecados & \\
Média \pm DP & $39,3 \pm 17,11$ & - \\
Min-max & $16-115$ & - \\
Estádio pTNM (8 ${ }^{a}$ edição) & \\
I & 127 & 33,1 \\
II & 87 & 22,7 \\
III & 169 & 44,1 \\
\hline
\end{tabular}




\subsection{Determinação do Ponto de Corte}

A obtenção do ponto de corte no valor do NLR foi realizada pela curva de Lausen, que estabelece um ponto de corte minimizando o p-valor da diferença de duas curvas de sobrevida, ou seja, usa informação de duas variáveis (recidiva e óbito) (Gráfico 1).

Gráfico 1 - Curva de Lausen para cálculo do valor de corte de 2,44 da relação neutrófilo-linfócito na população de 383 pacientes com adenocarcinoma gástrico

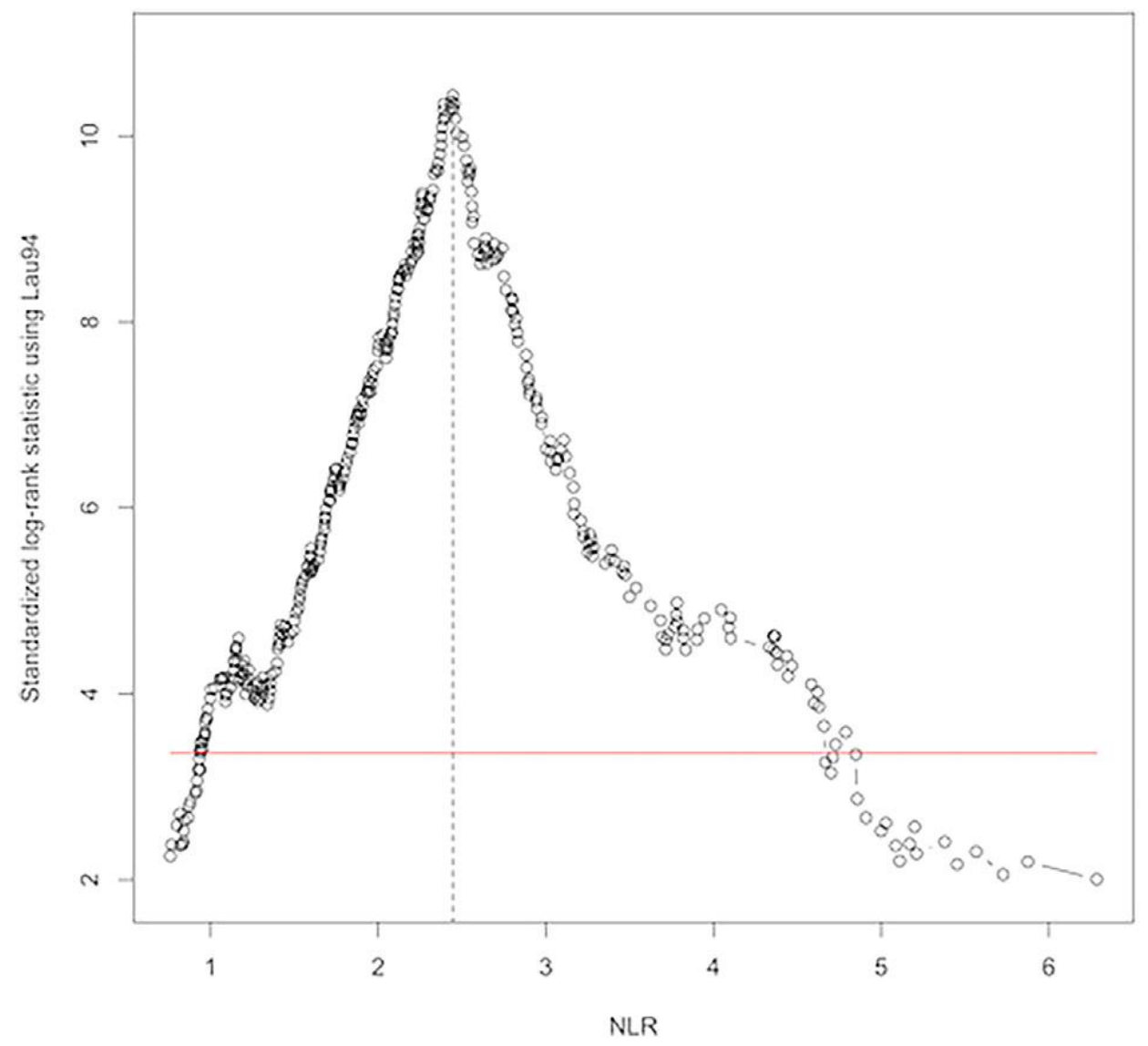

O valor de corte obtido foi de 2,44. Com isso, os pacientes foram divididos em dois grupos de acordo com o valor do NLR. Pacientes com NLR $<2,44$ e NLR $\geq 2,44$ foram denominados "NLR baixo" e "NLR alto", respectivamente. 


\subsection{Achados Histopatológicos}

O grau de invasão tumoral na parede gástrica mais frequente foi o pT3 (32,1\%). A média de linfonodos dissecados por peça foi de 39,7 (mínimo 16 máximo 115). O acometimento linfonodal ocorreu em 212 casos $(55,3 \%)$ e a média de linfonodos acometidos neste grupo foi de 8,5 (1-53).

\subsection{Relação Neutrófilo-Linfócito}

Considerando-se o valor de corte estabelecido de 2,44, 236 (61,6\%) pacientes apresentaram valor menor ao corte e 147 (38,3\%) apresentaram valor maior ou igual ao mesmo. O histograma de distribuição dos valores de NLR é demonstrado no Gráfico 2.

Gráfico 2 - Histograma de distribuição dos valores de NLR nos 383 pacientes com adenocarcinoma gástrico submetidos à gastrectomia potencialmente curativo

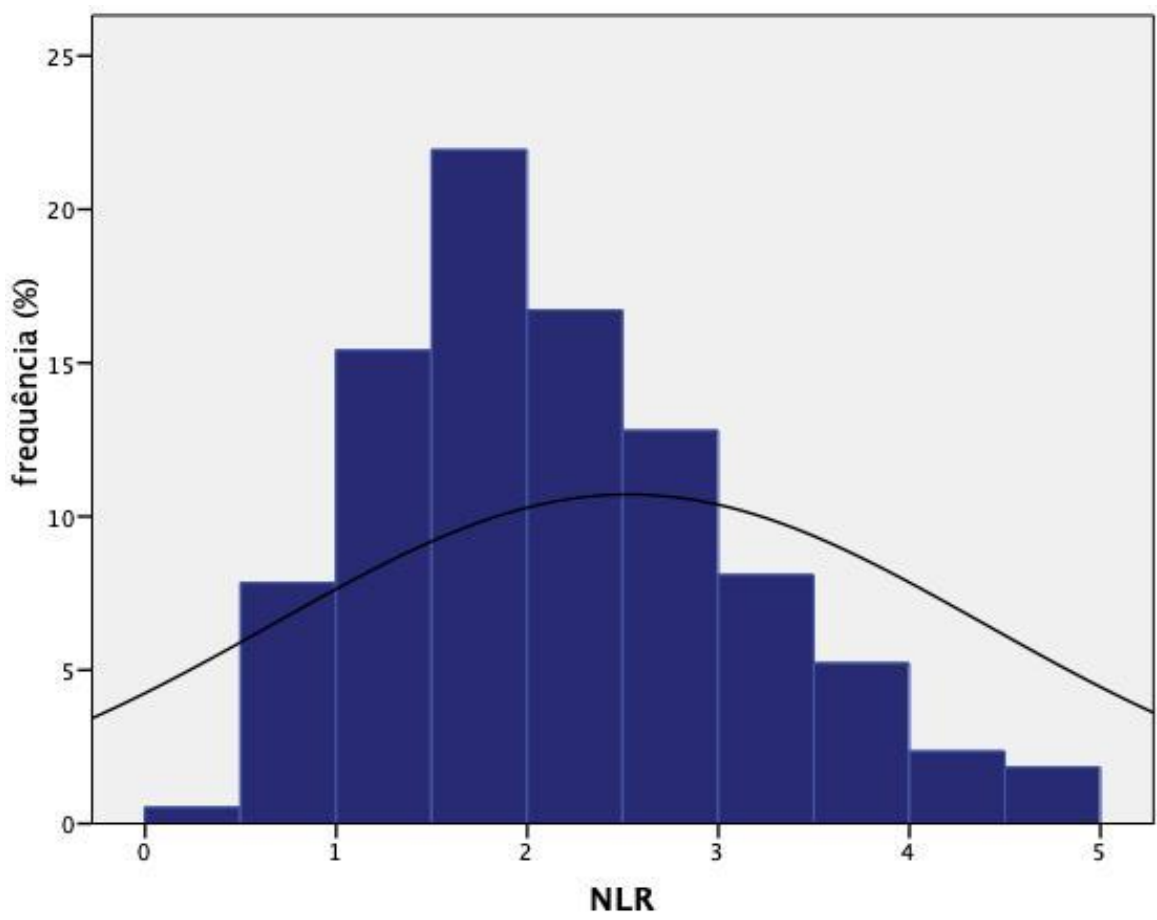


O NLR apresentou mediana de 2,12 (média de 2,53 - mínimo 0,37 máximo 17). Os valores médios dos neutrófilos e linfócitos foram $4294,9 / \mathrm{mm}^{3}$ (550-19100) e $1954,7 / \mathrm{mm}^{3}$ (260-11370), respectivamente (Tabela 1).

A distribuição dos valores de NLR de acordo com idade, sexo, IMC, plaquetas, grau de invasão tumoral, acometimento linfonodal, estádio, recidiva e óbito são demonstrados na Tabela 3.

Tabela 3 - Valores de NLR de acordo com características clínicas, laboratoriais e patológicas além de recidiva e óbito nos 383 pacientes com adenocarcinoma gástrico submetidos à gastrectomia potencialmente curativa

\begin{tabular}{|c|c|c|c|c|}
\hline & $n$ & Média & Mín & Máx \\
\hline $\mathrm{T} 1^{*}$ & 113 & 2,24 & 0,5 & 9,3 \\
\hline $\mathrm{T} 2^{*}$ & 47 & 2,36 & 0,67 & 10,67 \\
\hline T3* & 120 & 2,39 & 0,36 & 8,05 \\
\hline $\mathrm{T} 4^{*}$ & 103 & 3,10 & 0,75 & 16,98 \\
\hline $\mathrm{N}-$ & 169 & 2,38 & 0,5 & 10,67 \\
\hline $\mathrm{N}+$ & 214 & 2,64 & 0,36 & 16,98 \\
\hline $\mathrm{EI}^{*}$ & 132 & 2,33 & 0,5 & 10,67 \\
\hline EII ${ }^{*}$ & 81 & 2,50 & 0,67 & 8,05 \\
\hline EIII* & 170 & 2,75 & 0,36 & 16,98 \\
\hline Recidiva & 91 & 2,65 & 0,36 & 16,98 \\
\hline Sem recidiva & 292 & 2,49 & 0,5 & 15,22 \\
\hline Óbito & 112 & 2,76 & 0,36 & 16,98 \\
\hline Sem óbito & 271 & 2,44 & 0,5 & 15,22 \\
\hline$\leq 65$ anos & 207 & 2,46 & 0,36 & 13,64 \\
\hline$>65$ anos & 176 & 2,61 & 0,41 & 16,98 \\
\hline Plaquetas $\leq 350 \times 10^{3 * *}$ & 316 & 2,42 & 0,36 & 16,98 \\
\hline Plaquetas $>350 \times 10^{3 * *}$ & 67 & 3,05 & 0,74 & 13,64 \\
\hline Feminino & 152 & 2,14 & 0,5 & 9,3 \\
\hline Masculino & 231 & 2,79 & 0,36 & 16,98 \\
\hline $\mathrm{IMC} \leq 24,2^{* * * *}$ & 177 & 2,75 & 0,41 & 16,98 \\
\hline $\mathrm{IMC}>24,2$ & 182 & 2,32 & 0,55 & 13,64 \\
\hline
\end{tabular}

*critérios de acordo com 8 a edição AJCC; ** por milímetro cúbico; *** mediana de IMC dos 359 casos com valores de IMC disponíveis.

Min: valor mínimo de NLR; Max: valor máximo de NLR; T1: tumor invade mucosa e submucosa; T2: tumor invade muscular própria; T3: tumor invade subserosa; T4: tumor invade serosa / órgãos adjacentes; EI: estádio I; EII: estádio II; EIII: estádio III; N-: ausência de acometimento linfonodal; $\mathrm{N}+$ : presença de acometimento linfonodal. 


\subsection{Relação dos Valores de NLR com Características Clinicopatológicas}

Conforme o valor de corte estabelecido, pacientes foram divididos em grupos de alto e baixo NLR. Os dados clinicopatológico são apresentados na Tabela 4. Idade avançada $(p=0,038)$, sexo masculino $(p=<0,001)$, plaquetose $(p=0,015)$ e pT mais avançado $(p=0,027)$ se associaram com NLR elevado.

Tabela 4 - Relação dos grupos NLR baixo $(n=236)$ e alto $(n=147)$ com características clínicopatológicas dos 383 pacientes com adenocarcinoma gástrico submetidos à gastrectomia potencialmente curativa

\begin{tabular}{|c|c|c|c|}
\hline \multirow{2}{*}{ Variáveis } & NLR baixo & NLR alto & \multirow{2}{*}{$p$} \\
\hline & $n=236(\%)$ & $n=147(\%)$ & \\
\hline Idade $(\operatorname{anos})^{* *}$ & & & $\mathbf{0 , 0 3 8}$ \\
\hline Média $( \pm \mathrm{DP})$ & $61,9(12,2)$ & $64,6(12,8)$ & \\
\hline Sexo* $^{*}$ & & & $<0,001$ \\
\hline Masculino & $125(53)$ & $106(72,1)$ & \\
\hline Feminino & $111(47)$ & $41(27,9)$ & \\
\hline Albumina $(\mathrm{g} / \mathrm{dL})^{* *}$ & & & 0,821 \\
\hline Média ( \pm DP) & $4,0(0,5)$ & $4,0(0,6)$ & \\
\hline Plaquetas $\left(\times 10^{6 /} \mathrm{mm}^{3}\right)^{* *}$ & & & 0,015 \\
\hline Média ( \pm DP) & $252(88,6)$ & $305(25,3)$ & \\
\hline Tipo de Gastrectomia* & & & 0,377 \\
\hline Subtotal & $155(65,7)$ & $90(61,2)$ & \\
\hline Total & $81(34,3)$ & $57(38,8)$ & \\
\hline pT status ${ }^{*}$ & & & $\mathbf{0 , 0 2 7}$ \\
\hline $\mathrm{pT} 1 / \mathrm{T} 2$ & $109(46,2)$ & $51(34,7)$ & \\
\hline $\mathrm{pT} 3 / \mathrm{T} 4$ & $127(53,8)$ & $96(65,3)$ & \\
\hline Linfonodos dissecados ${ }^{* *}$ & & & 0,121 \\
\hline Média $( \pm \mathrm{DP})$ & $40,2(18,3)$ & $37,3(16)$ & \\
\hline pN status* & & & 0,234 \\
\hline Negativo & $111(47)$ & $60(40,8)$ & \\
\hline Positivo & $125(53)$ & $87(59,2)$ & \\
\hline Estádio TNM* & & & 0,224 \\
\hline I-II & $137(58,1)$ & $76(51,7)$ & \\
\hline III & $99(41,9)$ & $71(48,3)$ & \\
\hline
\end{tabular}

* teste de chi-quadrado; ** teste $t$ de student. 
A relação das médias de NLR com subgrupos de pacientes agrupados de acordo com seu índice de massa corpórea é demonstrada na Tabela 5. Os valores de NLR diminuem com o aumento do IMC.

Tabela 5 - Relação do NLR com o índice de massa corpórea

\begin{tabular}{|ccc|}
\hline $\mathbf{I M C}\left(\mathbf{k g} / \mathbf{m}^{2}\right)^{*}$ & NLR (média) & $\mathbf{N}$ \\
\hline $13,9-20$ & 2,79 & 63 \\
$20,1-25$ & 2,73 & 146 \\
$25,1-30$ & 2,32 & 115 \\
$30,1-35$ & 2,25 & 24 \\
$>35$ & 1,8 & 11 \\
\hline$* \mathrm{n}=359$ & & \\
\hline
\end{tabular}

\subsection{Seguimento}

Em um seguimento médio de 28,5 meses (mediana 24,3 meses 1-90 meses), um total de 91 pacientes apresentou recidiva da doença e 112 morreram. De acordo com o valor de corte do NLR, a sobrevida livre de doença e a sobrevida global foi significativamente pior no grupo de pacientes NLR alto quando comparados com o NLR baixo ( $p=0,047$ e $p=0,045$, respectivamente) (Gráfico 3).

A estratificação de risco de acordo com o NLR foi realizada em tumores com mesma profundidade (T4 e < T4), mesmo estádio pTNM (III e < III) e mesmo comprometimento linfonodal ( $\mathrm{N}+$ e $\mathrm{N}-)$. A sobrevida global foi significativamente menor quando o NLR estava alto no grupo de mesma profundidade do tumor $(p=0,032)$ e mesmo estádio $(p=0,020)$, mas não no mesmo status linfonodal. (Gráfico 4). 
Gráfico 3 - Curva de Kaplan-Meier demonstrando sobrevida global (A) e livre de doença (B) nos 383 pacientes agrupados de acordo com a relação neutrófilo-linfócito - NLR baixo $(<2,44)$ e NLR alto $(\geq$ 2,44)
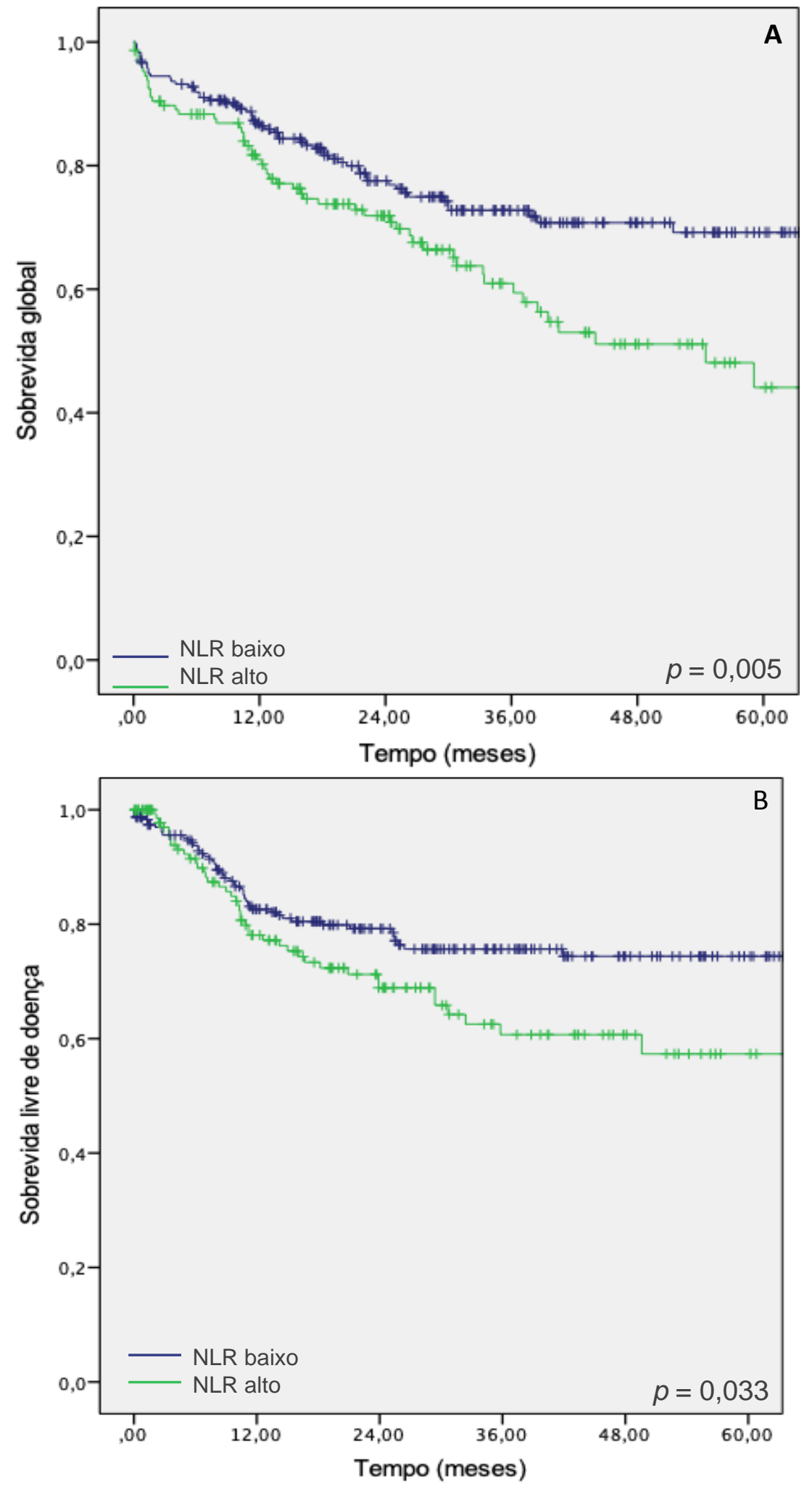
Gráfico 4 - Curva de Kaplan-Meier de acordo com pT (A), pN (B) e pTNM (C) estratificados pelo NLR - NLR baixo $(<2,44)$ e NLR alto $(\geq 2,44)$
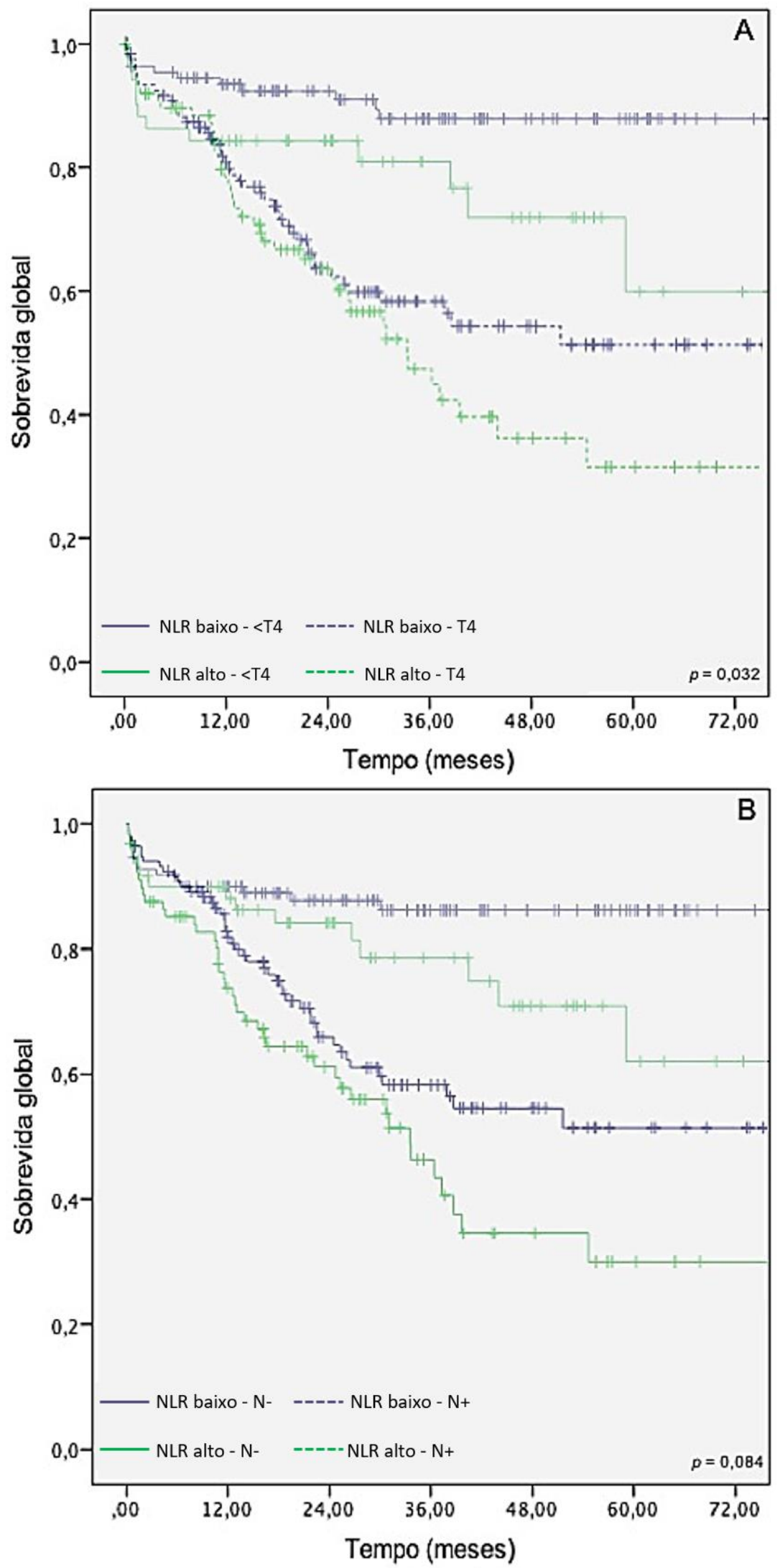


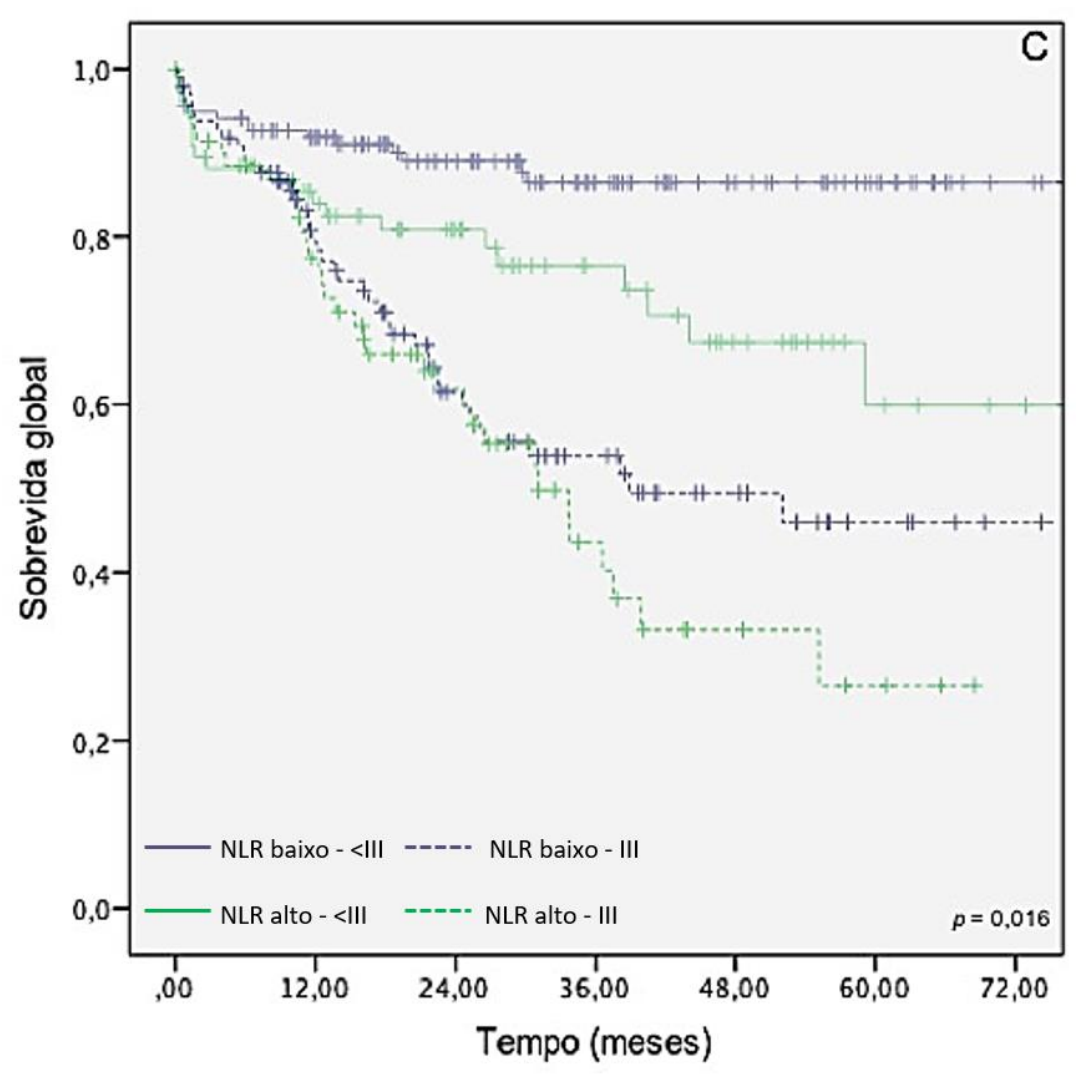




\subsection{Análise de Fatores Prognósticos}

A Tabela 6 mostra os fatores independentes de prognóstico para SLD e SG identificados na análise multivariada. Está análise foi realizada nos fatores identificados como significativos na análise univariada. Fatores prognósticos associados com pior SLD foram os baixos níveis de albumina, a gastrectomia total, tumores mais profundos e acometimento linfonodal. Em relação à SG, a análise revelou que a baixa albumina, o NLR alto, os tumores mais profundos e o acometimento linfonodal estão associados a pior sobrevida.

Tabela 6 - Análise univariada e multivariada para sobrevida livre de doença e sobrevida global nos 383 pacientes com adenocarcinoma gástrico submetidos à gastrectomia potencialmente curativa

\begin{tabular}{|c|c|c|c|c|c|c|}
\hline Sobrevida livre de doença & \multicolumn{2}{|c|}{ Univariada } & \multirow[b]{2}{*}{$p$} & \multicolumn{2}{|c|}{ Multivariada } & \multirow{2}{*}{$p$} \\
\hline Variáveis & HR & $\mathrm{IC} 95 \%$ & & HR & $\mathrm{IC} 95 \%$ & \\
\hline Idade $<65$ vs. $\geq 65$ anos & 0,82 & $0,54-1,24$ & 0,347 & - & - & - \\
\hline Feminino vs. masculino & 1,29 & $0,84-1,98$ & 0,251 & - & - & - \\
\hline Albumina* & 0,65 & $0,48-0,88$ & 0,006 & 0,58 & $0,41-0,81$ & 0,002 \\
\hline Plaquetas $^{*}$ & 1,00 & $0,99-1,00$ & 0,804 & - & - & - \\
\hline NLR baixo vs. NLR alto & 1,56 & $1,03-2,35$ & 0,034 & 1,42 & $0,91-2,21$ & 0,122 \\
\hline Gastrectomia subtotal vs. total & 2,13 & $1,41-3,21$ & $<0,001$ & 1,75 & $1,23-2,71$ & $\mathbf{0 , 0 1 3}$ \\
\hline Intestinal $v s$. difuso/misto & 1,61 & $1,06-2,45$ & 0,024 & 1,35 & $0,86-2,11$ & 0,186 \\
\hline $\mathrm{pT} 1 / \mathrm{T} 2$ vs. $\mathrm{pT} 3 / \mathrm{T} 4$ & 13,4 & $5,87-30,77$ & & 5,57 & $2,12-14,68$ & 0,001 \\
\hline pN0 vs. $\mathrm{pN} 1 / 2 / 3$ & 7,59 & $4,04-14,26$ & & 4,64 & $2,09-10,29$ & $<0,001$ \\
\hline Sobrevida Global & \multicolumn{2}{|c|}{ Univariada } & \multicolumn{3}{|c|}{ Multivariada } & \multirow{2}{*}{$p$} \\
\hline Variáveis & HR & $\mathrm{IC} 95 \%$ & & HR & IC95\% & \\
\hline Idade $<65 v s . \geq 65$ anos & 1,48 & $1,02-2,15$ & $\mathbf{0 , 0 3 7}$ & 1,42 & $0,95-2,11$ & 0,088 \\
\hline Feminino vs. masculino & 1,29 & $0,87-1,89$ & 0,200 & - & - & - \\
\hline Albumina* & 0,73 & $0,55-0,98$ & $\mathbf{0 , 0 3 8}$ & 0,69 & $0,50-0,94$ & 0,019 \\
\hline Plaquetas* & 0,79 & $0,99-1,00$ & 0,788 & - & - & - \\
\hline NLR baixo $v s$. NLR alto & 1,68 & $1,16-2,43$ & 0,006 & 1,50 & $1,01-2,23$ & 0,048 \\
\hline Gastrectomia subtotal vs. total & 1,64 & $1,13-2,38$ & 0,009 & 1,38 & $0,93-2,10$ & 0,107 \\
\hline Intestinal vs. difuso/misto & 1,25 & $0,86-1,82$ & 0,233 & - & - & - \\
\hline $\mathrm{pT} 1 / \mathrm{T} 2$ vs. $\mathrm{pT} 3 / \mathrm{T} 4$ & 3,37 & $2,13-5,33$ & $<0,001$ & 2,31 & $1,27-4,21$ & 0,006 \\
\hline $\mathrm{pN} 0$ vs. $\mathrm{pN} 1 / 2 / 3$ & 2,91 & $1,90-4,47$ & $<0,001$ & 2,18 & $1,24-3,82$ & $\mathbf{0 , 0 0 7}$ \\
\hline
\end{tabular}

* avaliados como variável contínua. 
5 DISCUSSÃO 
A relação neutrófilo-linfócito mostrou-se um marcador inflamatório prognóstico e valores elevados no período pré-operatório indicam menor sobrevida global após a gastrectomia com intuito curativo. Este resultado corrobora com trabalhos que concernem tumores gástricos e as neoplasias sólidas mais frequentes ${ }^{21}$. O principal potencial deste marcador é a capacidade de acrescentar informações ao sistema vigente de estádio, possibilitando a estratificação de risco em pacientes com mesma extensão da doença. Vale ressaltar que o NLR visa acrescentar informações, sem a presunção de substituir outros parâmetros rotineiramente empregados.

Nas últimas décadas, a importância atribuída à inflamação na tumorigênese, progressão tumoral e avaliação prognóstica aumentou. Vale lembrar que já no século XIX Rudolph Virchow, pioneiro nos estudos da patologia, sugeriu a relação entre inflamação e câncer ${ }^{45}$. Várias linhas de pesquisa identificaram marcadores e índices inflamatórios implicados no prognóstico de pacientes com câncer ${ }^{94}$. Parte deles utiliza dados laboratoriais solicitados na maioria dos pré-operatórios. A relação neutrófilolinfócito e plaqueta-linfócito necessitam apenas de um hemograma pré-operatório para serem calculadas. Outros índices mais rebuscados, como o Glasgow-Prognostic Index, utilizam as medidas pré-operatórias de albumina e proteína C-reativa ${ }^{95}$.

O presente estudo dedicou-se a avaliação do NLR em contrapartida ao GPI pela disponibilidade do valor da PCR antes da cirurgia. Este não é um exame rotineiramente solicitado nos pré-operatórios, ao contrário do hemograma, presente 
na totalidade dos casos. Acreditou-se, portanto, que para a reprodutibilidade dos métodos utilizados, o exame mais comumente utilizado deveria ser o foco. Interessante citar que outros autores também citam a disponibilidade da PCR no préoperatório como limitante para utilização do GPI ${ }^{96}$.

A comparação entre os diferentes tipos de marcadores inflamatórios prognósticos como o GPI, NLR, PLR e o Onodera Prognostic Nutritional Index mostra que todos eles são parâmetros prognósticos independentes para avaliação de sobrevida ${ }^{97}$. Proctor et al. ${ }^{98}$ avaliando pacientes pareados por tipo de tumor, idade e sexo indicam que há superioridade na utilização do GPI em relação aos outros marcadores. Vale ressaltar que o referido estudo avalia exames colhidos até 2 anos antes do diagnóstico e de uma população submetida à diferentes tipos de tratamento. Também, o valor de corte do NLR foi 5, muito alto comparado com o presente estudo, fator que tira a sua sensibilidade, colocando-o em posição desfavorável quando comparado ao GPI.

Ao avaliar os marcadores em 324 pacientes com câncer gástrico submetidos à gastrectomia curativa, uma população mais semelhante a este estudo, Wang et al. ${ }^{99}$ também concluíram que o GPI é superior ao NLR. Porém, foi identificada a mesma questão já abordada referente ao alto valor de 5 no corte do NLR. Eventualmente, se este corte fosse reduzido esta superioridade do GPI talvez não fosse encontrada.

Diversos grupos estudaram o valor do NLR em diferentes tipos de neoplasias e estádios ${ }^{21}$. Particularmente, no conjunto de estudos de neoplasias gastrointestinais, o NLR aparenta ser fator prognóstico independente de sobrevida mais frequentemente em lesões do trato gastrointestinal alto. Uma hipótese para tal fato seria a maior frequência de diagnóstico de lesões mais avançadas nesta topografia, o 
que resultaria em uma maior resposta inflamatória sistêmica. Mais ainda, dentre as lesões do TGI alto, o NLR aparenta maior relação com as lesões mais avançadas em comparação com as lesões precoces, fato que pode ser explicado pela hipótese previamente destacada ${ }^{100}$.

A importância do NLR como fator prognóstico em pacientes com tumores sólidos é confirmada por grandes metanálises como a realizada por Templeton et al. em $2014^{21}$. Os autores analisaram 100 artigos que envolveram mais de 40.000 pacientes com diferentes neoplasias sólidas. O risco de óbito nos grupos com NLR acima do valor de corte foi 1,81 vezes maior comparado ao grupo com NLR baixo. Esta característica estende-se para todos os grupos de pacientes, independente do sítio primário do tumor ou do estádio. Neste mesmo estudo, ao se avaliar em particular a população de 8.800 pacientes com tumores gastroesofágicos, o risco de óbito foi 1,66 vezes maior no grupo com NLR alto.

Dois importantes fatores nortearam a escolha do NLR como foco do presente estudo. Um deles é a reprodutibilidade dos resultados, uma vez que o perfil epidemiológico dos pacientes deste estudo assemelha-se ao da maioria dos pacientes com CG no mundo, com exceção daqueles no Leste Asiático ${ }^{101}$. Portanto, estima-se que os valores de NLR das populações sigam um padrão semelhante de distribuição.

Outro fator é a simplicidade do marcador. O hemograma pré-operatório traz informações valiosas sobre o prognóstico do paciente e dispensa procedimentos invasivos para sua obtenção. Esta questão foi tema do artigo "Parâmetros preditivos de desfechos cirúrgicos no câncer gástrico: simples é melhor que complexo"102 que mostra que a avaliação de neutrófilos e albumina foram fatores independentes de prognóstico, mostrando-se mais eficazes que escores mais complexos envolvendo perda ponderal, sarcopenia, IMC, entre outros ${ }^{102}$. 
A gastrectomia com linfadenectomia se mantém como principal forma de tratamento curativo na doença localizada, auxiliado pela quimioterapia perioperatória ou quimiorradiação pós-operatória. Em casos restritos à mucosa e submucosa, sem acometimento linfonodal, a cirurgia pode resultar em taxa de cura de aproximadamente $90 \%{ }^{103}$. Porém, o diagnóstico precoce das lesões gástricas não é regra neste meio, uma vez que não há políticas públicas de rastreamento como em países orientais ${ }^{104}$. Este fato tem por consequência elevada incidência de pacientes com doença avançada. Dos pacientes submetidos à gastrectomia com intuito curativo no serviço em que foi realizado o presente estudo, $67 \%$ apresentavam doença avançada.

Se faz necessário destacar a extensão da linfadenectomia realizada nos pacientes da casuística. A equipe realizou um total de 556 gastrectomias com linfadenectomia entre 2008 e $2017^{105}$, o que classifica o serviço como uma referência de alto volume. A média de linfonodos obtidos por peça após a gastrectomia com intuito curativo D1 ou D2 é de 39,5, número acima dos 16 considerados adequados para linfadenectomia ${ }^{106}$. Esse dado é importante pois destaca que o tratamento cirúrgico empregado é adequado e homogêneo entre os pacientes, possibilitando análise do NLR como fator prognóstico em um grupo de pacientes que recebeu tratamento semelhante, a despeito dos diferentes estádios.

É interessante demonstrar o que é considerado a normalidade do NLR em pacientes saudáveis. Dois grandes estudos, um americano e um sul-coreano, avaliaram diferentes populações somando mais de 20.000 indivíduos. A população sul-coreana avaliada não tinha nenhum antecedente médico digno de nota e suas amostras sanguíneas foram obtidas em exames de rotina. Já o estudo americano 
incluiu pacientes saudáveis que não utilizavam determinadas medicações como corticoides, antibióticos ou imunomoduladores. A média do NLR foi de 1,65 e 2,15 para população oriental e ocidental, respectivamente. Dentre os ocidentais, os negros e hispânicos apresentam valores menores quando comparados com brancos ${ }^{107,108}$. O valor mais elevado em populações ocidentais poderia ser atribuído a maior taxa de obesidade, fator implicado em maior inflamação sistêmica. A comparação com a média de NLR da amostragem do presente trabalho indica que a neoplasia efetivamente aumenta os valores do NLR.

O foco no NLR em doenças gástricas foi tema de um estudo com mais de 500 pacientes. Realizou-se a comparação dos valores de NLR entre pacientes com tumores gástricos, lesões gástricas benignas e indivíduos saudáveis sendo identificada diferença significativa nos níveis de NLR entre os pacientes com lesões malignas e os outros pacientes. Porém, não houve diferença entre pacientes com lesões benignas, como gastrite e úlcera, e indivíduos saudáveis ${ }^{109}$.

Nesta pesquisa utiliza-se a curva de Lausen para cálculo do valor de corte. Destaca-se que o método utilizado para cálculo deste valor é motivo de discussão na maioria dos artigos. Como consequência, diferentes valores de corte são considerados para avaliação de populações semelhantes. Uma metanálise sobre o tema abordou abordou tal questão ${ }^{89}$. Dentre os sete estudos avaliados em populações com câncer gástrico submetidas à tratamento curativo, foi obtido um valor de corte diferente para cada estudo, variando de 1,4 até 4,0. O método para estabelecimento do valor de corte também é variável, sendo que foram utilizados curva ROC, mediana e intervalo interquartil. 
Uma outra metanálise inglesa que aborda o mesmo tema e inclui o mesmo tipo de paciente avaliou sete outros artigos. A variação nos valores de corte do NLR foi de 1,44 até 5,5 e nenhum estudo utilizou o mesmo corte utilizado pelos outros. Os métodos empregados para cálculo do corte foram os mesmos descritos no parágrafo acima. A única diferença se dá pelo fato de dois artigos terem utilizado valores de corte previamente descritos e calculados por outros autores ${ }^{90}$.

Um aspecto importante relacionado ao NLR é o baixo custo associado à sua realização, uma vez que se baseia unicamente em parâmetros obtidos no hemograma completo. Todo o contexto que envolve o cuidado ao paciente oncológico demanda elevado gasto financeiro, desde exames diagnósticos, tratamento cirúrgico, quimioterápico e radioterápico, internações prolongadas, antibioticoterapia, exames de seguimento, entre outros. Estima-se que pacientes oncológicos apresentam custos diretos entre U\$20.000 e U\$ 100.000 com exames diagnósticos e tratamento ${ }^{110}$.

Ao se tratar especificamente dos exames laboratoriais preditores de prognóstico, o hemograma completo apresenta o menor custo tanto no Sistema Único de Saúde quanto na esfera particular. Como exemplo, o custo no sistema público e particular de um hemograma completo é de $\mathrm{R} \$ 4,11$ e $\mathrm{R} \$ 18,00$ respectivamente $^{111}$.

Ao se comparar o custo do hemograma com outros marcadores prognósticos descritos na literatura, observa-se a grande disparidade entre os valores. Classicamente, os seguintes marcadores tumorais e exames laboratoriais são utilizados: CA72.4, CA19,9, CEA, proteína C-reativa e albumina. O custo dos marcadores tumorais no mercado particular varia em torno de $\mathrm{R} \$ 70,00$ por exame. A proteína C-reativa e a albumina têm menor custo $(\mathrm{R} \$ 44,97$ e $\mathrm{R} \$ 11,25$, respectivamente $)^{111}$. Nota-se que o hemograma completo apresenta valor bastante 
inferior comparado aos outros marcadores. Em um contexto de saúde pública, a utilização rotineira do NLR não implicaria em sobrecarga no sistema de financiamento da área da saúde.

O prognóstico dos pacientes depende de determinadas variáveis clinicopatológicas, agrupadas em sistemas de estádio. Utiliza-se o grau de penetração tumoral na parede gástrica $(\mathrm{T})$, o acometimento linfonodal $(\mathrm{N})$ e a presença de metástases (M) para definição do estádio do paciente de acordo com o proposto pela AJCC/UICC oitava edição $2017^{15}$. É fato que pacientes com mesmo estádio podem apresentar diferentes evoluções, inclusive com sobrevidas distintas. Portanto, o prognóstico apoiaria-se mais do que somente em características tumorais e se expandiria para fatores relacionados ao paciente que hospeda o tumor. Essas variáveis e sua incorporação aos sistemas de estádio favoreceriam melhor caracterização individualizada do paciente e sua doença.

\subsection{Relação Neutrófilo-Linfócito e Características Clínico-laboratoriais}

O perfil epidemiológico dos pacientes avaliados no presente estudo assemelha-se ao classicamente presente na literatura ${ }^{101}$. Com média de idade de 63 anos e maior proporção de pacientes do sexo masculino (60\%), os dados do presente estudo reforçam a ideia de que o câncer gástrico incide com maior frequência em pacientes do sexo masculino com idade avançada.

Encontrou-se relação significativa entre sexo e NLR. O grupo de pacientes com NLR elevado apresentou $72 \%$ de pacientes do sexo masculino, contra $52 \%$ no grupo com NLR baixo. A média de NLR foi mais elevada no grupo de pacientes do sexo masculino, que apresentou valor de 2,79 contra 2,14 no sexo feminino. Não há 
consenso na literatura sobre valores de NLR de acordo com o sexo, provavelmente pela heterogeneidade dos estudos quanto à população avaliada e condutas adotadas. Quando o foco é dado em populações como a do presente estudo, encontra-se predomínio do sexo masculino quando o NLR é elevado ${ }^{89}$.

Não há uma justificativa exata para a prevalência de gêneros de acordo com o NLR. Uma das teorias é a grande influência de hormônios como a progesterona e o estrogênio na hematopoese. Uma vez que há variações fisiológicas nos níveis hormonais entre os gêneros e idades, a influência exercida sobre a hematopoese entre homens e mulheres de diferentes idades não é uniforme.

O estrogênio e a progesterona estimulam o recrutamento de neutrófilos da medula óssea ${ }^{112}$. Já na corrente sanguínea, os neutrófilos têm sua apoptose retardada pela ação do estrogênio que inibe a caspase 3 , proteína que promove a cascata da apoptose $^{113}$. Mesmo com a meia vida prolongada, a funcionalidade dos neutrófilos permanece preservada. Um exemplo prático desses mecanismos é a neutrofilia fisiológica da gestação, promovida pela elevação de quase 100 vezes das taxas de estrogênio e progesterona neste período ${ }^{114}$.

A queda nos níveis de estrogênio chega a $70 \%$ após a menopausa, que em geral ocorre após os 50 anos ${ }^{115,116}$. Como consequência, o estímulo ao recrutamento de neutrófilos se reduz e seu valor absoluto no sangue diminui. Com isso, o NLR também diminui uma vez que o valor dos linfócitos permanece estável. Portanto, como a maioria das pacientes do presente estudo apresenta-se na menopausa, observou-se declínio de sua prevalência no grupo de pacientes com NLR elevado ${ }^{116}$.

A incidência do CG aumenta progressivamente com a idade. De modo geral, $1 \%$ dos casos são diagnosticados abaixo dos 35 anos, $70 \%$ dos casos entre 35 e 75 anos e $29 \%$ acima dos $75 \operatorname{anos}^{117}$. A população estudada neste trabalho apresentou 
média de idade de 63 anos com variações entre os grupos de acordo com NLR. O grupo com valores baixos e elevados de NLR apresentaram médias de idade de 61,9 e 64,6 anos, respectivamente.

A idade se relaciona com os valores do NLR em outros trabalhos, seguindo a tendência de idade mais avançada com valores elevados de $\mathrm{NLR}^{118}$. Na Tabela 3 demonstra-se que a média do NLR é maior em pacientes acima dos 65 anos.

A obesidade é uma doença crônica que causa um estado inflamatório subclínico. Determinados marcadores inflamatórios foram estudados e relacionados com a obesidade visceral. Entre eles, a proteína $\mathrm{C}$ reativa, a adiponectina, IL-6, TNFalfa e o NLR ${ }^{119}$. Particularmente, em relação ao NLR, os estudos indicam aumento de seus valores com o aumento do IMC, porém não há significância estatística de tal dado em nenhuma análise. A justificativa dada pelos autores cita que o ganho ponderal resulta na elevação do total de leucócitos e de seus subtipos celulares proporcionalmente $^{120,121}$. Uma vez que tanto neutrófilos quanto linfócitos se elevam, não há modificação considerável nos valores da relação neutrófilo-linfócito.

O presente estudo identificou uma relação inversa entre NLR e obesidade comparada com os estudos citados no parágrafo anterior. A média do NLR apresenta queda gradual com o aumento do IMC, conforme demonstrado na Tabela 5. Vale destacar que a população avaliada é restrita à pacientes oncológicos, o que determina interações diferentes entre o peso, a neoplasia e os parâmetros inflamatórios.

O câncer gástrico caracteriza-se por promover a perda ponderal e a caquexia, por fatores mecânicos obstrutivos e sistêmicos. Um estudo que avaliou mais de 18.000 pacientes com câncer gástrico demonstra que a perda ponderal é o sintoma mais comum, atingindo $61 \%$ dos $\operatorname{casos}^{122}$. A ocorrência de doença mais avançada se 
reflete na maior perda ponderal e consequente menor IMC. Portanto, os casos mais avançados representados pelos pacientes com menor IMC apresentam valores mais elevados de NLR.

O papel das plaquetas como facilitadores do desenvolvimento tumoral é conhecido e a identificação da plaquetose como fator paraneoplásico foi descrita no século $\mathrm{XIX}^{123}$. Porém, referências históricas remetem a descrições de 1000 anos antes de Cristo sobre diferentes tipos de tumor, sendo que um deles "é um tumor que invade o sangue e comprime os vasos sanguíneos”. Esta primeira referência conhecida é do texto sânscrito da medicina indiana Sushruta Samhita ${ }^{124}$, que é considerada a primeira análise na história sobre a relação entre tumores e alterações sanguíneas. No século XIX Armand Trosseua descreveu a síndrome que leva o seu nome, que passou a ter maior aceitação na comunidade médica a partir do estudo da anatomista americana Edith Sproul em 1938. A autora descreve a necropsia de mais de 4.200 cadáveres de pacientes com carcinoma, aonde a presença de múltiplas tromboses chegou a $30 \%$ em tumores de cauda de pâncreas ${ }^{124}$.

Aproximadamente $40 \%$ dos pacientes com achado incidental de plaquetas acima de 400 mil por milímetro cúbico, na ausência de ferropenia ou doenças inflamatórias, possuem alguma neoplasia oculta, geralmente de trato gastrointestinal, pulmão, mama ou ovariana ${ }^{125}$. A prevalência de trombocitose entre as neoplasias sólidas é variável: $33 \%$ no câncer de cólon ${ }^{126}, 30 \%$ no câncer de colo uterino ${ }^{127} \mathrm{e}$ 6,4-11,4\% no câncer gástrico ${ }^{128-130}$.

Na presente casuística, a média de plaquetas foi de 275 mil por milímetro cúbico e 9,6\% dos pacientes apresentaram valores acima de 400 mil por milímetro cúbico. A média no valor absoluto das plaquetas aumentou de 235 mil por milímetro 
cúbico no grupo de NLR baixo para 305 mil por milímetro cúbico no grupo NLR alto, com significância estatística $(p=0,015)$. Porém, a plaquetose não foi um fator independente de pior prognóstico.

Trombocitose como fator independente de pior prognóstico em pacientes com câncer gástrico foi primeiro descrita em 2002 por Ikeda et al. ${ }^{128}$, a avaliação de 369 pacientes identificou $12 \%$ dos casos com valores acima de 400 mil plaquetas por milímetro cúbico, com pior sobrevida global em 1 e 3 anos nestes casos. Anteriormente à este estudo, a trombocitose já havia sido relacionada como fator prognóstico em outros tipos de neoplasias sólidas, como ginecológicas ${ }^{127}$, pulmonares $^{131}$ e urológicas ${ }^{132}$.

Um estudo recente com casuística acima de 4.600 pacientes com câncer gástrico submetidos à tratamento cirúrgico identificou prevalência de $2 \%$ de plaquetas acima de 400 mil por milímetro cúbico. Estabelecido um valor de corte de 255 mil por milímetro cúbico, a plaquetose foi considerada fator independente de pior prognóstico ${ }^{133}$. Uma metanálise de 2018 avaliou mais de 7000 pacientes com câncer gástrico em nove estudos. A sobrevida de um, três e cinco anos após o tratamento é menor nos pacientes com plaquetose. Esta metanálise destaca que o grande viés dos estudos que utilizam variáveis contínuas é o estabelecimento de um valor de corte resultando em valores entre 250 mil e 400 mil por milímetro cúbico de sangue estabelecidos nos estudos considerados ${ }^{134}$.

Em estudo avaliando pacientes e modelos murinos com tumores ovarianos, Stone et al. $^{135}$ demonstram que a síntese de trombopoetina hepática encontra-se elevada em resposta à interleucina-6 produzida pelo tumor. Esta trombopoetina eleva a síntese plaquetária, o que estimula o crescimento tumoral e consequente produção 
de mais Interleucina-6. Este é um mecanismo de retroalimentação que se perpetua ao longo do crescimento tumoral.

As particularidades envolvendo plaquetas no paciente com câncer vão além do aumento no número absoluto: alterações estruturais, com aumento no número de grânulos intraplaquetários, além de uma maior ativação plaquetária são observados nos pacientes com câncer. A influência das plaquetas no câncer é tão relevante que algumas células tumorais assumem fenótipo próprios das plaquetas, expressando receptores e moléculas de adesão semelhantes. Este mimetismo plaquetário foi descrito em 2005 por Timar et al. ${ }^{136}$.

O resultado prático de todos esses achados é o grande foco que ocorre desde a década de 1980 no uso de drogas antiplaquetárias e anticoagulantes no combate ao câncer. Diversos protocolos foram desenhados para avaliação de medicamentos como a aspirina, clopidogrel, mopidamol e dipiridamol. A aspirina em baixas doses é recomendada como profilaxia de câncer colorretal nos Estados Unidos. Devido aos riscos de sangramento, essa conduta não é recomendada nos países europeus. Outros estudos estendem o efeito profilático da aspirina para diferentes tipos de tumores: mama, próstata, pulmão, pâncreas e ovário ${ }^{137}$. Certamente, a terapia antiplaquetária é promissora contra o câncer, mas ainda existem desafios para tornar-se senso comum. Deve-se identificar quais tipos de tumores e pacientes são respondedores e mais ainda, identificar em quais pacientes os benefícios superam os riscos da terapia antiplaquetária. 


\subsection{Relação Neutrófilo-Linfócito e Características Patológicas}

A população estudada apresentou predomínio de tumores localmente avançados, fato encontrado com frequência em países em desenvolvimento como o Brasil $^{101}$. A invasão até a subserosa (pT3), o acometimento linfonodal e o estádio 3 foram as características mais frequentes totalizando $61,6 \%, 55,3 \%$ e $44 \%$ dos casos, respectivamente. O tipo histológico mais comum foi o intestinal $(51,1 \%)$, com localização na parte distal do estômago $(61,6 \%)$, características tumorais também associadas a pacientes de países em desenvolvimento ${ }^{101}$

Vale destacar que o diagnóstico do câncer gástrico precoce é fundamental para o bom prognóstico. A sobrevida global em 5 anos nesses casos é de $90 \%{ }^{103}$. Infelizmente, o Brasil não possui políticas de rastreamento endoscópico que permitam o diagnóstico precoce, o que resulta na elevada taxa de tumores avançados aqui demonstradas. Países do Leste asiático como o Japão, que aplicam programas de rastreamento, apresentam maior incidência de lesões precoces e melhores taxas de sobrevida ${ }^{103}$.

O tipo histológico apresentado na presente casuística segue a tendência global de queda na incidência de lesões do tipo intestinal. Como consequência, o diagnóstico de lesões do tipo difuso aumentou proporcionalmente, alcançando 30\% em casuísticas com mais de 2.000 pacientes $^{138}$. O tipo difuso da população estudada foi de $34,4 \%$.

O tipo histológico não foi fator independente de pior sobrevida livre e sobrevida global, apesar da histologia, seja classificada por Lauren ou por grau de diferenciação celular, influenciar o prognóstico em diversos estudos ${ }^{105,139,140}$. O tipo difuso caracteriza-se pela presença de metástases precoces, o que implica em seu pior prognóstico $^{11}$. Como o presente estudo excluiu os pacientes com metástases, ocorreu uma homogeinização entre os graus de progressão de doença entre os tipos intestinal e difuso, o que se traduziu em sua ausência de impacto prognóstico. 
As médias de NLR foram progressivamente maiores com o avançar da profundidade do tumor na parede gástrica. Destaca-se o fato que as lesões até a subserosa apresentam médias muito semelhantes, porém quando a lesão penetra a serosa ocorre uma grande elevação na média do NLR. Conforme se demonstra na Tabela 3, a diferença da média entre lesões T3 e T1 foi de 0,15. Já a diferença encontrada entre T4 e T3 foi de 0,71. Além disso, dos 147 pacientes com NLR alto, 65,3\% apresentavam lesões mais invasivas. Este dado vai ao encontro de uma série de publicações envolvendo tumores gástricos ${ }^{141,142}$ e outras neoplasias sólidas ${ }^{21}$. Uma das teorias formuladas para explicar tal fato é o remodelamento tissular em locais de invasão tumoral perigástrica. A penetração tumoral desencadearia uma forte reação inflamatória local, capaz de influenciar os níveis séricos de células inflamatórias ${ }^{141}$.

O acometimento linfonodal não apresentou relação estatisticamente significativa com os níveis do NLR, apesar do grupo com NLR elevado apresentar maior proporção $(60 \%)$ de pacientes $\mathrm{N}+\mathrm{O}$ acometimento linfonodal ocorre pelo alcance dos linfáticos presentes na submucosa gástrica, logo lesões mais invasivas relacionam-se com maior frequência ao comprometimento linfonodal. Lesões mais invasivas apresentam NLR elevado, logo, tal resultado também era esperado para o acometimento linfonodal, o que não ocorreu.

Hsu et al. ${ }^{143}$ identificaram a mesma questão em sua casuística com mais de mil pacientes com câncer gástrico operado. $\mathrm{O}$ acometimento linfonodal não se relacionou com o NLR. Os autores então analisaram a razão dos linfonodos (divisão dos linfonodos acometidos pelos linfonodos totais) o que resultou em relação significativa do NLR. 
Quando se avalia estudos que encontraram relação de NLR com acometimento linfonodal, identifica-se que a maioria inclui pacientes metastáticos. Por exemplo, na casuística de Zhang et al. ${ }^{118}, 24 \%$ e $80 \%$ dos pacientes apresentavam metástases e acometimento linfonodal, respectivamente. A proporção de pacientes $\mathrm{N}+$ é muito superior comparado com os $55 \%$ deste trabalho, o que pode ser entendido pela influência que o estádio IV determina sobre a taxa de acometimento linfonodal.

O estádio patológico também não se relacionou de modo significativo com valores de NLR, porém seus valores aumentam com a progressão dos estádios. Uma das possíveis explicações para esta falta de relação significativa foi a exclusão dos pacientes com doença metastática. A carcinomatose e as metástases à distância acentuam a resposta inflamatória e elevam o $\mathrm{NLR}^{144}$. A exclusão desses pacientes da amostragem do presente estudo levou a um grupo mais homogêneo de estádios, o que eventualmente traduziu-se nesta ausência de relação estatística.

Reforçando a ideia do impacto das metástases na condição inflamatória sistêmica, a casuística de Shimada et al. ${ }^{140}$ mostra elevação média de 1,23 pontos no NLR em pacientes com câncer gástrico metastático. Outro estudo mostra que há diferença significativa do NLR ao se comparar pacientes com câncer gástrico estádio III e IV ${ }^{145}$.

A questão que se coloca em inúmeros artigos e deve ser levantada é se o NLR reflete a situação do microambiente inflamatório. Os neutrófilos e linfócitos utilizados no cálculo são obtidos do sangue periférico e conforme definido por Shimada et al. ${ }^{140}$ "a relação entre NLR e infiltrado inflamatório peritumoral é altamente especulativa". Para responder tal questão, Choi et al. ${ }^{146}$ demonstraram que o NLR apresenta relação com a densidade de células imunes no microambiente 
tumoral gástrico, particularmente com os linfócitos T CD4+. Concluíram que um parâmetro laboratorial de sangue periférico pode ser utilizado para avaliação do microambiente tumoral.

\subsection{Estratificação de Risco}

A estratificação de risco pode ser definida como o processo de quantificação da probabilidade de um evento prejudicial ocorrer a um determinado indivíduo, resultado de uma gama de fatores internos ou externos ${ }^{147}$. O evento considerado é a recidiva e/ou o óbito e o NLR seria um dos fatores implicados.

É fato que pacientes classificados com mesmo estádio patológico podem apresentar diferentes prognósticos, com sobrevidas livre de doença e global completamente distintas. Esta afirmação pressupõe a existência de fatores não considerados na avaliação individual que apresentam potencial prognóstico.

As curvas de sobrevida de acordo com estádio patológico mostram que pacientes estádio 3 apresentam pior prognóstico comparados com estádios 1 e 2 . Mais ainda, ao se dividir os pacientes com mesmo estádio de acordo com seu NLR, observa-se pior sobrevida global no subgrupo com NLR elevado (Gráfico 4B). O mesmo fenômeno ocorre quando a estratificação de risco é realizada em pacientes com mesmo grau de invasão tumoral na parede gástrica (Gráfico 4A).

Poucos estudos realizaram este tipo de estratificação de risco. Hu et al. ${ }^{148}$ descrevem a estratificação por estádios, porém adotam um valor de corte do NLR diferente para cada um deles. Apesar do método diferente na estratificação, os autores têm conclusão semelhante ao descrito no presente estudo: o NLR tem o potencial de estratificar risco em pacientes com mesmo estádio. 


\subsection{Fatores Prognósticos}

A análise multivariada dos fatores relacionados com SLD e SG identificou a hipoalbuminemia, a gastrectomia total, os tumores pT3 e pT4 e o acometimento linfonodal como fatores de pior prognóstico tanto para SLD quanto para SG. O NLR elevado foi identificado como fator de pior prognóstico na análise multivariada somente ao se considerar a sobrevida global.

O NLR acima do valor de corte no pré-operatório implica em risco de óbito 1,5 vezes maior, fato confirmado pela regressão de Cox para a análise multivariada. Em metanálise que considerou mais de 3.000 pacientes com características semelhantes ao do presente estudo, o NLR foi fator independente de prognóstico para SLD e SG em todos os estudos, com exceção de um. Este único estudo mostrou relação do NLR com pior prognóstico somente na análise univariada, eventualmente por haver considerado um valor de corte baixo ${ }^{149}$.

O grau de invasão tumoral $(\mathrm{pT})$ e o acometimento linfonodal $(\mathrm{pN})$ são duas características consideradas no sistema de estadiamento e classicamente relacionadas ao prognóstico do câncer gástrico. A conclusão deste estudo que pT e pN são fatores independentes de pior prognóstico confirma uma informação já consagrada pela prática médica. Já na década de 1980, Maruyama et al. ${ }^{150}$ analisaram 25 variáveis em mais de 4.700 pacientes submetidos à ressecção cirúrgica. Profundidade de invasão na parede gástrica $(\mathrm{RR} 4,69)$ e acometimento linfonodal (RR 4,04) foram as duas principais variáveis relacionadas com prognóstico.

A gastrectomia total foi um fator independente de pior prognóstico relacionado com a sobrevida livre de doença. Este procedimento representa no geral lesões mais proximais ou distais e médias com invasão ascendente. As lesões 
proximais geralmente apresentam maiores proporções quando comparadas às distais. Tal fato se explica pela falta de sintomas obstrutivos em lesões proximais pequenas associado à política insatisfatória de rastreamento endoscópico. Portanto, o fato da gastrectomia total ser um fator de pior prognóstico é a tradução do tipo de lesão tratada por esta cirurgia. Outros grupos relatam achados semelhantes, com lesões proximais de maiores dimensões e apresentando pior prognóstico ${ }^{151,152}$.

A hipoalbuminemia apresentou-se como fator independente de pior prognóstico. Seu valor médio foi de $4,0 \mathrm{~g} / \mathrm{dL}$ e $14 \%$ dos pacientes apresentaram valores abaixo de 3,5 g/dL. Sua meia-vida é de 20 dias e valores baixos podem refletir o aumento do metabolismo sistêmico causado pelo tumor, associado à redução na ingesta alimentar e à caquexia relacionada ao câncer ${ }^{153}$. O pior prognóstico vai ao encontro com resultados de outras publicações em diferentes topografias ${ }^{154}$.

\subsection{Considerações Finais e Perspectivas}

O avanço no tratamento do câncer com intuito curativo debruça-se cada vez mais na individualização do paciente. Características próprias, tanto sistêmicas como tumorais, destacam o indivíduo dentro do grupo, permitindo intervenções mais específicas e eficientes. Esta individualização é possível graças a uma série de marcadores que complementam as informações fornecidas pelo sistema de estadiamento vigente.

O NLR mostra-se um marcador capaz de destacar características próprias do paciente e seu tumor, estratificando o risco e aperfeiçoando a predição prognóstica. É um marcador obtido de forma simples, facilmente reprodutível e com baixo custo. Depende unicamente do hemograma, exame amplamente disponível e solicitado mundialmente de maneira rotineira no pré-operatório da gastrectomia. 
Em 1977, nas primeiras classificações ditadas pela AJCC, um comentário pioneiro previa as futuras adaptações à luz de novos conhecimentos, deixando claro que os sistemas de estadiamento não eram estáticos. Este é o ponto chave do presente estudo, que objetiva fornecer informações capazes de implementar a avaliação do paciente com câncer gástrico, com intuito de aprimorar o estadiamento e como consequência embasar com maior solidez as opções de tratamento.

A partir dos resultados obtidos no presente estudo, alguns pontos apresentamse como perspectivas futuras. Em primeiro lugar, a análise longitudinal do NLR no seguimento do paciente poderia trazer mais informações sobre o grau de responsividade e eficiência dos tratamentos. Outro aspecto relevante é a relação entre os valores do NLR com o das citocinas séricas. Entender se a elevação do NLR se traduz também no aumento dos valores séricos de citocinas adicionaria maior compreensão dos mecanismos de ação pró-tumoral. Mais ainda, os tipos e proporções de células inflamatórias infiltrando o tumor precisam ser melhor correlacionados com o valor sérico do NLR.

Outro aspecto são as janelas de oportunidade apresentadas no tratamento do câncer com a melhor compreensão das complexas vias inflamatórias pró- e antitumorais. A depleção dos neutrófilos associada a repopulação clonal de linfócitos em pacientes com câncer seria uma alternativa terapêutica? A "normalização terapêutica" do NLR resultaria na regressão tumoral? 


\section{Conclusões}


a) A relação neutrófilo-linfócito de valor elevado é um fator independente de pior prognóstico, indicando menor sobrevida global em pacientes com câncer gástrico submetidos à gastrectomia com intuito curativo.

b) Relação neutrófilo-linfócito acima do valor de corte se relaciona com idade avançada, sexo masculino, plaquetose e tumores mais invasivos (T3/T4). 
7 ANEXos 


\section{Anexo A - Aprovação pelo Comitê de ética em Pesquisa da Faculdade de Medicina da Universidade de São Paulo}

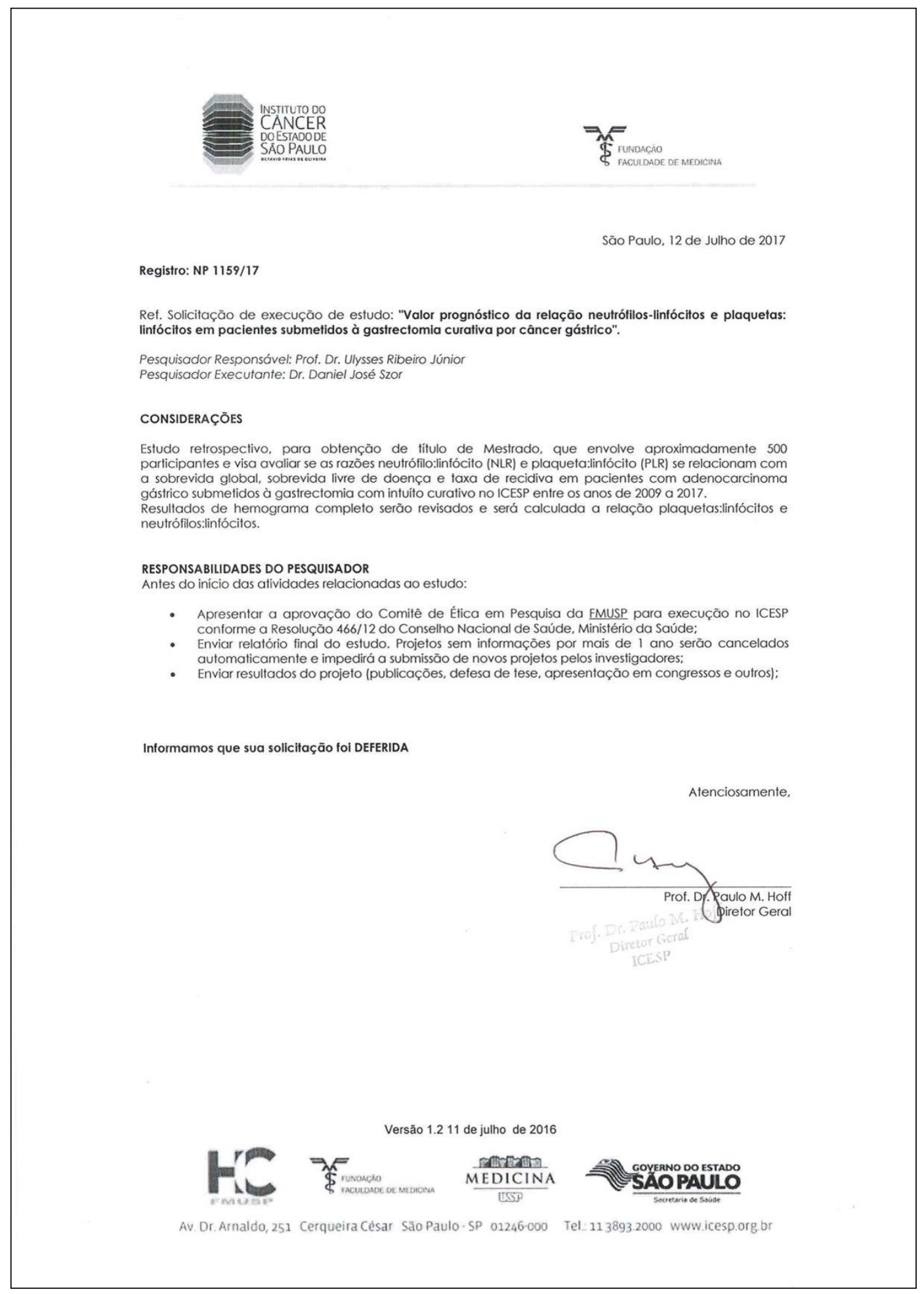




\section{Anexo B - Aprovação na Plataforma Brasil}

\section{USP - FACULDADE DE \\ MEDICINA DA UNIVERSIDADE DE SÃO PAULO - FMUSP}

\section{PARECER CONSUBSTANCIADO DO CEP}

\section{DADOS DO PROJETO DE PESQUISA}

Título da Pesquisa: Valor prognóstico das relą̧os lintócitosineutrófilos e plaquetas/lintócitos em pacientes submetidos a gastrectomia curativa por adenocarcinoma gástrico

Pesquisador: Ulysses Ribeiro Junior

Área Temática:

Versăo: 1

CAAE: 76483517.8 .0000 .0065

Instituiçăo Proponente: FUNDACAO FACULDADE DE MEDICINA

Patrocinador Principal: Financiamento Próprio

DADOS DO PARECER

Número do Parecer: 2.286 .610

\section{Apresentaçằo do Projeto:}

Trata-se de projeto com análise retrospectiva que utilizará dados de prontuarios de pacientes com adenoca gastrico. O projeto já foi aprovado no ICESP, de onde serăo utilizados dados de 550 pacientes.

\section{Objetivo da Pesquisa:}

Avaliar o valor prognostico das relaçóes lintócitosineutrótilos e plaquetas/intócitos em pacientes submetidos a gastrectomia curativa por adenocarcinoma gástrico

Avallaçăo dos Riscos e Benefícios:

Sem riscos pois trata-de de projeto retrospectivo com consulta a prontuários. Benefícios intormativos.

Comentários e Consideraçōes sobre a Pesquisa:

De acordo.

Consideraçōes sobre os Termos de apresentaçăo obrigatória:

De acordo.

Recomendaçőes:

Nenhuma.

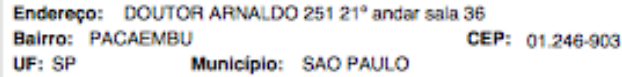




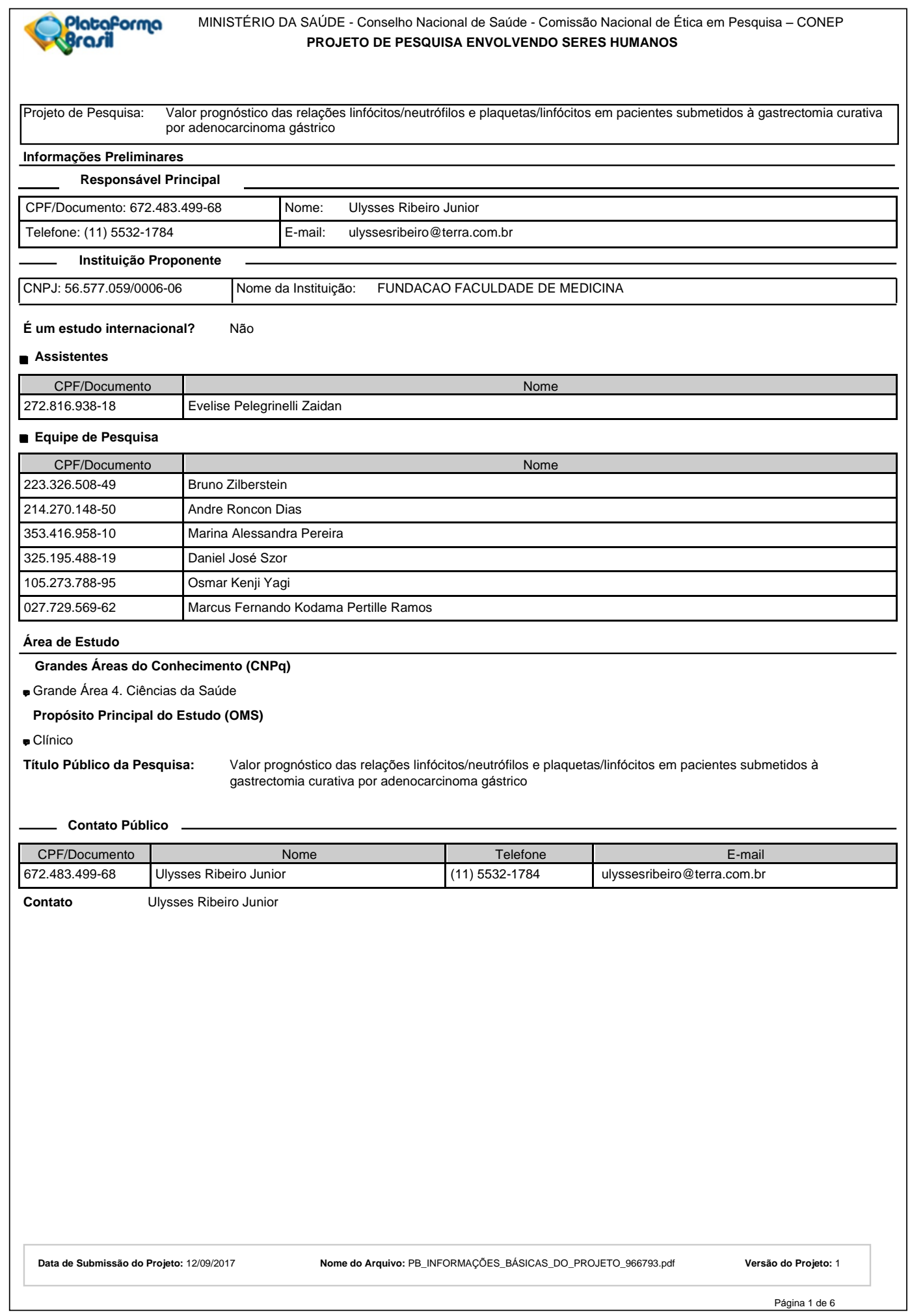




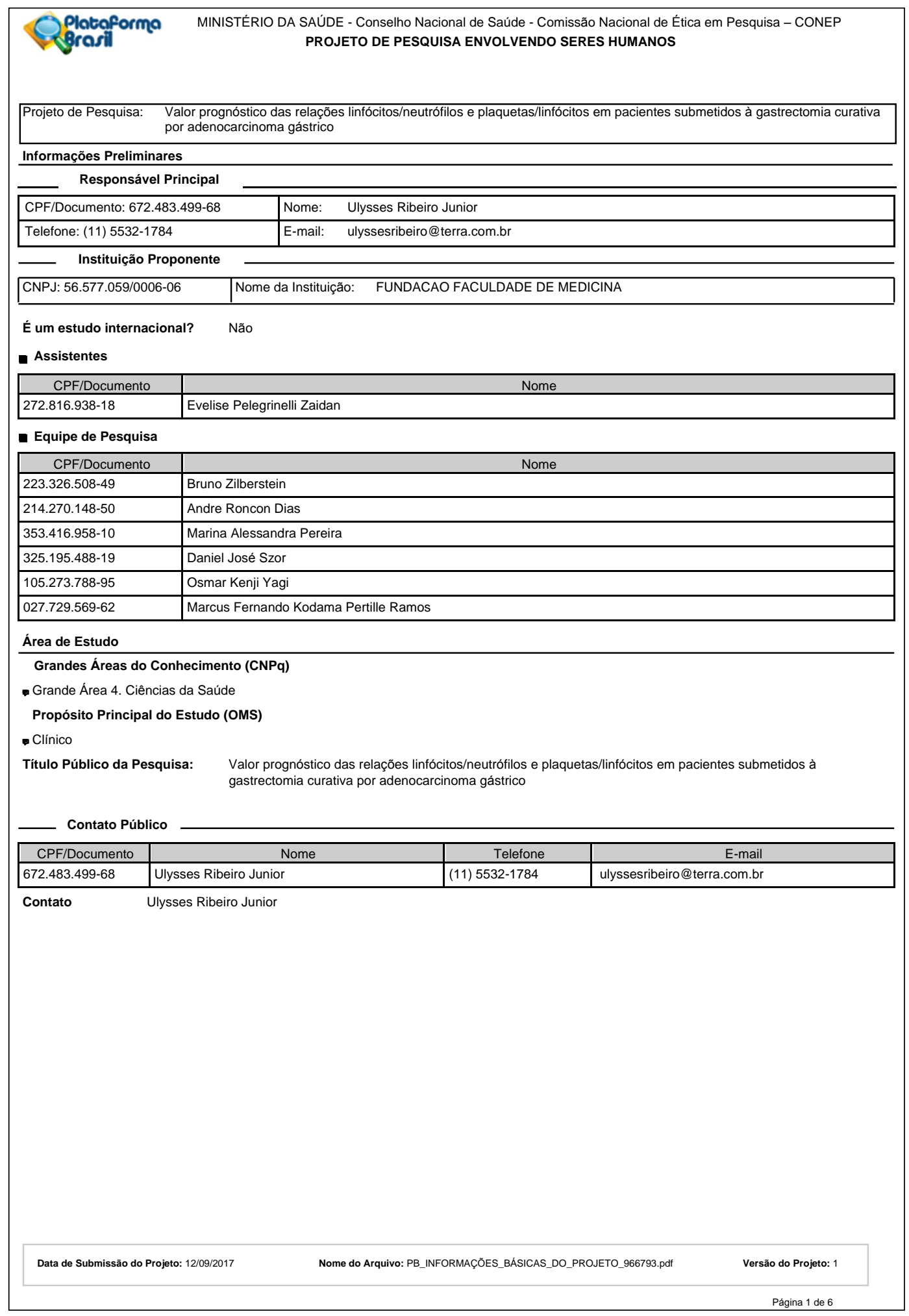




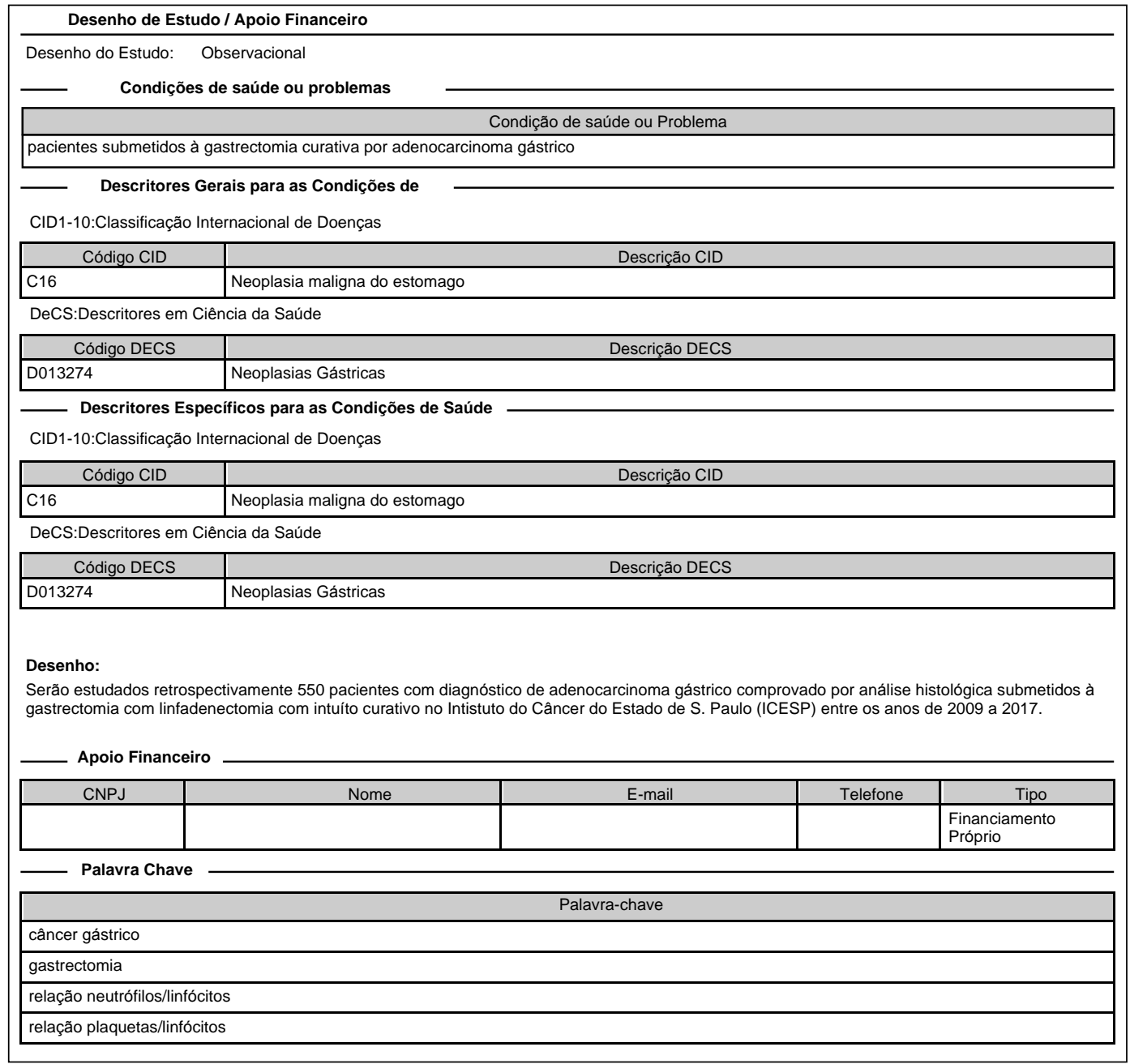




\section{Detalhamento do Estudo}

\section{Resumo:}

O câncer gástrico é uma das neoplasias sólidas mais frequentes; costumava ser a neoplasia de maior incidência até a década de 80 , quando foi superada pelo câncer de pulmăo[1]. Desde entăo sua incidência vem diminuindo devido ao reconhecimento e intervençōes contra os fatores predisponentes como o H. pylori[2] , padrōes de dieta e fatores ambientais. Apesar da reduçăo na incidência, o número absoluto de pacientes vem aumentando devido à maior expectativa de vida da populaçăo, com aproximadamene 1 milhăo de casos novos diagnosticados em 2012 [3].Objetivos: Objetivo primário: Avaliar se as razōes NLR e PLR se relacionam com a sobrevida global, sobrevida livre de doença e taxa de recidiva em pacientes com adenocarcinoma gástrico submetidos à gastrectomia com intuíto curativo.Método: Serăo estudados retrospectivamente 550 pacientes com diagnóstico de adenocarcinoma gástrico comprovado por análise histológica submetidos à gastrectomia com linfadenectomia com intuíto curativo no Intistuto do Câncer do Estado de S. Paulo (ICESP) entre os anos de 2009 a 2017.

\section{Introdução:}

O câncer gástrico é uma das neoplasias sólidas mais frequentes; costumava ser a neoplasia de maior incidência até a década de 80 , quando foi superada pelo câncer de pulmăo[1]. Desde entāo sua incidência vem diminuindo devido ao reconhecimento e intervençōes contra os fatores predisponentes como o H. pylori[2], padrōes de dieta e fatores ambientais. Apesar da reduçăo na incidência, o número absoluto de pacientes vem aumentando devido à maior expectativa de vida da populaçăo, com aproximadamene 1 milhăo de casos novos diagnosticados em 2012 [3]. É um tumor bastante agressivo com diagnóstico realizado na maior parte das vezes em pacientes sintomáticos, com doença avançada. Cerca de $50 \%$ dos casos apresentam doença com extensăo além do estômago no momento do diagnóstico e a sobrevida em 5 anos pode chegar à apenas $30 \%$ dependendo do estadio clínico de acordo com a Union for International Cancer Control (UICC). Em 2016, estima-se que 25.000 casos foram diagnosticados ressecçáo gastrica com a análise histopatologica da peça cirurgica. O paciente e inserido em uma curva de sobrevida de acordo com seu estadio afim de que sua sobrevida possa ser estimada. Por exemplo, um paciente com adenocarcinoma gástrico no estadio IA tem sobrevida em 5 anos estimada em 71\%; já um paciente estadio IV, $4 \%$ de acordo com a American Cancer Society[4].O estadiamento clínico do câncer gástrico pré tratamento e realizado atraves de exames de imagem como o ultrassom endoscópico (EUS) e a tomografia computadorizada de abdome (TC)[5]. Revisठes sistica acometimento linfonodal, a sensibilidade e especificidade do EUS é de $71 \%$ e $85 \%$, respectivamente, e $80 \%$ e $78 \%$ para TC, respectivamente. Notase que há espaço para melhora na acurácia do estadiamento clínico e nesse contexo, outros exames como os marcadores séricos ganham importância. Uma vez que a inflamaçăo é reconhecida como participante no desenvolvimento das neoplasias, sua mensuraçăo por meio das células inflamatórias circulantes pode demonstrar o status inflamatório sistêmico e indiretamente refletir a gravidade e o prognóstico de uma neoplasia. mensuraçăo da inflamaçăo sistêmica, através da relaçăo neutrófilo-linfócito (NLR) e plaqueta:linfócito (PLR) ganha importância e sentido. Sua associaçắo com exames de estadiamento clássicos aumentaria a acurácia diagnóstica, otimizando o tratamento.A menor parte dos tumores se origina de mutaçōes em células germinativas e a maior parte provém de mutaçōes somáticas e influência de fatores externos, que estăo intimamente relacionados com a inflamaçăo. Esta é peça chave no desenvolvimento de tumores, fato este exemplificado pela incidência aumentada de neoplasias em locais com infecçắo, irritaçắo crônica e inflamaçăo. Aproximadamente $15 \%$ das neoplasia se desenvolvem devido infecçăa [6]. Alguns exemplos clássicos săo o adenocarcinoma gástrico com o H. pylori, o câncer vesical com o Schistosoma hematobium [7], o hepatocarcinoma com a hepatite C [8] e o câncer colorretal com as doenças inflamatórias intestinais [9].A inflamaçăo está intimamente relacionada com a evoluçăo das neoplasia, fato já descrito desde o século 19 [10]. O microambiente tumoral é amplamente influenciado por células inflamatórias e a progressăo do câncer depende da complexa interaçăo entre o tumor e a resposta inflamatória do organismo. Os leucócitos produzem grande variedade de citocinas, quimiocinas e proteinases extracelulares que modificam os componentes do estroma peritumoral[11] produzindo um microambiente atrativo para o crescimento tumoral, facilitando a instabilidade genômica e promovendo a angiogênese e linfangiogênese [12]. Este fato ganha importância na prediçăo de prognóstico, uma vez que estados inflamatórios mais exacerbados associam-se com neoplasias mais avançadas de pior evoluçăo.A relaçăo entre inflamaçăo e tumores foi primeiro observada por Virchow em 1863, quando o mesmo observou a presença de leucócitos dentro de tumores, supondo o papel da inflamaçăo nas neoplasias. Sugeriu que na presença de fatores irritantes e injúria tecidual a inflamaçăo se instala promovendo a acelaraçăo da proliferaçăo celular [13]. Mais de um século depois, os tumores foram definidos como feridas que năo cicatrizam [14].O termo estado neoplásico subliminar foi criado em 1941, caracterizado por mutaçōes somáticas irreversiveis que podem existir indefinidamente em tecidos normais e săo causadas por vírus ou agentes químicos carcinogênicos[15]. Quando este grupo de células mutadas é exposto à determinados fatores (irritantes químicos, fatores liberados em inflamaçăo, ressecçōes de orgăos) ocorre a proliferaçáo celular desordenada, recrutamento de células inflamatórias, reduçăo no reparo e aumento no dano oxidativo do DNA. Essa proliferaçăo celular năo controlada, diferente da inflamaçăo normal mediada por fatores pró e anti-inflamatórios, resulta no surgimento da neoplasia [16]. A partir de então notou-se a importância do microambiente tumoral e da inflamaçăo peritumoral, que pode ter 2 origens distintas:1- células inflamatórias săo atraídas para deteminado local a partir de um estímulo, como por exemplo, a presença de Helicobacter pylori. Logo, essas células inflamatórias criam um microambiente propício par a carcinogênese e desenvolvimento tumoral.2- o próprio tumor tem o potencial de atrair células inflamatórias para seu microambiente, através da liberaçăo de citocinas inflamatórias por suas células ou por células vizinhas sadias. Estudos em modelos animais com supressăo de linfócitos natura -killers (células anti-tumorais), mostram que o estímulo por uma neoplasia leva ao aparecimento de infiltrado inflamatório peri-tumoral. As células inflamatórias suprem o microambiente tumoral com moléculas bioativas responsáveis pelo aparecimento, crescimento e desenvolvimento da neoplasia[12]. Essas moléculas atuam em diversas etapas da carcinogênese:1. Liberaçăo de fatores pró-proliferaçăo celular.2. Remoçăo de supressores de crescimento celular.3. Aumento resistência à morte celular.4. Induçắo de angiogênese.5. Ativaçăa de invasăo e envio de metástases.A neutrofilia apresenta alguns mecanismos pro-carcinogenicos: secreção de fatores angiogenenicos e induçăo de células neoplásicas a migrarem por estes vasos sanguineos neoformados promovendo metástases, aumento de adesão entre células tumorais circulantes e órgãos-alvo de metástases, ao secretar uma rede de cromatina e proteina que captura células tumorais circulantes, fato já demonstrado em modelos murinos[17] Os linfócitos assumem papel na resposta sistêmica anti-tumoral pois o infiltrado linfocitário intra-tumoral exibe atividade contra a angiogênese e contra a própria célula tumoral. A linfopenia, ao sinalizar o consequente menor efeito anti-tumoral, pode indicar um O sangue periferico reflete esta atividade inflamatoria, podendo ser estudado de modo não invasivo . Os marcadores inflamatónios atualmente utilizados podem ser bioquímicos (proteina C reativa, albumina) e hematologicos (neutrófilos, linfócitos, plaquetas). As relaçōes entre esses elementos e a sobrevida relacionada ao câncer já é descrita, inclusive com a criaçăo de escores prognosticos como o Glasgow Prognostic Score (GPS) que combina a proteina C reativa e a concentraçáo de albumina[19]. No inicio dos anos 2000, a confirmaçăo da relaçăo entre inflamaçăo e prognóstico foi realizada em estudos com neoplasia pulmonar de pequenas células. A definiçăo do tipo de tratamento era baseada em critérios como baixo status performance e perda ponderal, que, uma vez considerados subjetivos, motivaram a busca de marcadores serricos mais fidedignos. Nesse contexto, a utilizaçáo da albumina e da proteina c reativa for impulsionada de modo a criar um score preditor de prognóstico, o GPS[20]. Nos anos 70, foi descoberta a influência que células inflamatórias peritumorais exercem sobre o crescimento e desenvolvimento do tumor. Notou-se que a presença com infiltrado linfocitário resultava em tumores menos agressivos comparados com sua ausência, sendo atribuido um papel protetor aos linfócitos devido à açăo de células natural-killers contra a neoplasia. De 
forma semelhante, a presença de infiltrado neutrofilico resulta em maior agressăo. Estudos in vitro desta mesma época demonstraram que quando co-incubados, os neutrófilos inibem os efeitos citolíticos dos linfócitos ativados sugerindo que in vivo esta relaçăo também acontece [21]. A anergia linfocitária foi demonstrad a imunorreatividade contra estas células. Sabe-se que os neutrófilos, ao suprimir a açăo dos linfócitos e células natural-killers, inibem o sistema imun e aceleram a carcinogênese [22]. Săo responsáveis por secretar fator de crescimento endotelial, fator de crescimento hepatocitário interleucina-6,

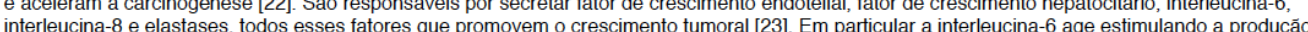
de proteínas da fase aguda, como a proteina $\mathrm{C}$ reativa, e suprimindo a produçăo de albumina pelo fígado. A concentraçăo sérica aumentada de IL-6 está relacionada com pior prognóstico. As células tumorais promovem o aumento do valor absoluto dos neutrófilos ao produzir citocinas esta relacionada com pior prognostico. As celulas tumorais promovem o aumento do valor absoluto dos neutrofilos ao produzir citocinas hematopoêticas e a neutrofilia indica portanto a natureza mais agressiva do tumor [24]. O NLR de valor elevado indica pior prognóstico de 2 formas: como fator independente e por estar relacionado com fatores de pior prognóstico no câncer gástrico (idade avançada, sexo masculino, caucasianos, histologia pouco diferenciada, maior T e N, infiltraçăo vascular). O alto valor de NLR é fator prognóstico independente do TNM; uma volume tumoral maior ao produzir mais inflamaçăo resulta em um alto NLR e este logicamente apresentará pior prognóstico. Porém, ao compararmos pacientes com volume tumoral semelhante, aqueles com maior NLR apresentarăo pior prognostico. Năo há valor de cutoff definido para NLR, com variaçōes entre relaciona com pior prognóstico em diversos tipos de tumores: colorretal, pancreático, hepatocarcinoma, ovariano, mieloma múltiplo, carcinoma de

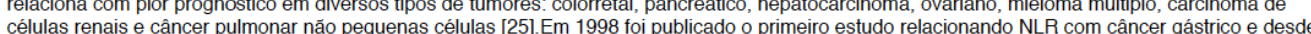
células renais e câncer pulmonar năo pequenas células [25].Em 1998 foi publicado o primeiro estudo relacionando NLR com câncer gástrico e desde entăo diversos estudos demonstraram que um alto valor NLR se relaciona com pior prognóstico [26]. Estima-se que para cada aumento de 1 p no NLR, ha aumento de $10 \%$ no risco de morte relacionada ao câncer gástrico[27]. O valor pode ser mensurado no pré-operatório logo após o
diagnóstico e sem nenhum tipo de tratamento instituído. Também pode ser medido nos primeiros dias de pós operatório, quando inicialmente até o diagnóstico e sem nenhum tipo de tratamento instituído. Também pode ser medido nos primeiros dias de pós operatório, quando inicialmente até o
$4^{\circ}$ pós-operatório costuma ocorrer uma elevaçăo no valor devido à resposta inflamatória pós-operatória. No $7^{\circ}$ pós-operatório observa-se um retorno no NLR aos niveis de pré-operatório. Com 1 mês de pré-operatório, a queda de NLR para valores inferiores ao do pós-operatório indica melhor prognóstico $[28,29]$. O acometimento linfonodal é um dos fatores de pior prognóstico no câncer gástrico e sua previsăo no pré-operatório pode ser progiostico [28,20.0 realizada atraves d tumorais circulantes săo danificadas por fatores imunes e trauma mecanico quando presentes na microcirculaçáo sanguinea. Porém, quan cobertas por plaquetas a intensidade do dano e e reduzida [30]. As plaquetas tambem promovem a angiogenese ao secretar fator vascular de efeitos. Clinicamente, observa-se como fenômenos paraneoplásicos a trombose e a embolia. A plaquetose se relaciona com estadios mais eva a d. incluindo cân méństase linfon ẩ cutoff do NLR P PLR Alguns estudos utilizam a curv ROC para determinar o valor mais fidedigno. A comparaça entre o valor prognóstico do NLR e do PLR já foi tema de estudo que concluiu que somente o NLR relaciona-se com menor sobrevida global no câncer gástrico ressecado [33]

\section{Hipótese:}

as razōes NLR e PLR têm relaçăo com a sobrevida global, sobrevida livre de doença e taxa de recidiva em pacientes com adenocarcinoma gástrico submetidos à gastrectomia com intuíto curativo.

Objetivo Primário:

Objetivo primário: Avaliar se as razōes NLR e PLR se relacionam com a sobrevida global, sobrevida livre de doença e taxa de recidiva em pacientes com adenocarcinoma gástrico submetidos à gastrectomia com intuito curativo.

Objetivo Secundário:

Identificar fatores de risco epidemiológicos (ex.: sexo, idade) para alta relaçăo NLR e PLR. Avaliar se a queda do NLR e PLR a partir do $30^{\circ}$ pós-operatório comparado com o valor pré-operatório indica menor taxa de recidiva e maior sobrevida livre de doença. Avaliar se a trombocitose e relacionada com estadios mais avançados. Avaliar se os valores NLR e PLR estăo relacionados com maior morbi-mortalidade até o $30^{\circ}$ pósoperatório. Avaliar se o status nutricional (demonstrado pelo valor de albumina sérica) influencia nos valores NLR e PLR. Avaliar a relaçăo entre NLR e PLR com o estadiamento patológico (TNM)

Metodologia Proposta:

PopulaçăoSerăo estudados retrospectivamente 550 pacientes com diagnóstico de adenocarcinoma gástrico comprovado por análise histológica submetidos à gastrectomia com linfadenectomia com intuito curativo no Intistuto do Câncer do Estado de S. Paulo (ICESP) entre os anos de 2009 a 2017. Exames laboratoriaisSerăo revisados resultados de exames laboratoriais realizados após a confirmaçăo diagnóstica e antes de qualquer tipo de intervenção terapêutica, como cirurgia ou quimioterapia neoadjuvante. Sabe-se que a cirurgia exacerba a resposta inflamatória sistêmica e que a quimitoterapia pode suprimi-la. Logo, o cuidado em se analisar exames em pacientes sem nenhum tipo de tratamento prévio visa impedir a

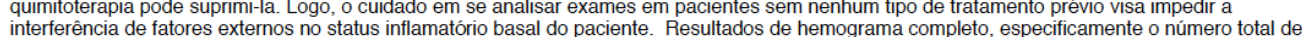
linfócitos, neutrófilos e plaquetas serăo revisados e será calculada a relaçăo plaquetas:linfócitos e neutrófilos:linfócitos.

Coleta de dados

Será utilizado banco de dados bom projeto já aprovado pelo Cômite de Ética do ICESP Registro no núcleo de pesquisa: NP 993/16 Registro na plataforma Brasil: CAAE: 62915516.2.0000.0065

Critério de Inclusão:

Serăo incluídos pacientes com adenocarcinoma gástrico submetidos à ressecçăo com intuito curativo.

\section{Critério de Exclusão:}

Submetidos à neoajuvância

metastática

Sem exames laboratoriais completos ao diagnóstico

Riscos:

Năo há riscos diretos para os participantes de pesquisa, pois trata-se de um estudo retrospectivo

Benefícios:

Năo há benefícios diretos para os participantes de pesquisa, pois trata-se de um estudo retrospectivo

Metodologia de Análise de Dados: 
Rudolph K. Hepatocellular Carcinoma: Epidemiology and Molecular Carcinogenesis. Gastroenterology. 2007;132: 2557-2576. 9. Itzkowitz SH. Inflammation and Cancer IV. Colorectal cancer in inflammatory bowel disease: the role of inflammation. AJP: Gastrointestinal and Liver Physiology 2004;287: G7-G17. 10. Bryant T. Remarks on Some Cases of Inflammation of the Breast Simulating Cancer. Br Med J. 1868;2: 608-609. 11 . Robinson SC, Coussens LM. Soluble Mediators of Inflammation During Tumor Development. Advances in Cancer Research. 2005. pp. 159-187. 12. Coussens LM, Werb Z. Inflammation and cancer. Nature. 2002;420: 860-867. 13. Balkwill F, Mantovani A. Inflammation and cancer: back to Virchow? Lancet. 2001;357: 539-545. 14. Flier JS, Underhill LH, Dvorak HF. Tumors: Wounds That Do Not Heal. N Engl J Med. 1986;315: 1650-1659. 15. Rous P, KIdd JG. CONDITIONAL NEOPLASMS AND SUBTHRESHOLD NEOPLASTIC STATES : A STUDY OF THE TAR TUMORS OF RABBITS. J Exp Med. 1941;73: 365-390. 16. Mackenzie I, Rous P. THE EXPERIMENTAL DISCLOSURE OF LATENT NEOPLASTIC CHANG IN TARRED SKIN. Exp Med. 1941;73: 391-416. 17. Mishalian I, Bayuh R, Levy L, Zolotarov L, Michaeli J, Fridlender ZG. Tumor-associated neutrophils (TAN) develop pro-tumorigenic properties during tumor progression. Cancer Immunol Immunother. 2013;62: 1745-1756. 18. Whiteside TL. The tumor microenvironment and its role in promoting tumor growth. Oncogene. 2008;27: 5904-5912. 19. Proctor MJ, Morrison DS, Talwar D,
Balmer SM. Fletcher CD. O'Reilly DSJ, et al. A comparison of inflammation-based prognostic scores in patients with cancer. A Glasgow Inflammation Balmer SM, Fletcher CD, O'Reilly DSJ, et al. A comparison of inflammation-based prognostic scores in patients with cancer. A Glasgow Inflamme
Outcome Study. Eur J Cancer. 2011:47: 2633-2641. 20. Forrest LM, McMillan DC, McArdle CS, Angerson WJ, Dagg K, Scott HR. A prospective longitudinal study of performance status, an inflammation-based score (GPS) and survival in patients with inoperable non-small-cell lung cancer. Br Cancer. 2005;92: 1834-1836. 21. Roubin R, Césarini JP, Fridman WH, Pavie-Fischer J, Peter HH. Characterization of the mononuclear cell infiltrate in human malignant melanoma. Int J Cancer. 1975;16: 61-73. 22. Petrie HT, Klassen LW, Kay HD. Inhibition of human cytotoxic T lymphocyte activity in vitro by autologous peripheral blood granulocytes. J Immunol. 1985;134: 230-234. 23. Kusumanto YH, Dam WA, Hospers GAP, Meijer C, Mulder NH. Platelets and granulocytes, in particular the neutrophils, form important compartments for circulating vascular endothelial growth factor. Angiogenesis. 2003;6: 283-287. 24. Granot Z, Jablonska J. Distinct Functions of Neutrophil in Cancer and Its Regulation. Mediators Inflamm.
2015-2015: 701067 25. Guthrie GJK, Charles KA, Roxburgh CSD, Horgan PG. McMillan DC, Clarke SJ. The systemic inflammation-based neutrophi 2015;2015: 701067. 25. Guthrie GJK, Charles KA, Roxburgh CSD, Horgan PG, McMillan DC, Clarke SJ. The systemic inflammation-based -lymphocyte ratio: experience in patients with cancer. Crit Rev Oncol Hematol. 2013;88: 218-230. 26. Hirashima M, Higuchi S, Sakamoto K, Nishiyama T, Okada $\mathrm{H}$. The ratio of neutrophils to lymphocytes and the phenotypes of neutrophils in patients with early gastric cancer. J Cancer Res Clin Oncol. 1998;124: 329-334. 27. Wang SC, Chou JF, Strong VE, Brennan MF, Capanu M, Coit DG. Pretreatment Neutrophil to Lymphocyte Ratio Independently Predicts Disease-specific Survival in Resectable Gastroesophageal Junction and Gastric Adenocarcinoma. Ann Surg. 2016;263: 292-297. 28. Lou N, Zhang L, Chen X-D, Pang W-Y, Arvine C, Huang Y-P, et al. A novel scoring system associating with preoperative

platelet/lymphocyte and cling L, Xia Y-Y, Zhou C, Shen X-M, LI X-L, Han S-G, et al. Application of platelet/ymphocyte and neutrophil/ymphocyte ratios in early diagnosis and prognostic prediction in patients with resectable gastric cancer. Cancer Biomark. 2015;15: 899-907. 30. Shou L-M, Zhang Q-Y, Li W, Xie X, Chen K, Lian L, et al. Cantharidin and norcantharidin inhibit the ability of MCF-7 cells to adhere to platelets via protein kinase C pathway-dependent downregulation of 2 integrin. Oncol Rep. 2013;30: 1059-1066. 31. Heras P, Hatzopoulos A, Kritikos N, Kritikos K. Platelet count and tumor progression in gastric cancer patients. Scand J Gastroenterol. 2010,45. 1005-1006. 32. Pang W, Lou N, Jin C, Hu C, Arvine C, Zhu G, et al. Combination of preoperative platelet/lymphocyte and neutrophil/ymphocyte rates and tumor-related factors to predict lymph node metastasis in patients with gastric cancer. Eur J Gastroenterol Hepatol. 2016,28. 493-502. 33. Kim EY, Lee JW, Yoo HM, Park CH, Song KY. The Platelet-toLymphocyte Ratio Versus Neutrophil-to-Lymphocyte Ratio: Which is Better as a Prognostic Factor in Gastric Cancer? Ann Surg Oncol. 2015;22: $4363-4370$

Upload de Documento

Arquivo Anexos:

\begin{tabular}{|l|l|}
\hline \multicolumn{1}{|c|}{ Tipo } & \multicolumn{1}{|c|}{ Arquivo } \\
\hline Folha de Rosto & FolhaRosto.pdf \\
\hline Projeto Detalhado / Brochura Investigador & ProjetoPesquisa.docx \\
\hline $\begin{array}{l}\text { TCLE / Termos de Assentimento / Justificativa de } \\
\text { Ausência }\end{array}$ & Dispensa_TCLE.pdf \\
\hline Outros & Anexoll.pdf \\
\hline Outros & Aprovacao_ICESP.pdf \\
\hline
\end{tabular}

Finalizar

Manter sigilo da integra do projeto de pesquisa:

Prazo: Até a publicaçăo dos resultados 
8 REFERÊNCIAS 
1. Balkwill F, Mantovani A. Inflammation and cancer: back to Virchow? Lancet. 200117;357(9255):539-45.

2. Bray F, Ferlay J, Soerjomataram I, Siegel RL, Torre LA, Jemal A. Global cancer statistics 2018: GLOBOCAN estimates of incidence and mortality worldwide for 36 cancers in 185 countries. CA Cancer $J$ Clin. 2018;68(6):394-424.

3. Howson CP, Hiyama T, Wynder EL. The decline in gastric cancer: epidemiology of an unplanned triumph. Epidemiol Rev. 1986;8:1-27.

4. Balakrishnan M, George R, Sharma A, Graham DY. Changing trends in stomach cancer throughout the world. Curr Gastroenterol Rep. 2017;19(8):36.

5. Ministério da Saúde. Instituto Nacional de Câncer. Câncer de estômago [internet]. 2019 jul 24 [acesso em 2019 ago 29]. Disponível em: https://www.inca.gov.br/tipos-de-cancer/cancer-de-estomago.

6. Zhang X, Li M, Chen S, Hu J, Guo Q, Liu R, Zheng H, Jin Z, Yuan Y, Xi Y, Hua B. Endoscopic screening in asian countries is associated with reduced Gastric cancer mortality: a meta-analysis and systematic review. Gastroenterology. 2018;155(2):347-54. 
7. Guggenheim DE, Shah MA. Gastric cancer epidemiology and risk factors. $J$ Surg Oncol. 2013;107(3):230-6.

8. Pharoah PD, Guilford P, Caldas C, International Gastric Cancer Linkage C. Incidence of gastric cancer and breast cancer in CDH1 (E-cadherin) mutation carriers from hereditary diffuse gastric cancer families. Gastroenterology. 2001;121(6):1348-53.

9. Umar A, Boland CR, Terdiman JP, Syngal S, de la Chapelle A, Rüschoff J, Fishel R, Lindor NM, Burgart LJ, Hamelin R, Hamilton SR, Hiatt RA, Jass J, Lindblom A, Lynch HT, Peltomaki P, Ramsey SD, Rodriguez-Bigas MA, Vasen HF, Hawk ET, Barrett JC, Freedman AN, Srivastava S. Revised Bethesda Guidelines for hereditary nonpolyposis colorectal cancer (Lynch syndrome) and microsatellite instability. J Natl Cancer Inst. 2004;96(4):2618.

10. Schulz C, Schutte K, Malfertheiner P. Rare Neoplasia of the stomach. Gastrointest Tumors. 2015;2(2):52-60.

11. Hu B, El Hajj N, Sittler S, Lammert N, Barnes R, Meloni-Ehrig A. Gastric cancer: classification, histology and application of molecular pathology. $J$ Gastrointest Oncol. 2012;3(3):251-61.

12. Hvid-Jensen F, Pedersen L, Drewes AM, Sorensen HT, Funch-Jensen P. Incidence of adenocarcinoma among patients with Barrett's esophagus. $N$ Engl J Med. 2011;365(15):1375-83. 
13. Cancer Genome Atlas Research N. Comprehensive molecular characterization of gastric adenocarcinoma. Nature. 2014;513(7517):202-9.

14. Pereira MA, Ramos M, Faraj SF, Dias AR, Yagi OK, Zilberstein B, Cecconello I, Alves VAF, de Mello ES, Ribeiro U Jr. Clinicopathological and prognostic features of Epstein-Barr virus infection, microsatellite instability, and PD-L1 expression in gastric cancer. J Surg Oncol. 2018 Apr;117(5):82939.

15. Amin MB, Greene FL, Edge SB, Compton CC, Gershenwald JE, Brookland RK, Meyer L, Gress DM, Byrd DR, Winchester DP.. The Eighth Edition AJCC Cancer Staging Manual: Continuing to build a bridge from a population-based to a more "personalized" approach to cancer staging. $C A$ Cancer J Clin. 2017;67(2):93-9.

16. Sano T, Sasako M, Yamamoto S, Nashimoto A, Kurita A, Hiratsuka M, Tsujinaka T, Kinoshita T, Arai K, Yamamura Y, Okajima K. Gastric cancer surgery: morbidity and mortality results from a prospective randomized controlled trial comparing D2 and extended para-aortic lymphadenectomy-Japan Clinical Oncology Group study 9501. J Clin Oncol. 2004;22(14):276773.

17. Bourke MJ, Neuhaus H, Bergman JJ. Endoscopic Submucosal dissection: indications and application in western endoscopy practice. Gastroenterology. 2018;154(7):1887-900. 
18. Ronellenfitsch U, Schwarzbach M, Hofheinz R, Kienle P, Kieser M, Slanger TE, Jensen K; GE Adenocarcinoma Meta-analysis Group. Perioperative chemo(radio)therapy versus primary surgery for resectable adenocarcinoma of the stomach, gastroesophageal junction, and lower esophagus. Cochrane Database Syst Rev. 2013;(5):CD008107.

19. Japanese Gastric Cancer Association Registration Committee, Maruyama K, Kaminishi M, Hayashi K, Isobe Y, Honda I, Katai H, Arai K, Kodera Y, Nashimoto A. Gastric cancer treated in 1991 in Japan: data analysis of nationwide registry. Gastric Cancer. 2006;9(2):51-66.

20. Kwee RM, Kwee TC. Predicting lymph node status in early gastric cancer. Gastric Cancer. 2008;11(3):134-48.

21. Templeton AJ, McNamara MG, Šeruga B, Vera-Badillo FE, Aneja P, Ocaña A, Leibowitz-Amit R, Sonpavde G, Knox JJ, Tran B, Tannock IF, Amir E. Prognostic role of neutrophil-to-lymphocyte ratio in solid tumors: a systematic review and meta-analysis. J Natl Cancer Inst. 2014;106(6):dju124.

22. Templeton AJ, Ace O, McNamara MG, Al-Mubarak M, Vera-Badillo FE, Hermanns T, Seruga B, Ocaña A, Tannock IF, Amir E. Prognostic role of platelet to lymphocyte ratio in solid tumors: a systematic review and metaanalysis. Cancer Epidemiol Biomarkers Prev. 2014;23(7):1204-12.

23. Hanahan D, Weinberg RA. Hallmarks of cancer: the next generation. Cell. 2011;144(5):646-74. 
24. Grivennikov SI, Greten FR, Karin M. Immunity, inflammation, and cancer. Cell. 2010;140(6):883-99.

25. Dvorak HF. Tumors: wounds that do not heal. Similarities between tumor stroma generation and wound healing. N Engl J Med. 1986;315(26):1650-9.

26. Kuper H, Adami HO, Trichopoulos D. Infections as a major preventable cause of human cancer. J Intern Med. 2000;248(3):171-83.

27. Bernstein CN, Blanchard JF, Kliewer E, Wajda A. Cancer risk in patients with inflammatory bowel disease: a population-based study. Cancer. 2001;91(4):854-62.

28. El-Serag HB, Rudolph KL. Hepatocellular carcinoma: epidemiology and molecular carcinogenesis. Gastroenterology. 2007;132(7):2557-76.

29. Badawi AF, Mostafa MH, Probert A, O'Connor PJ. Role of schistosomiasis in human bladder cancer: evidence of association, aetiological factors, and basic mechanisms of carcinogenesis. Eur J Cancer Prev. 1995;4(1):45-59.

30. Uemura N, Okamoto S, Yamamoto S, Matsumura N, Yamaguchi S, Yamakido M, Taniyama K, Sasaki N, Schlemper RJ. Helicobacter pylori infection and the development of gastric cancer. $N$ Engl $J$ Med. 2001;345(11):784-9.

31. Pajecki D, Zilberstein B, dos Santos MA, Quintanilha AG, Cecconello I, Gama-Rodrigues J. Megaesophagus microbiota and carcinogenesis. Arq Gastroenterol. 2003;40(1):16-9. 
32. Koehne CH, Dubois RN. COX-2 inhibition and colorectal cancer. Semin Oncol. 2004;31(2 Suppl 7):12-21.

33. Hanahan D, Weinberg RA. The hallmarks of cancer. Cell. 2000;100(1):57-70.

34. Witz IP. Yin-yang activities and vicious cycles in the tumor microenvironment. Cancer Res. 2008;68(1):9-13.

35. Mantovani A, Allavena P, Sica A, Balkwill F. Cancer-related inflammation. Nature. 2008;454(7203):436-44.

36. de Visser KE, Eichten A, Coussens LM. Paradoxical roles of the immune system during cancer development. Nat Rev Cancer. 2006;6(1):24-37.

37. Bhowmick NA, Moses HL. Tumor-stroma interactions. Curr Opin Genet Dev. 2005;15(1):97-101.

38. Witz IP, Levy-Nissenbaum O. The tumor microenvironment in the postPAGET era. Cancer Lett. 2006;242(1):1-10.

39. Yuan J, Glazer PM. Mutagenesis induced by the tumor microenvironment. Mutat Res. 1998;400(1-2):439-46.

40. Bindra RS, Glazer PM. Genetic instability and the tumor microenvironment: towards the concept of microenvironment-induced mutagenesis. Mutat Res. 2005;569(1-2):75-85.

41. Harris AL. Hypoxia--a key regulatory factor in tumour growth. Nat Rev Cancer. 2002;2(1):38-47. 
42. Hida K, Klagsbrun M. A new perspective on tumor endothelial cells: unexpected chromosome and centrosome abnormalities. Cancer Res. 2005;65(7):2507-10.

43. Streubel B, Chott A, Huber D, Exner M, Jager U, Wagner O, Schwarzinger I. Lymphoma-specific genetic aberrations in microvascular endothelial cells in B-cell lymphomas. N Engl J Med. 2004;351(3):250-9.

44. Ocana A, Nieto-Jimenez C, Pandiella A, Templeton AJ. Neutrophils in cancer: prognostic role and therapeutic strategies. Mol Cancer. 2017;16(1):137.

45. Coussens LM, Werb Z. Inflammation and cancer. Nature. 2002;420(6917):860-7.

46. Compton C. Precision medicine core: progress in prognostication-populations to patients. Ann Surg Oncol. 2018;25(2):349-50.

47. In H, Solsky I, Palis B, Langdon-Embry M, Ajani J, Sano T. Validation of the 8th Edition of the AJCC TNM Staging System for Gastric Cancer using the National Cancer Database. Ann Surg Oncol. 2017;24(12):3683-91.

48. Amri R, England J, Bordeianou LG, Berger DL. Risk stratification in patients with stage II colon cancer. Ann Surg Oncol. 2016;23(12):3907-14.

49. Baniak N, Senger JL, Ahmed S, Kanthan SC, Kanthan R. Gastric biomarkers: a global review. World J Surg Oncol. 2016;14(1):212. 
50. Strimbu K, Tavel JA. What are biomarkers? Curr Opin HIV AIDS. 2010;5(6):463-6.

51. Dolan RD, Lim J, McSorley ST, Horgan PG, McMillan DC. The role of the systemic inflammatory response in predicting outcomes in patients with operable cancer: Systematic review and meta-analysis. Sci Rep. 2017;7(1):16717.

52. Coffelt SB, Wellenstein MD, de Visser KE. Neutrophils in cancer: neutral no more. Nat Rev Cancer. 2016;16(7):431-46.

53. Borregaard N. Neutrophils, from marrow to microbes. Immunity. 2010;33(5):657-70.

54. Dancey JT, Deubelbeiss KA, Harker LA, Finch CA. Neutrophil kinetics in man. J Clin Invest. 1976;58(3):705-15.

55. Semerad CL, Liu F, Gregory AD, Stumpf K, Link DC. G-CSF is an essential regulator of neutrophil trafficking from the bone marrow to the blood. Immunity. 2002;17(4):413-23.

56. Strauss L, Sangaletti S, Consonni FM, Szebeni G, Morlacchi S, Totaro MG, Porta C, Anselmo A, Tartari S, Doni A, Zitelli F, Tripodo C, Colombo MP, Sica A. RORC1 regulates tumor-promoting "emergency" granulomonocytopoiesis. Cancer Cell. 2015;28(2):253-69. 
57. Knaapen AM, Gungor N, Schins RP, Borm PJ, Van Schooten FJ. Neutrophils and respiratory tract DNA damage and mutagenesis: a review. Mutagenesis. 2006;21(4):225-36.

58. Houghton AM, Rzymkiewicz DM, Ji H, Gregory AD, Egea EE, Metz HE, Stolz DB, Land SR, Marconcini LA, Kliment CR, Jenkins KM, Beaulieu KA, Mouded M, Frank SJ, Wong KK, Shapiro SD. Neutrophil elastase-mediated degradation of IRS-1 accelerates lung tumor growth. Nat Med. 2010;16(2):219-23.

59. Karadayi N, Kandemir NO, Yavuzer D, Korkmaz T, Gecmen G, Kokturk F. Inducible nitric oxide synthase expression in gastric adenocarcinoma: impact on lymphangiogenesis and lymphatic metastasis. Diagn Pathol. 2013;8:151.

60. Viallard C, Larrivee B. Tumor angiogenesis and vascular normalization: alternative therapeutic targets. Angiogenesis. 2017;20(4):409-26.

61. Liang W, Ferrara N. The Complex Role of Neutrophils in Tumor Angiogenesis and Metastasis. Cancer Immunol Res. 2016;4(2):83-91.

62. Bronte $\mathrm{V}$, Zanovello P. Regulation of immune responses by L-arginine metabolism. Nat Rev Immunol. 2005;5(8):641-54.

63. Lu T, Gabrilovich DI. Molecular pathways: tumor-infiltrating myeloid cells and reactive oxygen species in regulation of tumor microenvironment. Clin Cancer Res. 2012;18(18):4877-82. 
64. Colotta F, Re F, Polentarutti N, Sozzani S, Mantovani A. Modulation of granulocyte survival and programmed cell death by cytokines and bacterial products. Blood. 1992;80(8):2012-20.

65. Keane MP, Belperio JA, Xue YY, Burdick MD, Strieter RM. Depletion of CXCR2 inhibits tumor growth and angiogenesis in a murine model of lung cancer. J Immunol. 2004;172(5):2853-60.

66. Tazzyman S, Barry ST, Ashton S, Wood P, Blakey D, Lewis CE, Murdoch C. Inhibition of neutrophil infiltration into A549 lung tumors in vitro and in vivo using a CXCR2-specific antagonist is associated with reduced tumor growth. Int J Cancer. 2011;129(4):847-58.

67. Yang L, DeBusk LM, Fukuda K, Fingleton B, Green-Jarvis B, Shyr Y, Matrisian LM, Carbone DP, Lin PC. Expansion of myeloid immune suppressor $\mathrm{Gr}+\mathrm{CD} 11 \mathrm{~b}+$ cells in tumor-bearing host directly promotes tumor angiogenesis. Cancer cell. 2004;6(4):409-21.

68. Yan Y, Zhang J, Li JH, Liu X, Wang JZ, Qu HY, Wang JS, Duan XY. High tumor-associated macrophages infiltration is associated with poor prognosis and may contribute to the phenomenon of epithelial-mesenchymal transition in gastric cancer. Onco Targets Ther. 2016;9:3975-83.

69. Raiha MR, Puolakkainen PA. Tumor-associated macrophages (TAMs) as biomarkers for gastric cancer: a review. Chronic Dis Transl Med. 2018;4(3):156-63. 
70. Mildner A, Jung S. Development and function of dendritic cell subsets. Immunity. 2014;40(5):642-56.

71. Herberman RB, Nunn ME, Lavrin DH. Natural cytotoxic reactivity of mouse lymphoid cells against syngeneic acid allogeneic tumors. I. Distribution of reactivity and specificity. Int J Cancer. 1975;16(2):216-29.

72. Curiel TJ, Coukos G, Zou L, Alvarez X, Cheng P, Mottram P, EvdemonHogan M, Conejo-Garcia JR, Zhang L, Burow M, Zhu Y, Wei S, Kryczek I, Daniel B, Gordon A, Myers L, Lackner A, Disis ML, Knutson KL, Chen L, Zou W. Specific recruitment of regulatory $\mathrm{T}$ cells in ovarian carcinoma fosters immune privilege and predicts reduced survival. Nat Med. 2004;10(9):942-9.

73. Boon T, Cerottini JC, Van den Eynde B, van der Bruggen P, Van Pel A. Tumor antigens recognized by $\mathrm{T}$ lymphocytes. Annu Rev Immunol. 1994;12:337-65.

74. Kim R, Emi M, Tanabe K. Cancer immunoediting from immune surveillance to immune escape. Immunology. 2007;121(1):1-14.

75. Ribatti D. The concept of immune surveillance against tumors. The first theories. Oncotarget. 2017;8(4):7175-80.

76. Mortaz E, Tabarsi P, Mansouri D, Khosravi A, Garssen J, Velayati A, Adcock IM. Cancers related to immunodeficiencies: update and perspectives. Front Immunol. 2016;7:365. 
77. Saito T, Kuss I, Dworacki G, Gooding W, Johnson JT, Whiteside TL. Spontaneous ex vivo apoptosis of peripheral blood mononuclear cells in patients with head and neck cancer. Clin Cancer Res. 1999;5(6):1263-73.

78. Petrie HT, Klassen LW, Kay HD. Inhibition of human cytotoxic T lymphocyte activity in vitro by autologous peripheral blood granulocytes. $J$ Immunol. 1985;134(1):230-4.

79. Bobb GA, Fairchild EJ. Neutrophil-to-lymphocyte ratio as indicator of ozone exposure. Toxicol Appl Pharmacol. 1967;11(3):558-64.

80. Varenko Iu S, Lekakh VA, Shidlovskaia MP. Significance of the ratio of blood lymphocytes to polymorphonuclear neutrophils in pneumonia and bronchitis patients. Vrach Delo. 1985;(8):102-3.

81. Hirashima M, Higuchi S, Sakamoto K, Nishiyama T, Okada H. The ratio of neutrophils to lymphocytes and the phenotypes of neutrophils in patients with early gastric cancer. J Cancer Res Clin Oncol. 1998;124(6):329-34.

82. Tamhane UU, Aneja S, Montgomery D, Rogers EK, Eagle KA, Gurm HS. Association between admission neutrophil to lymphocyte ratio and outcomes in patients with acute coronary syndrome. Am J Cardiol. 2008;102(6):653-7.

83. Ahsen A, Ulu MS, Yuksel S, Demir K, Uysal M, Erdogan M, Acarturk G. As a new inflammatory marker for familial Mediterranean fever: neutrophil-tolymphocyte ratio. Inflammation. 2013;36(6):1357-62. 
84. Akil E, Bulut A, Kaplan I, Ozdemir HH, Arslan D, Aluclu MU. The increase of carcinoembryonic antigen (CEA), high-sensitivity C-reactive protein, and neutrophil/lymphocyte ratio in Parkinson's disease. Neurol Sci. 2015;36(3):423-8.

85. Castro E, Lozano R, Olmos D. Neutrophil to lymphocyte ratio: another drop in the ocean of CRPC biomakers? Ann Oncol. 2015;26(4):622-3.

86. Roxburgh CS, McMillan DC. Role of systemic inflammatory response in predicting survival in patients with primary operable cancer. Future Oncol. 2010;6(1):149-63.

87. Yamanaka T, Matsumoto S, Teramukai S, Ishiwata R, Nagai Y, Fukushima M. The baseline ratio of neutrophils to lymphocytes is associated with patient prognosis in advanced gastric cancer. Oncology. 2007;73(3-4):215-20..

88. Wang SC, Chou JF, Strong VE, Brennan MF, Capanu M, Coit DG. Pretreatment neutrophil to lymphocyte ratio independently predicts diseasespecific survival in resectable gastroesophageal junction and gastric adenocarcinoma. Ann Surg. 2016;263(2):292-7.

89. Szor DJ, Dias AR, Pereira MA, Ramos M, Zilberstein B, Cecconello I, Ribeiro-Júnior U. Prognostic role of neutrophil/lymphocyte ratio in resected gastric cancer: a systematic review and meta-analysis. Clinics (Sao Paulo). 2018;73:e360. 
90. Mellor KL, Powell A, Lewis WG. Systematic review and meta-analysis of the prognostic significance of neutrophil-lymphocyte ratio (NLR) after R0 gastrectomy for cancer. J Gastrointest Cancer. 2018;49(3):237-44.

91. Japanese Gastric Cancer Association. Japanese gastric cancer treatment guidelines 2014 (ver. 4). Gastric Cancer. 2017;20(1):1-19.

92. Charlson ME, Pompei P, Ales KL, MacKenzie CR. A new method of classifying prognostic comorbidity in longitudinal studies: development and validation. J Chronic Dis. 1987;40(5):373-83.

93. Owens WD, Felts JA, Spitznagel EL, Jr. ASA physical status classifications: a study of consistency of ratings. Anesthesiology. 1978;49(4):239-43.

94. Powell A, Parkinson D, Patel N, Chan D, Christian A, Lewis WG. Prognostic significance of serum inflammatory markers in gastric cancer. $J$ Gastrointest Sur. 2018;22(4):595-605.

95. Gao Y, Huang D. The value of the systematic inflammation-based Glasgow Prognostic Score in patients with gastric cancer: a literature review. J Cancer Res Ther. 2014;10(4):799-804.

96. Walsh SR, Cook EJ, Goulder F, Justin TA, Keeling NJ. Neutrophillymphocyte ratio as a prognostic factor in colorectal cancer. J Surg Oncol. 2005;91(3):181-4. 
97. Fruchtenicht AVG, Poziomyck AK, Reis AMD, Galia CR, Kabke GB, Moreira LF. Inflammatory and nutritional statuses of patients submitted to resection of gastrointestinal tumors. Rev Col Bras Cir. 2018;45(2):e1614.

98. Proctor MJ, Morrison DS, Talwar D, Balmer SM, Fletcher CD, O'Reilly DS, Foulis AK, Horgan PG, McMillan DC. A comparison of inflammation-based prognostic scores in patients with cancer. A Glasgow Inflammation Outcome Study. Eur J Cancer. 2011;47(17):2633-41.

99. Wang DS, Ren C, Qiu MZ, Luo HY, Wang ZQ, Zhang DS, Wang FH, Li $\mathrm{YH}, \mathrm{Xu} \mathrm{RH}$. Comparison of the prognostic value of various preoperative inflammation-based factors in patients with stage III gastric cancer. Tumour Biol. 2012;33(3):749-56.

100. Guthrie GJ, Charles KA, Roxburgh CS, Horgan PG, McMillan DC, Clarke SJ. The systemic inflammation-based neutrophil-lymphocyte ratio: experience in patients with cancer. Crit Rev Oncol Hematol. 2013;88(1):21830.

101. Crew KD, Neugut AI. Epidemiology of gastric cancer. World $J$ Gastroenterol. 2006;12(3):354-62.

102. Guner A, Kim SY, Yu JE, Min IK, Roh YH, Roh C, Seo WJ, Cho M, Choi S, Choi YY, Son T, Cheong JH, Hyung WJ, Noh SH, Kim HI. Parameters for predicting surgical outcomes for gastric cancer patients: simple is better than complex. Ann Surg Oncol. 2018;25(11):3239-47. 
103. Onodera H, Tokunaga A, Yoshiyuki T, Kiyama T, Kato S, Matsukura N, Masuda G, Tajiri T. Surgical outcome of 483 patients with early gastric cancer: prognosis, postoperative morbidity and mortality, and gastric remnant cancer. Hepatogastroenterology. 2004;51(55):82-5.

104. Forman D, Burley VJ. Gastric cancer: global pattern of the disease and an overview of environmental risk factors. Best Pract Res Clin Gastroenterol. 2006;20(4):633-49.

105. Ramos M, Pereira MA, Yagi OK, Dias AR, Charruf AZ, Oliveira RJ, Zaidan EP, Zilberstein B, Ribeiro-Júnior U, Cecconello I. Surgical treatment of gastric cancer: a 10-year experience in a high-volume university hospital. Clinics (Sao Paulo). 2018;73(suppl 1):e543s.

106. Ichikura T, Ogawa T, Chochi K, Kawabata T, Sugasawa H, Mochizuki H. Minimum number of lymph nodes that should be examined for the International Union Against Cancer/American Joint Committee on Cancer TNM classification of gastric carcinoma. World J Surg. 2003;27(3):330-3.

107. Lee JS, Kim NY, Na SH, Youn YH, Shin CS. Reference values of neutrophillymphocyte ratio, lymphocyte-monocyte ratio, platelet-lymphocyte ratio, and mean platelet volume in healthy adults in South Korea. Medicine. 2018;97(26):e11138.

108. Azab B, Camacho-Rivera M, Taioli E. Average values and racial differences of neutrophil lymphocyte ratio among a nationally representative sample of United States subjects. PloS One. 2014;9(11):e112361. 
109. Wu Y, Jiang M, Qin Y, Lin F, Lai M. Single and combined use of neutrophillymphocyte ratio, platelet-lymphocyte ratio and carcinoembryonic antigen in diagnosing gastric cancer. Clin Chim Acta. 2018;481:20-4.

110. Pisu M, Henrikson NB, Banegas MP, Yabroff KR. Costs of cancer along the care continuum: What we can expect based on recent literature. Cancer. 2018;124(21):4181-91.

111. Associação Médica Brasileira. Classificação Brasileira Hierarquizada de Procedimentos Médicos [internet]. 2018 [acesso em 2019 abr 29]. Disponível em: https://amb.org.br/cbhpm/.

112. Markle JG, Fish EN. SeXX matters in immunity. Trends Immunol. 2014;35(3):97-104.

113. Zhang Y, Tounekti O, Akerman B, Goodyer CG, LeBlanc A. 17-betaestradiol induces an inhibitor of active caspases. $J$ Neurosci. 2001;21(20):RC176.

114. Chandra S, Tripathi AK, Mishra S, Amzarul M, Vaish AK. Physiological changes in hematological parameters during pregnancy. Indian J Hematol Blood Transfus. 2012;28(3):144-6.

115. Gubbels Bupp MR. Sex, the aging immune system, and chronic disease. Cell Immunol. 2015;294(2):102-10. 
116. Chen Y, Zhang Y, Zhao G, Chen C, Yang P, Ye S, Tan X. Difference in leukocyte composition between women before and after menopausal age, and distinct sexual dimorphism. PloS One. 2016;11(9):e0162953.

117. Karimi P, Islami F, Anandasabapathy S, Freedman ND, Kamangar F. Gastric cancer: descriptive epidemiology, risk factors, screening, and prevention. Cancer Epidemiol Biomarkers Prev. 2014;23(5):700-13.

118. Zhang Y, Lu JJ, Du YP, Feng CX, Wang LQ, Chen MB. Prognostic value of neutrophil-to-lymphocyte ratio and platelet-to-lymphocyte ratio in gastric cancer. Medicine. 2018;97(12):e0144.

119. Despres JP, Lemieux I. Abdominal obesity and metabolic syndrome. Nature. 2006;444(7121):881-7.

120. Furuncuoğlu Y, Tulgar S, Dogan AN, Cakar S, Tulgar YK, Cakiroglu B. How obesity affects the neutrophil/lymphocyte and platelet/lymphocyte ratio, systemic immune-inflammatory index and platelet indices: a retrospective study. Eur Rev Med Pharmacol Sci. 2016;20(7):1300-6.

121. Bahadır A1, Baltacı D, Türker Y, Türker Y, Iliev D, Öztürk S, Deler MH, Sarıüzel YC. Is the neutrophil-to-lymphocyte ratio indicative of inflammatory state in patients with obesity and metabolic syndrome? Anatol J Cardiol. 2015;15(10):816-22.

122. Wanebo HJ, Kennedy BJ, Chmiel J, Steele G, Jr., Winchester D, Osteen R. Cancer of the stomach. A patient care study by the American College of Surgeons. Ann Surg. 1993;218(5):583-92. 
123. Erpenbeck L, Schon MP. Deadly allies: the fatal interplay between platelets and metastasizing cancer cells. Blood. 2010;115(17):3427-36.

124. Menter DG, Tucker SC, Kopetz S, Sood AK, Crissman JD, Honn KV. Platelets and cancer: a casual or causal relationship: revisited. Cancer Metastasis Rev. 2014;33(1):231-69.

125. Levin J, Conley CL. Thrombocytosis associated with malignant disease. Arch Int Med. 1964;114:497-500.

126. Costantini V, Zacharski LR, Moritz TE, Edwards RL. The platelet count in carcinoma of the lung and colon. Thromb Haemost.. 1990;64(4):501-5.

127. Hernandez E, Lavine M, Dunton CJ, Gracely E, Parker J. Poor prognosis associated with thrombocytosis in patients with cervical cancer. Cancer. 1992;69(12):2975-7.

128. Ikeda M, Furukawa H, Imamura H, Shimizu J, Ishida H, Masutani S, Tatsuta M, Satomi T. Poor prognosis associated with thrombocytosis in patients with gastric cancer. Ann Surg Oncol. 2002;9(3):287-91.

129. Hwang SG, Kim KM, Cheong JH, Kim HI, An JY, Hyung WJ, Noh SH. Impact of pretreatment thrombocytosis on blood-borne metastasis and prognosis of gastric cancer. Eur J Surg Oncol. 2012;38(7):562-7.

130. Li FX, Wei LJ, Zhang H, Li SX, Liu JT. Significance of thrombocytosis in clinicopathologic characteristics and prognosis of gastric cancer. Asian Pac J Cancer Prev. 2014;15(16):6511-7. 
131. Pedersen LM, Milman N. Prognostic significance of thrombocytosis in patients with primary lung cancer. Eur Resp J. 1996;9(9):1826-30.

132. Symbas NP, Townsend MF, El-Galley R, Keane TE, Graham SD, Petros JA. Poor prognosis associated with thrombocytosis in patients with renal cell carcinoma. BJU Int. 2000;86(3):203-7.

133. Oh SE, Seo JE, An JY, Lee JH, Sohn TS, Bae JM, Kim S, Choi MG. Prognostic Impact of Increased Perioperative Platelet Count in Gastric Cancer Patients. J Surg Res. 2019;242:296-303.

134. Wang YH, Kang JK, Zhi YF, Zhang Y, Wang ZQ, Zhou Q, Niu WY, Ma MJ. The pretreatment thrombocytosis as one of prognostic factors for gastric cancer: A systematic review and meta-analysis. Int J Surg. 2018 May;53:30411.

135. Stone RL, Nick AM, McNeish IA, Balkwill F, Han HD, Bottsford-Miller J, Rupairmoole R, Armaiz-Pena GN, Pecot CV, Coward J, Deavers MT, Vasquez HG, Urbauer D, Landen CN, Hu W, Gershenson H, Matsuo K, Shahzad MM, King ER, Tekedereli I, Ozpolat B, Ahn EH, Bond VK, Wang R, Drew AF, Gushiken F, Lamkin D, Collins K, DeGeest K, Lutgendorf SK, Chiu W, Lopez-Berestein G, Afshar-Kharghan V, Sood AK. Paraneoplastic thrombocytosis in ovarian cancer. New Engl J Medicine. 2012;366(7):610-8.

136. Timar J, Tovari J, Raso E, Meszaros L, Bereczky B, Lapis K. Plateletmimicry of cancer cells: epiphenomenon with clinical significance. Oncology. 2005;69(3):185-201. 
137. Xu XR, Yousef GM, Ni H. Cancer and platelet crosstalk: opportunities and challenges for aspirin and other antiplatelet agents. Blood. 201819;131(16):1777-89.

138. Ikeda Y, Mori M, Kamakura T, Haraguchi Y, Saku M, Sugimachi K. Improvements in diagnosis have changed the incidence of histological types in advanced gastric cancer. Br J Cancer. 1995;72(2):424-6.

139. Jiang N, Deng JY, Liu Y, Ke B, Liu HG, Liang H. The role of preoperative neutrophil-lymphocyte and platelet-lymphocyte ratio in patients after radical resection for gastric cancer. Biomarkers. 2014;19(6):444-51.

140. Shimada H, Takiguchi N, Kainuma O, Soda H, Ikeda A, Cho A, Miyazaki A, Gunji H, Yamamoto H, Nagata M. High preoperative neutrophil-lymphocyte ratio predicts poor survival in patients with gastric cancer. Gastric Cancer. 2010;13(3):170-6.

141. Aizawa M, Gotohda N, Takahashi S, Konishi M, Kinoshita T. Predictive value of baseline neutrophil/lymphocyte ratio for $\mathrm{T} 4$ disease in wallpenetrating gastric cancer. World J Surg. 2011;35(12):2717-22.

142. Chen J, Hong D, Zhai Y, Shen P. Meta-analysis of associations between neutrophil-to-lymphocyte ratio and prognosis of gastric cancer. World J Surg. $2015 ; 13: 122$.

143. Hsu JT, Liao CK, Le PH, Chen TH, Lin CJ, Chen JS, Chiang KC, Yeh TS. Prognostic value of the preoperative neutrophil to lymphocyte ratio in resectable gastric cancer. Medicine. 2015;94(39):e1589. 
144. Nakamura N, Kinami S, Fujii Y, Miura S, Fujita J, Kaida D, Tomita Y, Miyata T, Fujita H, Ueda N, Iida Y, Kosaka T. The neutrophil/lymphocyte ratio as a predictor of peritoneal metastasis during staging laparoscopy for advanced gastric cancer: a retrospective cohort analysis. World J Surg Oncol. 2019;17(1):108.

145. Jung MR, Park YK, Jeong O, Seon JW, Ryu SY, Kim DY, Kim YJ. Elevated preoperative neutrophil to lymphocyte ratio predicts poor survival following resection in late stage gastric cancer. J Surg Oncol. 2011;104(5):504-10.

146. Choi Y, Kim JW, Nam KH, Han SH, Kim JW, Ahn SH, Park DJ, Lee KW, Lee HS, Kim HH. Systemic inflammation is associated with the density of immune cells in the tumor microenvironment of gastric cancer. Gastric Cancer. 2017;20(4):602-11.

147. Watson EK, Rose PW, Neal RD, Hulbert-Williams N, Donnelly P, Hubbard G, Elliott J, Campbell C, Weller D, Wilkinson C. Personalised cancer followup: risk stratification, needs assessment or both? Br J Cancer. 2012;106(1):15.

148. Hu D, Zhang H, Lin X, Chen G, Li C, Liang B, Chen Y, Cui Z, Peng F, Zheng X, Niu W. Elevated preoperative neutrophil-to-lymphocyte ratio can predict poor survival in early stage gastric cancer patients receiving radical gastrectomy: The Fujian prospective investigation of cancer (FIESTA) study. J Cancer. 2017;8(7):1214-22. 
149. Lee DY, Hong SW, Chang YG, Lee WY, Lee B. Clinical significance of preoperative inflammatory parameters in gastric cancer patients. J Gastric Cancer. 2013;13(2):111-6.

150. Maruyama K. The most important prognostic factors for gastric cancer patients: a study using univariate and multivariate analyses. Scan J Gastroenterol. 1987;22(sup133):63-8.

151. Yu X, Hu F, Li C, Yao Q, Zhang H, Xue Y. Clinicopathologic characteristics and prognosis of proximal and distal gastric cancer. OncoTargets and therapy. 2018;11:1037-44. PubMed PMID: 29520154. Pubmed Central PMCID: PMC5833755. Epub 2018/03/10. eng.

152. P Pacelli F, Papa V, Caprino P, Sgadari A, Bossola M, Doglietto GB. Proximal compared with distal gastric cancer: multivariate analysis of prognostic factors. Am Surg. 2001;67(7):697-703.

153. Van Cutsem E, Arends J. The causes and consequences of cancer-associated malnutrition. Eur J Oncol Nurs. 2005;9(Suppl 2):S51-63.

154. Ataseven B, du Bois A, Reinthaller A, Traut A, Heitz F, Aust S, Prader S, Polterauer S, Harter P, Grimm C. Pre-operative serum albumin is associated with post-operative complication rate and overall survival in patients with epithelial ovarian cancer undergoing cytoreductive surgery. Gynecol Oncol. 2015;138(3):560-5. 


\section{APÊNDICES}




\section{Apêndice A - Artigo publicado}

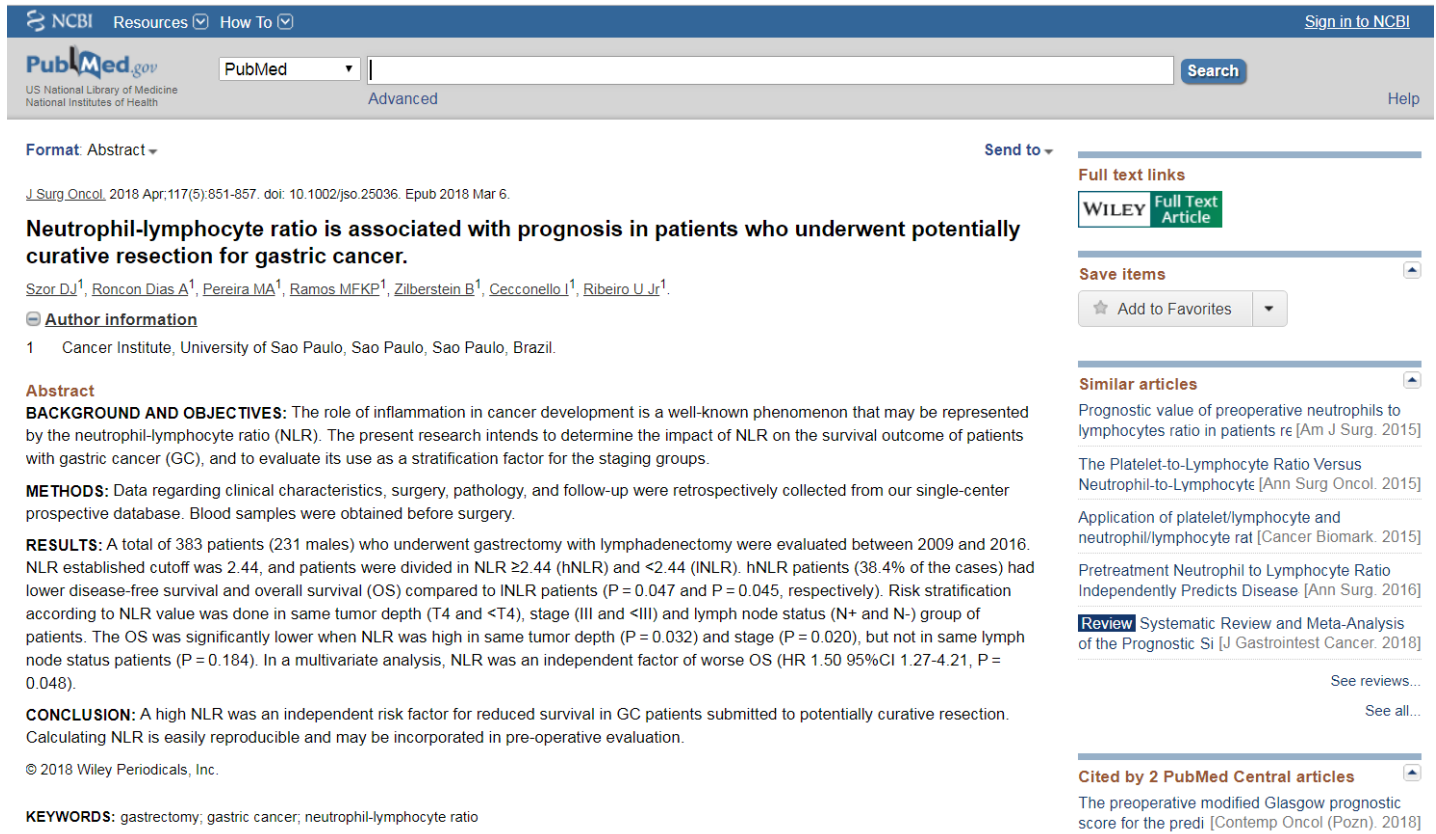

Disponível em: <https://www.ncbi.nlm.nih.gov/pubmed/29509963> 


\section{Apêndice B - Demais artigos relacionados}

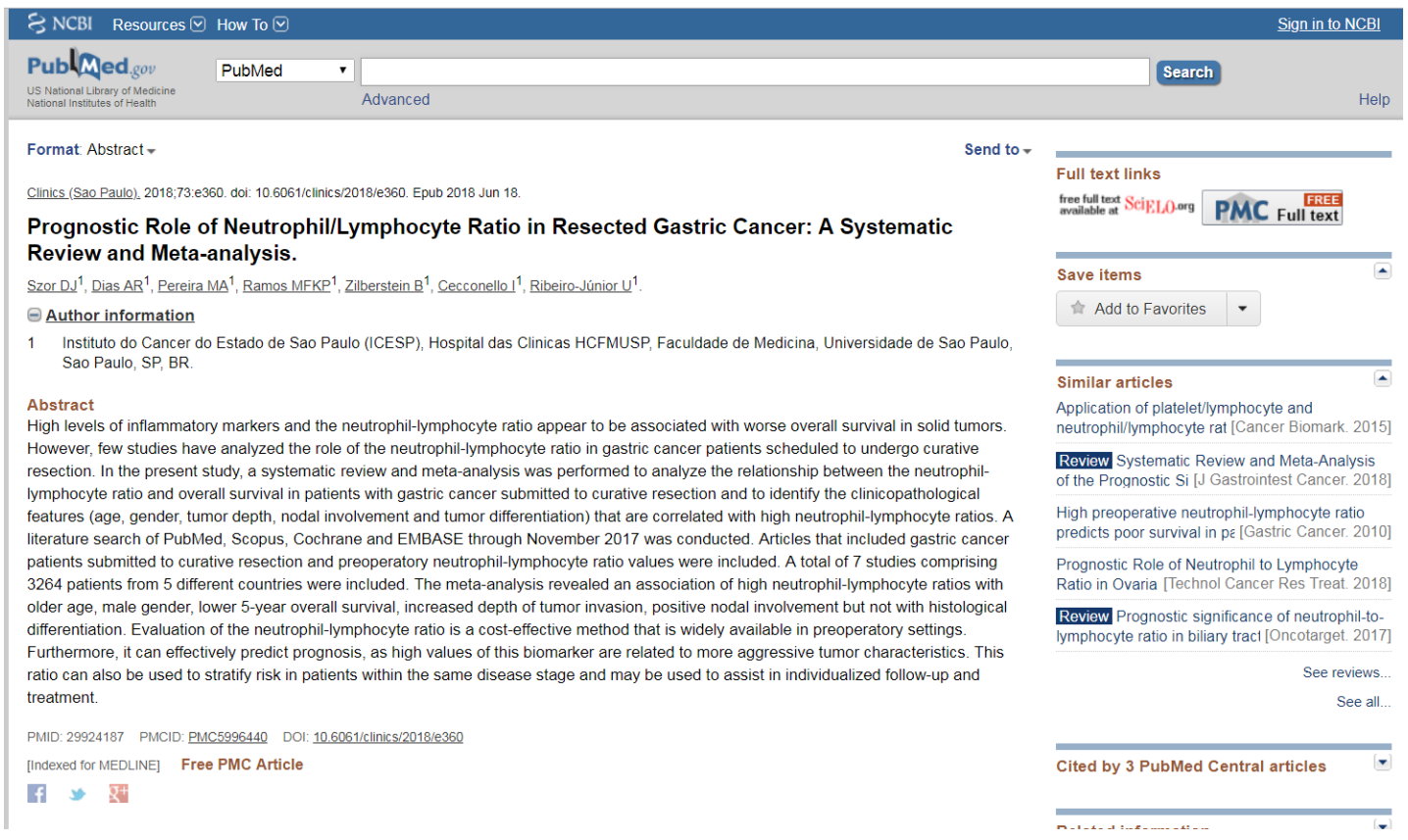

Disponível em: <https://www.ncbi.nlm.nih.gov/pubmed/29924187>

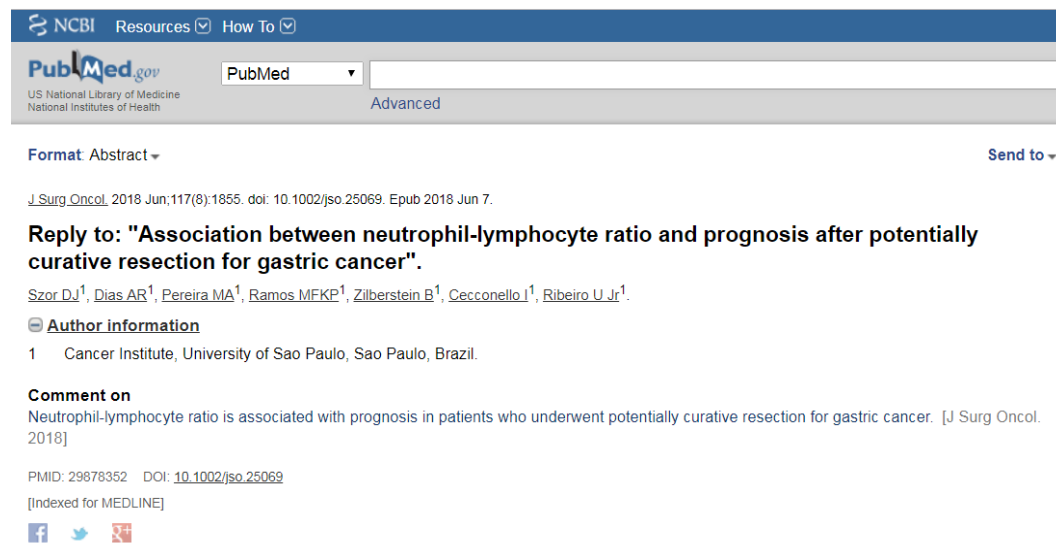

Disponível em: https://www.ncbi.nlm.nih.gov/pubmed/29878352 


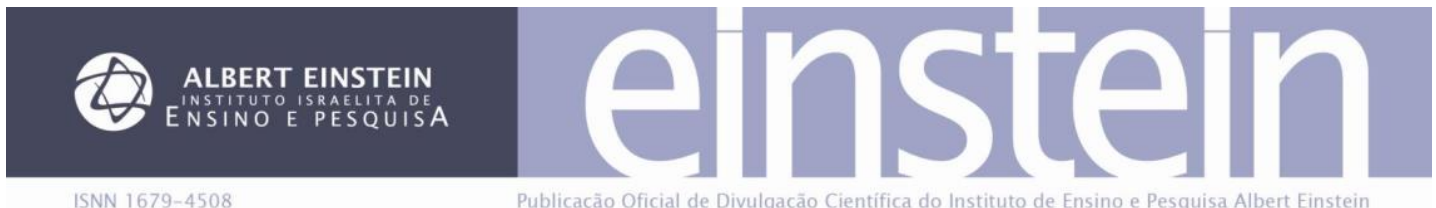

São Paulo, 26 de agosto de 2019.

\section{DECLARAÇÃO}

Declaramos que o artigo protocolo AO-4860: Evolução da relação neutrófilo-linfócito após gastrectomia curativa por câncer gástrico: análise de subgrupos de autoria de Daniel José Szor, André Roncon Dias, Marina Alessandra Pereira, Marcus Fernando Kodama Pertille Ramos, Bruno Zilberstein, Ivan Cecconello, Ulysses Ribeiro Junior, foi aceito para publicação na seção Artigo Original em 07/06/2019 e será publicado em uma próxima edição da einstein (São Paulo).

Atenciosamente,

\footnotetext{
Sidrey Gline

Prof. Dr. Sidney Glina

Editor Responsável
} 


\section{Apêndice C - Trabalhos apresentados}

\section{CERTIFICADO}

CERTIFICADO DE MENÇÃO HONROSA
XVI Semana Brasileira do Aparelho Digestivo

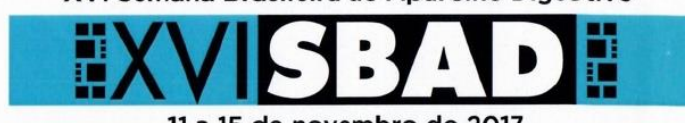

11 a 15 de novembro de 2017

CICB | Brasília | DF

www.sbad2017.com.br

Conferimos ao trabalho VALOR PROGNÓSTICO DA RELAÇÃO NEUTRÓFILOS/LINFÓcITOS NO CÂNCER GÁSTRICO dos autores Daniel José Szor; André Roncon Dias; Marcus Fernando Kodama Pertille Ramos; Bruno Zilberstein; Ulysses Ribeiro Junior; Marina Alessandra Pereira; Ivan Cecconello; esta menção honrosa em reconhecimento pelo excelente trabalho científico apresentado na modalidade Tema Livre durante a XVI Semana Brasileira do Aparelho Digestivo, realizada de 11 de novembro a 15 de novembro de 2017, no Centro Internacional de Convenções do Brasil, em Brasília - DF.

Brasília, 15 de novembro de 2017.
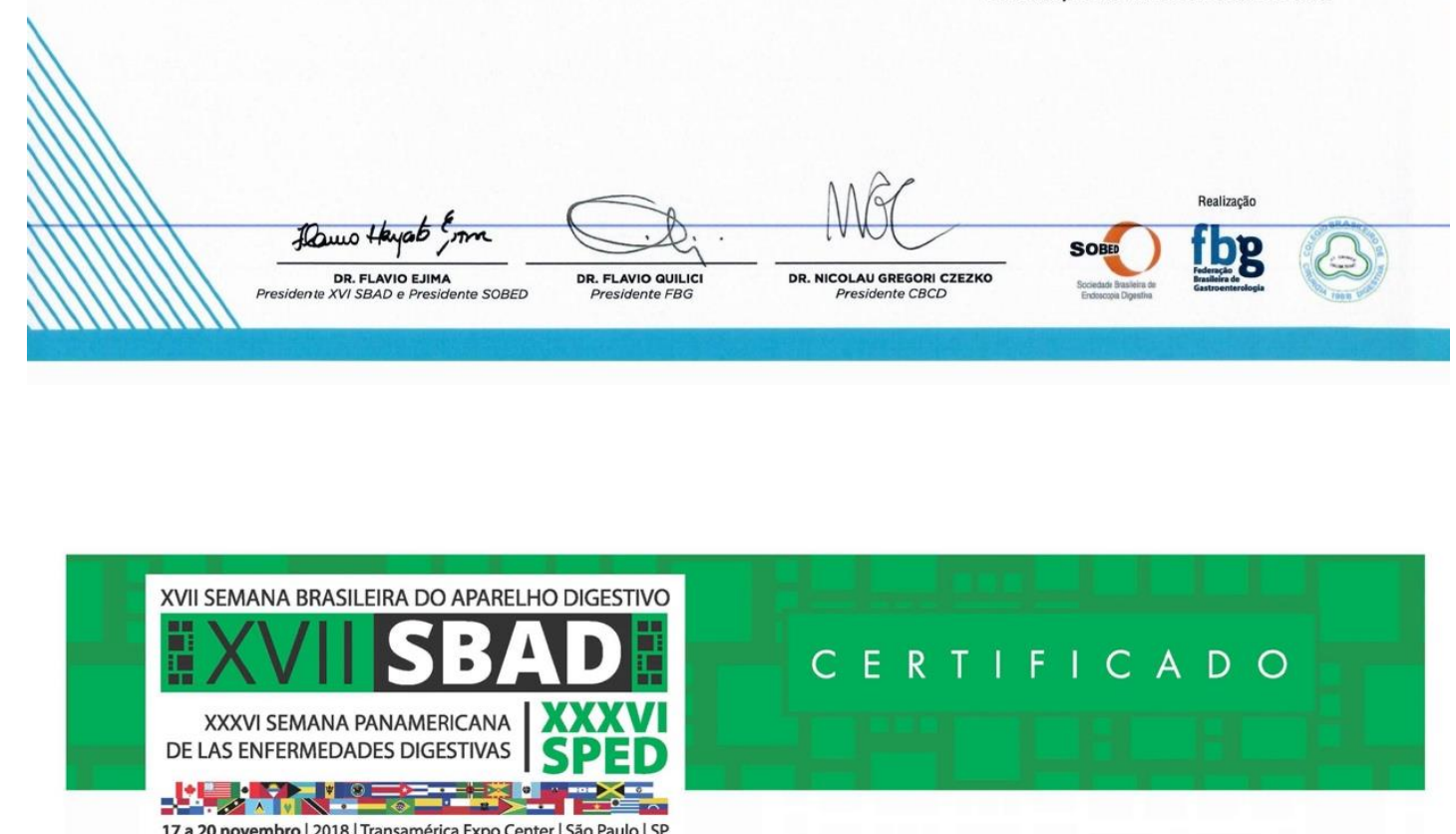
17 a 20 novembro | 2018 | Transamérica Expo Center | Săo Paulo| SP

Conferimos ao trabalho

VALOR PROGNÓSTICO DA RELAÇÃO NEUTRÓFILO-LINFÓCITOS PERIOPERATÓRIA EM PACIENTES

COM CÂNCER GÁSTRICO SUBMETIDOS À GASTRECTOMIA CURATIVA

dos autores DANIEL; ANDRE RONCON DIAS; MARINA ALESSANDRA PEREIRA; MARCUS FERNANDO KODAMA PERTILLE RAMOS; BRUNO ZILBERSTEIN; IVAN CECCONELLO; ULYSSES RIBEIRO JUNIOR a "Menção Honrosa" pelo trabalho apresentado na modalidade Aprovado para Tema Livre - CBCD, durante o XVII

Semana Brasileira do Aparelho Digestivo \& XXXVI Semana Panamericana de las Enfermidades Digestivas, realizado de 17 a 20 de novembro de 2018 no Transamerica Expo Center em São Paulo/SP.

$$
\text { São Paulo, } 20 \text { de novembro de } 2018
$$

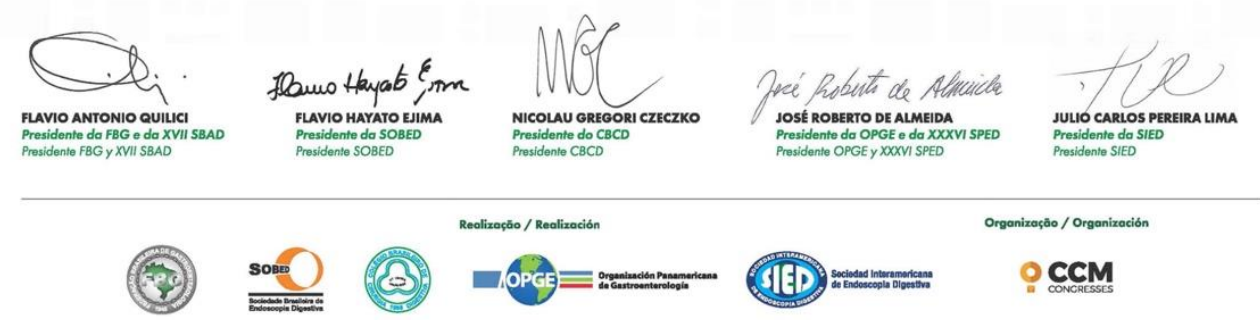




\section{SS2018}

GP3: Neutrophil-Iymphocyte Ratio is Associated with Prognosis in Patients who Underwent Potentially Curative Resection for Gastric Cancer

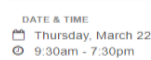

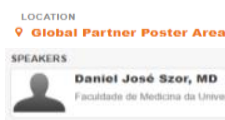

ofscraption

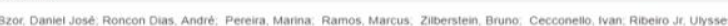

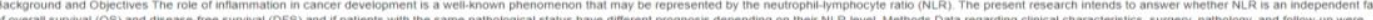

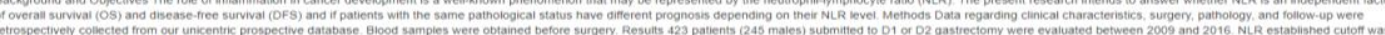
2.44 and patients were divioded in NLR 22.44 (NNLR) and

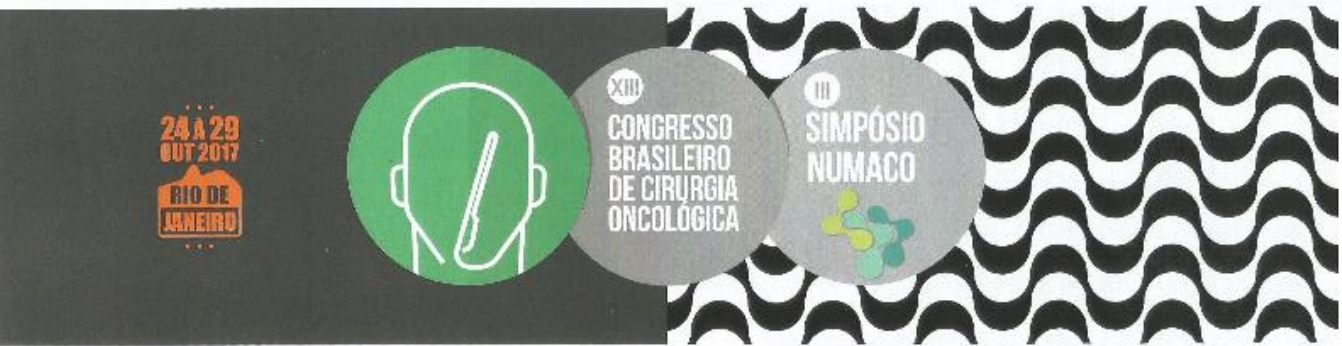

\section{CERTIFICAD 0}

Conferimos ao trabaho

RELAÇÃO NEUTRÓFILOS/LINFÓCITOS COMO FATOR PROGNÓSTICO EM PACIENTES SUBMETIDOS Ȧ GASTRECTOMIA POR CÂNCER GÁSTRICO

Dos autores: Daniel José Szor, André Roncon Dias, Marcus Fernando Kodama Pertille Ramos, Marina Pereira, Osmar Kenji Yagi, Bruno Zilberstein, Ulysses Riteiro Juniar, Ivan Cecconelic

O Prêmio de Melhor Trabalho Cientifico - 40 lugar, arresentado na modalidade Tema Livre, durante o XIII Congresso Brasileiro de Cirurgia Oncológica, realizado de 25 a 28 de outubro de 2017 , no Windsor Barra Hotel, Rio ce Janeiro - R.S.

Ric cle Janeiro, 28 de outubro de 2017

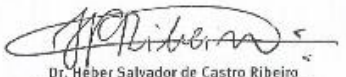

Dr

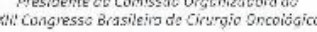

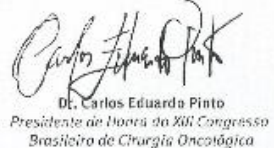

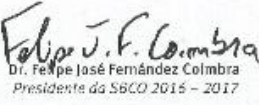

